\title{
IV. Biographie nach den Regeln der Gattung? Suetons Kaiserviten
}

\author{
"Es ist in diesem Bereich wie sonst: die aus \\ dem Rocken des griechischen Geistes einmal \\ abgesponnenen Fäden sind nicht wieder ge- \\ rissen, aber oft ineinandergewirrt worden \\ und nicht immer leicht zu entwirren. "
}

Friedrich Leo ${ }^{\prime}$

\section{Sueton in der Forschung: \\ Von der historischen Quelle zum Biographen in seiner Zeit}

Die Wahrnehmung Suetons in der Forschung wurde lange Zeit maßgeblich von zwei Arbeiten bestimmt, die zu Beginn des 20. Jh. entstanden waren und das Bild eines literarisch unambitionierten, allein um die Sammlung von Faktenwissen bemühten Autors etabliert haben. Dies gilt für die besonders durch die systematische Aufarbeitung des damals verfügbaren Materials wertvolle Untersuchung von ALCIDE MACÉ, ${ }^{2}$ deren Tendenz in der Wertschätzung Suetons vielleicht am deutlichsten in GINO FUNAIOLIs oft zitierten Diktum „ma un vero scrittore non è ${ }^{\text {c63 }}$ zum Ausdruck kommt, ebenso wie für die von FRIEDRICH LEO vorgelegte Studie „Die griechisch-römische Biographie nach ihrer litterarischen Form", ${ }^{4}$ deren Einfluß auf die Suetonforschung der ersten Hălfte des vergangenen Jahrhunderts nicht zu gering veranschlagt werden kann. LEOs Thesen konnten ihre enorme Wirkung vor allem deswegen entfalten, weil sie Teil seines großangelegten Versuches waren, die biographische Produktion der Antike einer einheitlichen Klassifikation nach formalen Kriterien zu unterziehen. ${ }^{5}$

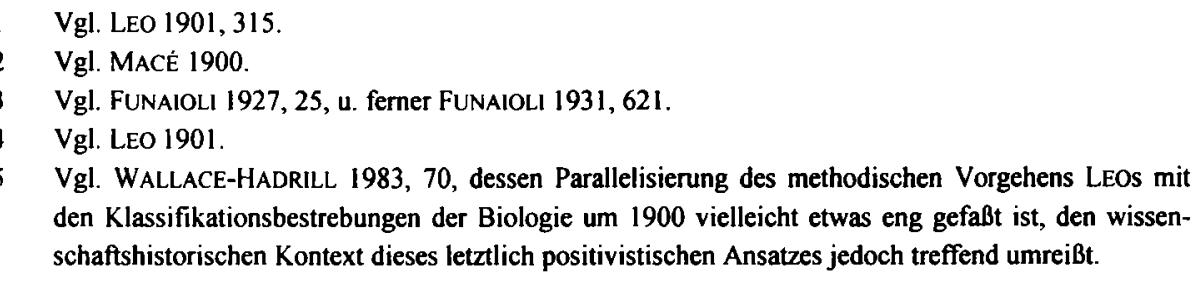
den Klassifikationsbestrebungen der Biologie um 1900 vielleicht etwas eng gefaßt ist, den wissenschaftshistorischen Kontext dieses letztlich positivistischen Ansatzes jedoch treffend umreißt. 
Zu diesem Zwecke postulierte LEO die Existenz zweier sich in Stil und Gegenstand fundamental unterscheidender Formen antiker Biographie. Die eine zeichnete sich für ihn durch eine belletristisch getönte Diktion und einen literarisch ambitionierten Aufbau aus und diente der Beschreibung des Lebens von Königen, Feldherren und anderen historisch bedeutsamen Persönlichkeiten. Die zweite Form mit ihrer nüchternen Sprache und sachorientierten Gliederung sei für die Vermittlung biographischen Wissens über Personen des literarischen, künstlerischen und philosophischen Lebens entwickelt worden. ${ }^{6}$ Diese beiden Subgattungen hătten seit den biographischen Arbeiten im Umfeld des Peripatos einerseits und im Kontext der Bibliothek von Alexandria andererseits vorgelegen. Sueton, dem das alexandrinische Model von der Arbeit an de viris illustribus vertraut gewesen sei, habe sie dann bei der Abfassung seiner Caesares kontaminiert, das heißt die mit Rubriken arbeitende und durch eine wissenschaftlichnüchterne Diktion geprägte Form der Darstellung für den ihr unangemessenen Inhalt der Herrscherbiographien verwendet.?

Diese ausgesprochen formalistische Einteilung der antiken biographischen Literatur war zwar schon 1912 erstmals ins Wanken geraten, als der Papyrus Oxyrhynchus 1176 ein umfangreiches Fragment aus der Euripides-Vita des Satyros zutage förderte, das in Dialogform gehalten war. Bereits LEO selbst gelang es nur mit Mühe, die Abfassung einer Dichter-Vita in einer literarisch derart anspruchsvollen Technik in sein Lehrgebäude zu integrieren. ${ }^{8}$ Die Kritik an LEO beschränkte sich aber in der Folgezeit nicht auf die großen Linien seines kühnen Entwurfes, ${ }^{9}$ sondern setzte auch an seinen häufig apodiktisch formulierten Urteilen über einzelne Autoren an. Weder konnte sein Versuch überzeugen, Plutarch ausschließlich der peripatetischen Traditionslinie zuzuordnen, indem er die thematisch gegliederten Abschnitte seiner Biographien als für den Aufbau irrelevante Exkurse deklarierte, ${ }^{10}$ noch erwies sich die Konstatierung eines starren Dispositionsschemas für die suetonischen Kaiserviten ${ }^{11}$ in ihrer Gesamtheit als zutreffend.

Vor allem WOLF STEIDLE sorgte Mitte des 20. Jh. mit seiner sich zum Teil explizit gegen LEOs Thesen richtenden Untersuchung „Sueton und die antike Biographie“ für eine deutliche Zäsur in der Forschungsliteratur. ${ }^{12}$ Ausgehend von der seitdem beinahe zu einem Allgemeinplatz der Biographieforschung gewordenen Feststellung, daß sich die biographische Literatur der Antike in formalen Kategorien nur unzureichend

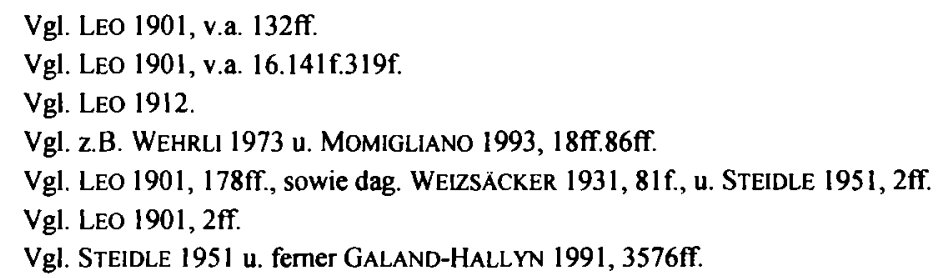


beschreiben läßt, ${ }^{13}$ trat STEIDLE den Beweis an, daß es sich bei den Kaiserviten um ein von Sueton in dieser Form bewußt gestaltetes literarisches Werk handelt, ${ }^{14}$ in dem sich eine spezifisch römische ,Tradition biographischen Sehens' manifestiert habe, die sich an zahlreichen inhaltlichen Aspekten sowie auf der formalen Ebene an der Gliederung in Rubriken und der durch sie erreichten Betonung des ,Faktischen' ablesen lasse. ${ }^{15}$ Mit dem aus heutiger Perspektive eher moderat formulierten Fazit, $\mathrm{da} ß$ der Verfasser der Caesares als Schriftsteller und nicht als bloßer Kompilator $\mathrm{zu}$ verstehen ist, gab STEIDLE der Suetonforschung der nächsten Jahrzehnte das Stichwort für ihren zentralen Diskussionsgegenstand.

Ohne den Verlauf der Debatte hier im einzelnen nachzeichnen zu wollen, ${ }^{16}$ läßt sich resümierend festhalten, daß im Zuge einer generell zunehmenden Bereitschaft, bei der Beurteilung von Autoren der römischern Kaiserzeit nicht einseitig die Abweichung von den Normen der klassischen Epoche zu betonen, sondern den Kontext ihrer Entstehungszeit stärker zu berücksichtigen, ${ }^{17}$ sich auch das Suetonbild zusehends aufhellte. Schließlich setzte sich mit den beiden unabhängig voneinander 1983 erschienenen Monographien von BARRY BALDWIN und ANDREW WALLACE-HADRILL ${ }^{18}$ diejenige Richtung durch, die in Suetons Kaiserbiographien ein von seinem Autor bewußt gestaltetes Werk mit einem unbestreitbaren, wenn auch nicht mit den Stilanforderungen der antiken Historiographie deckungsgleichen literarischen Anspruch erblickt. ${ }^{19}$

Vor allem die von WALLACE-HADRILL vorgetragenen Thesen haben der Suetonforschung vielfältig neue Impulse gegeben. Als einer der ersten hat er in der Beschäftigung mit den Biographien der ersten zwölf römischen principes die Blickrichtung

13 Vgl. Steidle 1951, 5.129.176, sowie femer Z.B. Wehrl 1973, 193; Gugel 1977, 11; BaldWIN 1983, 66; WALLACE-HADRILL 1983, 66ff.; GENTILI / CERRI 1988, 80; LEWIS 1991, 3672ff.; MOMIGLIANO 1993, 11 ff., U. SONNABEND 2002, 13 ff.; ferner s.o. S. $42 \mathrm{ff}$.

14 Vgl. STEIDLE 1951, 108: „Als Ergebnis ... laßt sich zusammenfassend feststellen, daß Suetons Caesares ein klarer Gestaltungswille, verbunden mit festen, wenn auch ohne Reflexion vorgebrachten moralischen Urteilen zugrunde liegt. Dabei bedient er sich, abgesehen von den Mitteln der Stoffauswahl, Anordnung. Steigerung und des Kontrastes auch einer Reihe von Mittein, die nach Leo sonst nur der künstlerisch gestaltenden Biographie gelăufig sind, so der dauemden Hervorhebung leitender Gesichtspunkte, der grundlegenden Eingangscharakteristik und der überlegten Zusammenstellung und Verknüfung der einzelnen Rubriken und Gesichtspunkte."

15 Vgl. STEIDLE 1951, 108ff.175f: „Zugespitzt formuliert könnte man sagen: Suetons Originalităt beruht auf seinem Römertum, wăhrend sie da, wo Leo sie suchte, in der Disposition, nicht zu finden ist." STEIDLE formuliert seine Betonung des spezifisch Romischen in den Biographien Suetons in kritischer Anlehnung an die Beobachtungen von STUART 1928, 189ff.

16 In die Nachfolge StEIDLEs lassen sich unter anderem MOUCHOVÁ 1968; GUGEL 1977 und LOUNSBURY 1987 einordnen, während entschiedener Widerspruch bereits in der Rezension von DIHLE 1954 sowie von D'ANNa 1954, PARATORE 1959, BRINGMANN 1971 und FLACH 1972 formuliert wurde.

17 Vgl. SCHWIND 2000, $19 f$.

18 Vgl. BaLdWIN 1983, u. WALLACE-HADRILL 1983, sowie femer die Rezension von BradLEy 1985.

19 Vgl. jedoch auch die Gegenstimmen von z.B. ALFOLDY 1986, 399f., u. DiHLE 1987, 36 f. 
dahingehend gewechselt, daß er Suetons Text nicht als Quelle für die in ihnen dargestellte julisch-claudische und flavische Epoche herangezogen hat, sondern versuchte, mit ihrer Hilfe Erkenntnisse über die literarischen und kulturellen Entwicklungen ihrer Entstehungszeit in der ersten Hälfte des 2. Jh. n. Chr. zu gewinnen. Zu diesem Zweck brachte er das Bild ihres Verfassers, das sich aus seinem umfangreichen, aber größtenteils nur in fragmentarischer Form erhaltenen antiquarischen Euvre und den antiken Zeugnissen zu seinem Leben, etwa der Bezeichnung als scholasticus durch Plinius den Jüngeren, ${ }^{20}$ ergibt, mit der gestiegenen gesellschaftlichen Wertschătzung literarischer und kultureller Kompetenz in trajanisch-hadrianischer Zeit in Verbindung. Auf diese Weise konnte er Sueton nicht nur von dem Stigma des wirklichkeitsfremden Stubengelehrten befreien, ${ }^{21}$ sondern zugleich einen vielversprechenden Ausgangspunkt zur Interpretation seiner Kaiserbiographien gewinnen. ${ }^{22}$

Dies gelang ihm vor allem, indem er eine Interdependenz zwischen seinem literarischen Schaffen und den sozialen Rollen des Gelehrten, aber auch des Funktionsträgers am kaiserlichen Hof beispielsweise in der Auswahl seiner Kategorien bei der Beschreibung der römischen Herrscher plausibel machen konnte. ${ }^{23}$ Eine Analyse der zentralen Momente in Suetons Darstellung der frühen Kaiserzeit erlaubt dabei unter anderem Rückschlüsse auf die zeitgenössische Wahrnehmung des Prinzipats aus der Perspektive der mit den Herrschenden sozial unmittelbar agierenden Personenkreise. Zugleich gelang es WALLACE-HADRILL, der Frage nach dem Publikum der Caesares, das von FRANCESCO DELLA CORTE mit dem Ritterstand, dem Sueton selbst entstammte, sicherlich zu eng gefaßt worden war, ${ }^{24}$ eine neue Richtung zu geben. ${ }^{25}$ Der wesentlich durch diese Monographie bewirkte Neuansatz läßt sich in den Sueton gewidmeten Beiträgen des 1991 erschienen Bandes der Reihe ,Aufstieg und Niedergang der römischen Welt' in seiner anregenden Wirkung auf nachfolgende Interpreten, aber auch in der daraus resultierenden Heterogenităt des aktuellen Suetonbildes ablesen. ${ }^{26}$

20 Vgl. Plin. ep. 1,24,4 u. ferner Lyd. mag. 1,34 sowie Suda 4,581,18 ADLeR. Vor einer Überschătzung dieser Zeugnisse hat zwar schon DELLA CORTE 1958, 29f., gewarnt, doch kann die von WALLACEHADRILL 1983, 4f., verwendete Deutung als weitgehend akzeptiert gelten.

21 Vgl. auch BrADLEY 1991, 3712f:: „On a traditional view Suetonius was a bookish figure whose early attempts in public life were disastrous, who was dragged from the study in middle age to serve the emperor for a brief moment, and who quickly, and willingly, returned to studious retirement. That picture cannot be altogether accurate, however, since it underestimates, first, the efforts both needed and made to begin an equestrian career; the effects, secondly, of proximity to Pliny and entry to his circle; the literary repute, thirdly, that brought Suetonius to the attention of emperors; ..."

22 Vgl. WALLACE-HADRILL 1983, 26ff.50ff.

23 Vgl. WALLACE-HADRILL 1983, 73ff. $142 \mathrm{ff}$.

24 Vgl. DELLA CORTE 1958.

25 Vgl. WallaCe-HadRILl 1983, 99ff., zum Publikum s.u. S. 321 ff.

26 Vgl. Galand-Hallyn 1991; LEWIS 1991; De ConinCK 1991; BradLey 1991; GiUa 1991; LounsBURY 1991; MURPHY 1991; SCHMIDT 1991 u. VILJAMAa 1991. 


\title{
2. Die Kaiserbiographien im Kontext der Bildungskultur
}

\author{
a) Suetons viri illustres und Plutarchs Kaiserviten: \\ Modelle der suetonischen Caesares?
}

Der Nachwelt ist Sueton zwar ebenso wie der rund zwei Jahrzehnte ältere Plutarch ${ }^{27}$ in erster Linie als Verfasser von Biographien bekannt, doch können beide Autoren eine umfangreichere literarische Produktion vorweisen, die einen deutlichen Schwerpunkt auf einem Gebiet erkennen läßt, für das sich die Bezeichnung als antiquarisches Schrifttum eingebürgert hat. Von diesen Abhandlungen mit in weiterem Sinne kulturwissenschaftlichem Inhalt hat sich in der als moralia bezeichneten Sammlung plutarchischer Schriften eine illustrative Fülle erhalten. Für Sueton ist die Überlieferungslage hingegen vergleichsweise schlecht, und in der Forschung herrscht wenig Einigkeit über die Rekonstruktion dieses Teiles seines literarischen Schaffens. Schon die Frage, ob der sich aus den erhaltenen Fragmenten und bezeugten Titeln zunächst ergebende Eindruck eines Konglomerates aus thematisch disparaten Einzelschriften zutreffend ist oder ob Sueton - unter dem Titel pratum oder prata ${ }^{28}$ - ein enzyklopädisch angelegtes Werk verfaßt hat, dessen Konturen sich aus den etymologiae des Isidor von Sevilla rekonstruieren lassen, ${ }^{29}$ ist umstritten. Allerdings legt der Vergleich mit der essayistischen Schreibweise Plutarchs sowie mit den generellen literarischen

27 Die Lebensdaten Suetons sind nicht unabhăngig überliefert und konnen nur aus seinen Schriften erschlossen werden. Das wichtigste Zeugnis stellt seine eigene Bezeichnung als adulescens furr das Jahr 88 n. Chr. dar (vgl. Suet. Nero 57,2 sowie ferner Dom. 12,2 u. gramm. 4,6). Damit ergibt sich das Epochenjahr 69 als mögliches und von einigen favorisiertes Geburtsdatum (vgl. z.B. MACÉ 1900, 35ff.), doch muß jede genauere Eingrenzung Spekulation bleiben (vgl. die Diskussion bei SCHERBERICH 1995, 2f.). Für Plutarch wird ubereinstimmend ein Geburtsdatum um $45 \mathrm{n}$. Chr. angesetzt.

28 Zur Frage des genauen Titels vgl. SCHMIDT 1991, 3801f., der sich unter Berufung auf das alteste Testimonium (Gell. praef. 8) für den Singular entscheidet.

29 Die antiquarischen Sueton-Fragmente wurden von REIFFERSCHEID 1860 in Anlehnung an Isidor und unter dem Titel pratum angeordnet (vgl. dag. die Edition der derperditorum librorum reliquae durch ROTH 1858, 273ff.). Die seitdem anhaltende Forschungsdiskussion wird von SCHMIDT 1991, 3795ff., zusammengefaßt, der sich zugleich entschieden auf die Seite derjenigen stellt, die in Sueton den Fortsetzer der enzyklopadischen Tradition Varros oder des alteren Plinius sehen (S. 3807): „Die trotz des prătensiós-manieristischen Titels erkennbare sorgfaltige Anlage des Ganzen fuhrt unterhalb der etwas schillernden Oberflăche auf eine Tiefenstruktur, die sich als Abfolge von gesellschaftlicher und naturlicher Ordnung, von Traditions- und Literaturgeschichte charakterisieren laßt." (vgl. ferner SALLMANN / SCHMIDT 1997a, 16ff.). Daß Sueton die nur mit griechischen Titeln bezeugten Schriften auch Griechisch abgefaßt hat, wird mehrheitlich angenommen (vgl. z.B. SCHMIDT 1991, 3816ff., aber auch dag. WARDLE 1993). 
Entwicklungen der $\mathrm{Zeit}^{30}$ die Vermutung nahe, daß wir es eher mit einem nicht systematisch angelegtem Corpus von Einzelschriften zu tun haben. ${ }^{31}$

Doch nicht nur in der Frage nach dem allgemeinen Charakter seiner antiquarischen Schriften muß letztlich unbeantwortet bleiben, sondern auch bei der relativen Chronologie des gesamten Cuvres sind wir mangels externer Zeugnisse auf Vermutungen angewiesen. Die verbreitete, gleichsam ,evolutionistische' Sichtweise, die Sueton mit seinen antiquarischen Kleinschriften beginnen und über das biographische Sammelwerk de viris illustribus schließlich zu den Kaiserviten gelangen läßt, ${ }^{32}$ lăuft zwar Gefahr, Werturteile spăterer Rezipienten zur Grundlage der Argumentation zu machen ${ }^{33}$ erweist sich jedoch als Ausgangshypothese fur verschiedene Fragestellungen durchaus als fruchtbar und trägt auf diese Weise wieder zu ihrer Plausibilität bei.

Falls diese chronologische Reihung tragfähig ist, so haben wir in den Briefen seines Förderers Plinius einen Sueton vor uns, der am Anfang seiner Karriere steht und beginnt, sich mit antiquarischen Schriften - wie seiner bei späteren Autoren viel beachteten Abhandlung de spectaculis ${ }^{34}$ - einen Namen zu machen. Plinius selbst war es aufgrund seines frühen Todes kurz nach $113 \mathrm{n}$. Chr. nur zum Teil vergönnt, Zeuge der Erfolge seines Protegés zu werden, so daß uns seine Korrespondenz als Quelle für die folgenden Jahre fehlt; doch scheint Sueton in dieser Zeit mit der Arbeit an de viris illustribus begonnen zu haben. ${ }^{35}$ Angesichts der in dieser Zeit vielfältig nachweisbaren gesellschaftlichen Wertschätzung kultureller Kompetenz ist es nicht unwahrscheinlich, daß sich Sueton gerade mit diesen Veröffentlichungen für hochrangige Ämter im Kaiserdienst empfohlen hat. ${ }^{36}$ In die Zeit seiner Tătigkeit als ab epistulis unter Had-

30 S.o. S. $30 \mathrm{ff}$.

31 Vgl. Steinmetz 1982, 276; Wallace-HadRill 1983, 42f., u. SAllmanN 2001, 1086: „Suetons antiquarisches Hauptwerk ... scheint eher aktuellen Moden der curiositas zu folgen als einer konzeptionellen Systematik ...“. Möglicherweise wurden Suetons ,Opuscula' auch erst postum unter dem Titel pratum zusammengestellt (vgl. BRUGNOLI 1968, 137ff.).

32 Vgl. z.B. Wallace-Hadrill 1983, 44f., u. SallmanN / SChmidt 1997a, 28.

33 Zur im Vergleich mit den Caesares hăufig unterschătzten Wirkungsgeschichte der antiquarischen Schriften vgl. SaLLMANN / SCHMIDT 1997a, 41 f.

$34 \mathrm{DaB}$ es sich bei der Publikation, zu der Sueton $105 \mathrm{n}$. Chr. von Plinius gedrăngt wird (vgl. Plin. ep. 5,10 ) um diese Schrift gehandelt hat, wird von WALLACE-HADRILL 1983, 46f., vermutet, wahrend die Mehrheit der Forschung die viri illustres hinter dem namenlos bleibenden Wert vermutet (vgl. z.B. MACÉ 1900, 66ff.; SALLMANN / SCHMIDT 1997a, 28, u. zurückhaltend BALDWIN 1983, 15ff.).

35 Vgl. Cizek 1977, 13f.; Wallace-Hadrill 1983, 59f., u. Kaster 1995, xxi. Von SallmanN / SCHMIDT 1997a, 28, wird eine Abfassung der viri illustres nach den antiquarischen Schriften in den Jahren zwischen 105 und $109 \mathrm{n}$. Chr. angesetzt und zugleich vermutet, daB die Biographien in die unter dem Titel pratum gesammelten antiquarischen Schriften aufgenommen wurden.

36 Sueton wăre unter Trajan und Hadrian nicht der einzige, der sich fur ein Amt als ab epistulis, a bibliothecis oder $a$ studiis auf diese Weise qualifiziert hat (vgl. WALLACE-HADRILL 1983, 7f.26ff.79ff., u. allg. MratscheK-HaLfmanN 1993, 18ff.), doch war bereits sein Vater (Suet. Otho 10,1) und sein Großvater (vgl. Suet. Cal. 19,3) in der kaiserlichen Verwaltung tatig, wie Sueton seine Leser wissen 
rian und die Zeit nach seiner Absetzung $122 \mathrm{n}$. Chr. ${ }^{37}$ fällt sodann nach gängiger Auffassung die Beschäftigung mit den Kaiserviten. ${ }^{38}$

Einen entscheidenden Schritt auf dem Weg zu den literarischen Lebensbeschreibungen der ersten zwölf römischen Kaiser bildet in diesem chronologischen Modell die Schrift de viris illustribus, die zwar nicht in toto überliefert wurde, von der wir uns aber aus verschiedenen Quellen ein recht genaues Bild machen können. Einerseits erlaubt das prosopographische Material in der Chronik des Hieronymus Rückschlüsse auf den Inhalt der verlorenen Teile. ${ }^{39}$ Andererseits haben die Viten einiger prominenter Dichter aus Suetons Sammelwerk als Einleitung zu den Schriften der entsprechenden Autoren offenbar einen unabhängigen Weg in die Handschriftentradition gefunden. ${ }^{40}$ Außerdem ist durch einen glücklichen Zufall der Überlieferungsgeschichte mit de grammaticis et rhetoribus der Text zweier beinahe vollständiger Kategorien erhalten. ${ }^{41}$

Die Überlieferungsumstände des Abschnittes de grammaticis et rhetoribus lassen zwar keine Rückschlüsse auf eine besonders intensive Rezeption gerade dieses Segmentes der Schrift zu, da der Text lediglich von einer einzigen Handschrift, dem im 15. Jh. wiederentdeckten und auch Tacitus' kleine Schriften enthaltenden codex Hersfeldensis, überliefert wird. ${ }^{42}$ Dennoch scheint es sich um den innovativsten und daher

laßt. Die Auffindung einer Ehreninschrift im nordafrikanischen Hippo Regius in den 1950er Jahren (AE 1953, 73) hat eine langjahrige Diskussion um die Herkunft seiner Familie ausgelőst, in der die Befürworter einer afrikanischen Abstammung (vgl. z.B. TOWNEND 1961 a, 105; SYME 1980b, 80, u. BRADLEY 1991, 3705) denen gegenüberstehen, die alternative Erklärungen fur die Lokalisierung der Inschrift favorisieren (vgl. GASCOU 1978, 441 ff.; BALDWIN 1983, 29ff., u. LINDSAY 1994, 464).

37 Sueton bekleidete diesen prestigetrăchtigen Posten wohl vom Regierungsantritt Hadrians $117 \mathrm{n}$. Chr. bis zu seiner - allerdings nur in der historia Augusta uberlieferten (SHA Hadr. 11,3) - Absetzung 122 n. Chr. Weil sich an die Frage, wie lange Sueton als ab epistulis Zugang zu den kaiserlichen Archiven hatte, Überlegungen zur Abfassungszeit der Kaiserviten knupfen, ist dieser Punkt vielfach und kontrovers behandelt worden (s.u. S. 252ff). Eine präzis informierende Übersicht über die mit Suetons Karriere verbundenen Probleme bietet HURLEY 2001, 3f.

38 Vgl. CIZEK 1977, 13f.; WALLACE-HADRILL 1983, 59f., sowie dag. BALDWIN 1983, 380: ,.. there is no evidence that the De viris illustribus was antecedent to the imperial biographies. For all we know, it was subsequent; indeed, Suetonius might have worked on the projects concurrently." u. fermer LINDSAY 1994, 459.464.

39 Vgl. die Edition der Fragmente durch REIFFERSCHEID 1860, 363ff., sowie ferner MOMMSEN 1909 [1850], 610ff.; WALLACE-HADRILL 1983, 51 ff., u. SALLMANN / SCHMIDT 1997a, 27ff.

40 Ihre Zuschreibung ist allerdings umstritten (zur Authentizităt der vita Horatii vgl. LINDSAY 1995b); insbesondere uber den Verfasser der vita Vergili herrscht keine Einigkeit (für Sueton als Autor vgl. NAUMANN 1981, dag. aber auch die zurückhaltende Argumentation bei BALDWIN 1983, 385ff., sowie ferner die Forschungsuberblicke bei SALLMANN / SCHMIDT 1997a, 31 ff., u. BAYER 2002, 339ff.).

41 Vgl. VILJAMAa 1991, 3831 ff., u. KASTER_1995, liiiff.

42 Zu moglichen Rezeptionszeugnissen aus der Antike vgl. KASTER 1995 xlviiiff. 
vielleicht auch interessantesten Teil des Werkes gehandelt zu haben. ${ }^{43}$ Denn wăhrend die übrigen für Sueton bezeugten Rubriken wie de poetis, de oratoribus oder de historicis innerhalb der Gattung der Sammelbiographie auf eine lange Tradition zurückblicken können, handelt es sich bei der Aufnahme der Grammatik- und Rhetoriklehrer um eine auffällige Neuerung. ${ }^{44}$

Diese Entscheidung läßt sich allerdings überzeugend erklären, wenn man sich neben den individuellen Interessen des Autors, der sich innerhalb seines antiquarischen Schriftums auch mit grammatischen Fragen beschäftigte, ${ }^{45}$ die spätestens seit flavischer Zeit ungemein gestiegene gesellschaftliche Anerkennung des Berufsstandes der professores vor Augen hält. Handelte es sich, wie wir nicht zuletzt aus Suetons Kurzbiographien wissen, bei den Grammatik- und Rhetoriklehrern in der Republik zumeist um Sklaven oder Freigelassene, so setzt mit der wachsenden Bedeutung gerade literarischer Bildung in der Kaiserzeit auch der kontinuierliche soziale Aufstieg der mit ihrer Vermittlung betrauten Personen ein. Dieser läßt sich an einzelnen Punkten wie der Bestellung Quintilians zum staatlich besoldeten Rhetoriklehrer durch Vespasian ${ }^{46}$ oder an der Verherrlichung der Tătigkeit als grammaticus, die Florus im Prolog seiner in der ersten Hälfte des 2 . Jh. $\mathbf{n}$. Chr. entstandenen Schrift Vergilius orator an poeta? verfaßt hat, ${ }^{47}$ paradigmatisch ablesen läßt. ${ }^{48}$

Vor diesem Hintergrund erweist sich Suetons Entscheidung, in seinem, Who's Who?' der literarischen Welt Roms ${ }^{49}$ mit den professores deren prominenteste Vermittler zu berücksichtigen, als in hohen Maße zeitgemäß und richtungsweisend. ${ }^{50}$ In

43 Dagegen wurde von BrUGNOLI 1968, 33f., die These vertreten, daß es sich bei diesen beiden Rubriken um eine Art Appendix gehandelt haben könnte (vgl. femer VILAMAA 1991, 3826f.).

44 Vgl. BALDWIN 1983, 385, u. KASTER 1995, xxiiiff. Der innovative Charakter von Suetons Sammelbiographie würde noch einmal verstärkt, wenn sich die von LEO 1901, 141, angestellte Beobachtung verifizieren ließe: „Wir kőnnen aber auch auf romischem Boden vor Sueton kein Werk $\pi \varepsilon \varrho i ~ E v \delta \delta o ́ \xi \omega v$

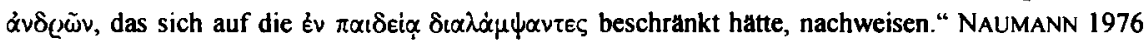
erblickt in Sueton überhaupt den ersten Biographen von viri litteris illustres in Rom.

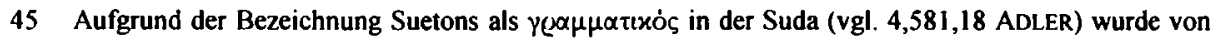
MACÉ 1900, 53ff., auf eine eigene Lehrtătigkeit geschlossen, doch läBt sich diese Annahme nicht weiter belegen und muß angesichts seiner ritterlichen Herkunft als unwahrscheinlich gelten (vgl. WALLACE-HADRILL 1983, 30).

46 Vgl. Hier. chron. 190 HELM mit Suet. Vesp. 18.

47 Vgl. Flor. Verg. praef. 3,2-8 u. ferner STEINMETZ 1982, 90f.

48 Vgl. allgemein MARrou 1957, 435ff.; Christes 1975, 228ff.; STEINMETZ 1982, 79ff;; WALlaCeHADRILL 1983, 31 ff., U. MRATSCHEK-HALFMANN 1993, $15 f$.

49 Vgl. BALDWIN 1983, 514: „The De viris illustribus can hardly be deemed biography in any of our senses of the word. More accurate and fair, by far, to compare that compilation to a Who's Who register."

50 Über mögliche Nachfolger Suetons auf diesem Gebiet ist wenig bekannt; immerhin verfaßte im aus-

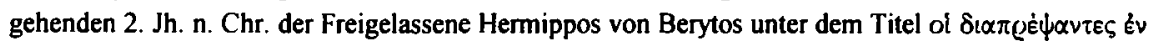


ähnlicher Weise innovativ dürften die beiden von Sueton als praefationes den einzelnen Rubriken vorangestellten kulturhistorischen Überblicke über die Entwicklung der Grammatik und Rhetorik in Rom gewesen sein, ${ }^{51}$ zumindest läßt sich aus den erhaltenen Fragmenten hellenistischer oder republikanischer Literatur $\pi \varepsilon \varrho i ~ z \nu \delta \delta o \dot{\xi} \omega \nu \alpha \dot{\alpha} \nu \delta \varrho \tilde{\omega} \nu$ kein Vorgănger rekonstruieren. ${ }^{52}$ Mit großer Wahrscheinlichkeit wurden auch die übrigen Kategorien mit einer solchen Zusammenfassung eingeleitet. Suetons biographisches Sammelwerk berührt sich hier mit zahlreichen anderen Schriften, die im Laufe des 2. Jh. n. Chr. im Kontext der Wissensvermittlung entstanden sind und die Absicht verfolgten, dem breiter gewordenen Publikum eine knappe Einfuhrung in ein Fachgebiet zu geben. ${ }^{53}$

In der engen Interaktion mit den kulturellen und gesellschaftlichen Rahmenbedingungen besteht wohl auch der wesentliche Unterschied zu den in der späten Republik von Varro, Nepos oder Hygin verfaßten biographischen Sammelwerken. ${ }^{54}$ Von diesen Autoren war durch ihre Adaption des hellenistischen Formats $\pi \varepsilon \varrho i ~ \varepsilon ́ v \delta \dot{\delta} \xi \omega \nu \alpha \dot{\alpha} \delta \varrho \tilde{\omega} \nu$ mit einem Schwerpunkt auf den literarischen viri illustres in Rom ein wichtiger Beitrag zur Initiierung jenes Prozesses geleistet worden, ${ }^{55}$ der in der frühen Kaiserzeit kontinuierlich an Dynamik gewann ${ }^{56}$ und im 2. Jh. $n$. Chr. kulturelles und literarisches Wissen zu einer entscheidenden gesellschaftlichen Qualifikation werden ließ. Obwohl Sueton also gewissermaßen auf der anderen Seite einer langjährigen und durch diese Form der biographischen Wissensvermittlung mitgestalteten Entwicklung steht, bleibt die Form seines Werkes de viris illustribus doch vergleichsweise traditionell. ${ }^{57}$

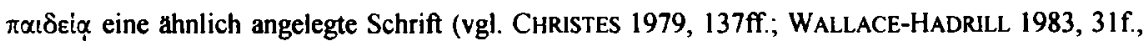
u. KASTER 1995, xlviii-xlix).

51 Vgl. Suet. gramm. 1-4 u. 25.

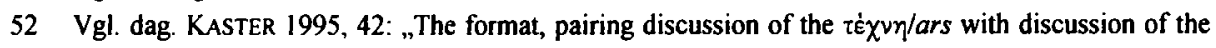

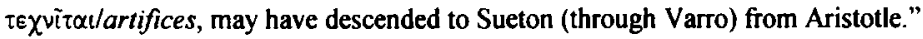

53 Vgl. STEINMETZ 1982, $116 \mathrm{f}$.

54 Neuere Forschungsansätze haben allerdings auch fur Nepos eine stärkere Bezugnahme auf die gesellschaftlichen Verănderungen der spăten Republik plausibel machen können. Dies gilt vor allem für die Vita des Atticus, der als Modell eines vor dem Hintergrund der republikanischen Tradition, alternativen' Lebensentwurfes präsentiert wird (vgl. LEPPIN 2002 u. MUTSCHLER 2003), aber auch fur die Berucksichtigung politischer und gesellschaftlicher Implikationen in seinen literarhistorischen Schriften (vgl. SCHWINDT 2000, 122ff.).

55 Vgl. dag. NAUMANN 1976, fur den die literarische Biographie in Rom erst mit Sueton beginnt.

56 Biographien scheinen in dieser Zeit allerdings nur vereinzelt entstanden zu sein. Als gut bezeugt konnen die Schriften des alteren Plinius über Pomponius Secundus (vgl. Plin. ep. 3,5,3), die des Julius Secundus über Julius Africanus (vgl. Tac. dial. 14) und die 1820 als Palimpsest zum Vorschein gekommene Schrift de vita patris des jüngeren Seneca (vgl. PETER HRR II 98 Frg 1) gelten (vgl. BALDWIN 1983, 79f.); wahrend die Persius-Vita, die von Leo 1901, 139, Valerius Probus zugeschrieben wurde, heute im allgemeinen fur ein Werk Suetons gehalten wird.

57 Vgl. SALLMANN / SCHMIDT 1997a, 28f. Eine interessante Parallele sowohl zur Entwicklung der hellenistischen Sammelbiographie im Umfeld der Etablierung der Bibliothek von Alexandria als auch zur 
Das gilt zunächst für die gerade in Relation zu den Kaiserbiographien auffällige Kürze der allermeisten Viten, ${ }^{58}$ die zwar die von modernen Rezipienten an eine Biographie gestellten Erwartungen nicht erfüllen kann, den antiken Gepflogenheiten bei der Beschreibung des Lebens von Dichtern oder Gelehrten aber durchaus entspricht. ${ }^{59}$ Gegenüber neuzeitlichen Vorstellungen einer Biographie ist noch ein weiteres ,Defizit' besonders augenfällig: Sueton ,geht es nicht um die Zeichnung eines geschlossenen Lebensbildes als eines moralischen Phänomens, sondern darum, daß alle Informationen über eine Person geordnet mitgeteilt werden, die für das Gebiet, auf dem sie sich ausgezeichnet und zu dessen Entwicklung sie beigetragen hat, wissenswert und von Bedeutung sind. ${ }^{600}$ In diesem Punkt unterscheiden sich Suetons Biographien von der etwa bei Plutarch greifbaren Tradition einer antiken Lebensbeschreibung, die sich - wenn auch nur in gewissem Umfang $-{ }^{61}$ mit den für die Neuzeit zentralen Fragen des Charakters und seiner Entwicklung beschäftigt.

FRIEDRICH LEO hat, wie bereits gesehen, diesen Unterschied gattungshistorisch erklärt, indem er Plutarchs Biographiemodell auf die Moralphilosophie des Peripatos und die Schriften de viris illustribus auf die Bedürfnisse der alexandrinischen Philologie zurückführte. ${ }^{62}$ Damit hat er trotz aller berechtigten Kritik insoweit etwas Richtiges getroffen, als er geschichtliche Situationen bestimmt hat, in denen unterschiedliche Konzeptionen biographischen Schreibens entstanden sind. Seine weitergehenden Folgerungen gehen jedoch von einem zu starren Gattungsmodell aus und lassen unberücksichtigt, daß für spătere Epochen beide Formen bereitlagen und von ihnen je nach ihren Bedürfnissen aufgegriffen, modifiziert und kombiniert werden konnten. So dürfte auch für Sueton die funktionale Eignung des von ihm gewählten biographischen Formates zur zielgerichteten Vermittlung kulturhistorischen Wissens ausschlaggebend gewesen sein und nicht die Treue gegenüber hellenistischen Vorbildern. ${ }^{63}$

biographischen Schriftstellerei Varros, der von Caesar mit der Einrichtung der ersten offentlichen Bibliothek Roms betraut worden war (vgl. Suet. lul. 44,2), ergabe sich, wenn die verschiedentlich geaußerte (vgl. WALLACE-HADRILL 1983, 82, u. LiNDSAY 1995, 2), Vermutung zutreffend wăre, daß Sueton von Trajan mit der Leitung der $113 \mathrm{n}$. Chr. gegrundeten bibliotheca Ulpiana beauftragt wurde.

Die vita Vergilii erreicht in etwa den Umfang der Biographien von Titus oder Otho.

59 Vgl. BALDWIN 1983, 384.514.

60 Vgl. DIHLE 1987, 64.

61 Vgl. WEHRLI 1973, 193: „Ein gemeinsames Merkmal beinahe aller erhaltenen Biographien besteht darin, dass ihnen eine durchgehende Erzahlung des Lebenslaufes fehlt, dass sie vielmehr ein im wesentlichen statisches Bild der Persönlichkeit und ihrer Lebensweise (bios) zu vermitteln suchen." Ein Gegenbeispiel erblickt LAMBrECHT 1995, 528f., in der Domitiansvita Suetons.

62 Vgl. LEO 1901, v.a. 132ff., u. s.o. S. 233 f.

63 Vgl. z.B. SallmanN / SCHMidT 1997a, 46f., der Sueton in die Tradition der „literarisch ambitionierten, vom Peripatos (...) ausgebildeten ethopathologischen Personlichkeitsbiographie“ stellt und damit eine fur den komplexen Charakter der suetonischen Biographien bezeichnende Kontrărposition zu den 
In welchem Maße für Sueton bei der Abfassung von de viris illustribus die Wissensvermittlung im Mittelpunkt stand, verdeutlicht neben seinem Verzicht auf eine aufwendigere literarische Stilisierung ${ }^{64}$ besonders ein Blick auf die Organisation des Textes. Bislang wurde die Frage, ob die in der handschriftlichen Tradition enthaltenen und von REIFFERSCHEID in seine Fragmentausgabe aufgenommenen Indizes zu den einzelnen Rubriken auf Sueton zurückgehen, mehrheitlich verneint. ${ }^{65}$ Doch aufgrund der vergleichenden Untersuchung verschiedener Schriften des 1 . und 2. Jh. $n$. Chr. ist in die Bewertung solcher paratextuellen Elemente, die von den Editoren bislang eher stiefmütterlich behandelt wurden, Bewegung gekommen. Vor diesem Hintergrund kann es inzwischen als durchaus wahrscheinlich gelten, daß spätestens seit der naturalis historia des älteren Plinius Inhaltsverzeichnisse in lateinischer Prosa, speziell bei Autoren der Fachschriftstellerei, bekannt waren und als ,neue Dienstleistungen des Autors gegenüber dem Leser ${ }^{466}$ auch vielfach verwendet wurden. ${ }^{67}$

Doch auch der eigentliche Text weist bereits eine Struktur auf, die eindeutig der raschen Orientierung und Information des Lesers den Vorzug gegenüber einer ambitionierteren, etwa dem Prinzip der variatio verpflichteten Form der Präsentation gibt. Nach einer jeweils den Inhalt der ganzen Rubrik angebenden Gesamtuberschrift am Ende der praefatio, ${ }^{68}$ die nach dem Vorbild von de grammaticis und de rhetoribus mit einer gewissen Plausibilität auch für die nicht erhaltenen Abschnitte angesetzt werden kann, beginnen die einzelnen Kurzbiographien mit dem Namen des Porträtierten im Nominativ sowie in der Regel einer knappen Angabe zu seiner Herkunft in variierender Form. ${ }^{69}$ Auf diese Weise entsteht - zumal wenn man von der Zuhilfenahme der im Rahmen der antiken Möglichkeiten gegebenen optischen Akzentuierungen wie der

Thesen LEOs einnimmt. Die Unterschiede zu den erhaltenen Beispielen griechischer Biographien werden von LINDSAY 1995b, 70f., zusammengestellt.

64 Zur , wissenschaftichen' Diktion als Charakteristikum der Gelehrtenbiographie vgl. LEO 1901, 134.

65 Vgl. gegen ihre Authentizitat z.B. KASTER 1995, 41f.

66 Vgl. KRASSER 1999, 62; ausfuhrlicher s.o. S. 7.23f.30ff.

67 Vgl. KRASSER 1996, 148.166; KrASSER 1999, 62, u. SCHRÖDER 1999, 92ff.106ff.I56ff., die außerdem plausibel machen $k a n n, \mathrm{da} B$ sich diese Indizes aufgrund der gewandelten Rezeptionsbedingungen im Laufe der handschriftlichen Überlieferung als besonders gefahrdet erweisen mußten. Zur Bedeutung der naturalis historia vgl. CONTE 1991, 95ff.; SCHMIDT 1997a, 225f.; NIKITINSKI 1998, 345ff., u. SCHRODER 1999, 92ff.).

68 Vgl. Suet. gramm. 4,7 (clari professores et de quibus prodi possit aliquid-dumtaxat a nobis-fere $h i$ fuerunt) u. 25,6 (illustres professores et quorum memoria aliqua exstet non temere alii reperientur quam de quibus tradam).

69 Aus dem vorangestelltem Lemma im Nominativ entwickelt sich die Kapiteluberschrift, die in Texten, die nicht primăr aber Eigennamen erfaßt werden, schließlich (u.a. wegen der Konvergenz mit dem Inhaltsverzeichnis) vorwiegend die Form einer indirekten Frage oder eines Prapositionalausdrucks mit de annimmt (vgl. SCHRODER 1999, 125f.). 
ह̌x $\theta \varepsilon \sigma ı \zeta$ oder der Rubrizierung des ersten Wortes eines Kapitels ausgeht ${ }^{70}-$ der Eindruck eines Kataloges ${ }^{71}$ oder eines biographischen Lexikons, zumindest aber einer Textform, die neben der durchgängigen Lektüre auch für das gezielte Nachschlagen geeignet ist. Bei diesem als Orientierungshilfe dienenden Präskript scheint es sich, wie ein Vergleich mit den erhaltenen Passagen des von Nepos in den letzten Jahrzehnten der Republik unter dem gleichen Titel verfaßten Werkes zeigt, um einen traditionellen Zug der Sammelbiographie zumindest in ihrer römischen Ausprägung gehandelt zu haben. ${ }^{72}$

Gegenüber diesem standardisierten, der Orientierung des Lesers dienenden Kopfteil erweist sich der darstellende Teil der einzelnen Viten je nach den individuellen Gegebenheiten der beschriebenen Person sowie moglicherweise der Quellenlage als in hohem Maße flexibel. ${ }^{73}$ Zwar gibt es einige wiederkehrende Themen, die entweder für Sueton und seine Leser oder furr eine Biographie generell von zentralem Interesse sind, wie soziale Herkunft, verfaßte Schriften, gesellschaftliche Anerkennung oder die Umstände des Lebensendes. Aber selbst diese Punkte werden nicht in jeder Biographie, sondern nur nach ihrer Relevanz fưr die jeweils dargestelite Person angesprochen. ${ }^{74}$ Die nüchterne Vermittlung von Fakten geht dabei nahtlos in die Charakterisierung mittels Anekdoten oder der Wiedergabe von Originalzitaten aus den Werken der betreffenden Personen ${ }^{75}$ über, ohne daß sich eine strenge Scheidung zwischen reiner Informationsvermittlung und ausschließlicher Charakterschilderung vornehmen ließe. Dabei beachtet Sueton in der Regel eine ungefähre chronologische Reihung, die nach

70 Vgl. SCHRODER 1999, $103 \mathrm{f}$.

71 Vgl. SCHMidt 1891, 43; FUNAIOLI 1931, 599, u. VILJAMAa 1991, 3840f., sowie ferner BRUGNOLI 1968, 41 ff., u. SALLMANN / SCHMIDT 1997a, 27, die calalogus virorum illustrium als Titel des Werkes vorschlagen.

72 Es zeigen sich allerdings auch einige Unterschiede zwischen den beiden Autoren: Auf der inhaltlichen Seite ist auffallig, daß Nepos abweichend von Sueton in der Regel den Namen des Vaters nennt, doch ist diese Differenz zu einem Großteil wohl auf die sozialen Unterschiede der dargestellten Personen zurückzufuhren. Kompositorisch erweist sich Sueton insofem als geschickter, als bei ihm durchgängig der vorangestellte Namen im Nominativ auch syntaktisch mit dem Folgenden verbunden ist, wahrend dies bei Nepos nur in etwa der Halfte der erhaltenen Beispiele der Fall ist. Nepos gibt dafur im ersten Satz hăufig eine Art Quintessenz der folgenden Biographie, eine Technik, die von Sueton jedoch spăter innerhalb einzelner Rubriken der Kaiserbiographien angewandt wird (s.u. S. 266).

73 Vgl. ViljamaA 1991, 3840f., u. mit stärkerer Betonung des ,Schemas der Preisrede' in der Mikrostruktur der Einzelviten SALLMANN/SCHMIDT 1997a, 28f.

74 Vgl. VILJAMAa 1991, 3846f., u. LINDSAY 1995b, 77, sowie dag. mit stärkerer Betonung des Rubrikenschemas SCHMIDT 1891, $42 \mathrm{ff}$.

75 Vgl. LINDSAY 1995b, 75: „Moreover, Suetonius appears to use the actual words of a subject in the same way as anecdotal material; quotation is used to highlight characteristics of the subject, or occasionally to throw light on a realtionship with a significant person." 
dem Ausweis der beiden umfänglicher erhaltenen Rubriken auch grosso modo für die Anordnung der Biographien untereinander ausschlaggebend war. ${ }^{76}$

Suetons Entscheidung, die Porträtierten in einer gleichsam wertneutralen chronologischen Reihung zu präsentieren, enthebt ihn zwar der Entscheidung, den einzelnen Vertretern innerhalb einer Kategorie ihren Platz nach ihrer Bedeutung zuzuweisen, dennoch beinhaltet natürlich bereits die Aufnahme oder Nichtaufnahme der einzelnen Person in die jeweilige Rubrik ein nicht zu unterschätzendes $\mathrm{Ma} \beta$ an Wertung. Sueton versucht den Eindruck, daß mit seiner Sammelbiographie ein Kanon etabliert wird, in den Abschnitten de grammaticis und de rhetoribus zu vermeiden und versichert in der praefatio ausdrücklich, daß es sich um alle noch bekannten Vertreter der betreffenden Disziplin handelt. ${ }^{77}$ Es ist allerdings nur schwer vorstellbar, daß dieser Anspruch von ihm glaubhaft auch für die Rubriken de poetis oder de oratoribus erhoben werden konnte. Hier lassen sich die den professores-Viten eher implizit zugrundeliegenden Wertungskategorien ${ }^{78}$ deutlich fassen. Sueton erweist sich dabei als ein den Anschauungen Quintilians nahestehender Klassizist. Seine Interessen lassen einen deutlichen Schwerpunkt auf der Literatur der späten Republik und der augusteischen Zeit erkennen, während die Autoren der frühen Kaiserzeit nur vereinzelt Berücksichtigung finden. Mit dem Erreichen der eigenen Zeit dürfte seine Darstellung gemäß dem auch bei Quintilian greifbaren Grundsatz, keine lebenden Schriftsteller zu nennen, ihr Ende gefunden hatte. $^{79}$

Die Einzelviten sind als abgeschlossene Einheiten konzipiert und weisen keinerlei explizit gemachte Bezüge untereinander auf. Dies mag seinen Grund zum einen darin haben, daß übergreifende Aspekte bereits in den jeweiligen praefationes zur Sprache gebracht werden. Es zeigt sich zum anderen hierin aber auch erneut, daß Sueton mit einem Rezipienten rechnet, der die viri illustres in der Art eines thematisch geordneten biographischen Lexikons bei der gezielten Suche nach bestimmten Informationen konsultiert und deswegen an Querverweisen nur bedingt interessiert ist. Das schließt nicht aus, daß Sueton auch solche Rezipienten im Blick hatte, die seine Sammelbiographie von der ersten bis zur letzten Seite lesen wollten. Aber gerade ein Vergleich mit Nepos, dessen Schrift sich noch schwerer zwischen den Polen eines Nachschlagewerkes und eines zur durchgängigen Lektüre bestimmten Buchs einordnen läßt, ${ }^{80}$

76 Vgl. VILJAMAa 1991, 3841.

77 Vgl. Suet. gramm. 4,7 (clari professores et de quibus prodi possit aliquid-dumtaxat a nobis-fere hi fuerunt) u. 25,6 (illustres professores et quorum memoria aliqua exstet non temere alii reperientur quam de quibus tradam).

78 Vgl. CizEK 1974. 306ff., mit der These einer impliziten, vor allem durch die Auswahl und Anordnung des anekdotischen Materials erreichten klassizistischen Wertung in de grammaticis et rhetoribus.

79 Vgl. Wallace-HadRILL 1983, 52ff., u. VILJAMAa 1991, $3841 \mathrm{f}$.

80 Dies wird beispielsweise an den verschiedentlich eingestreuten Überleitungen deutlich: vgl. Nep. Alk. 11,6; Timoth. 4,4-6 u. Hann. 13,4 sowie ferner HOLZBERG 1989, 165. 
zeigt, daß die suetonischen viri illustres in erster Linie der schnellen und übersichtlichen Vermittlung biographischen Wissens dienen sollen.

Wie verhält sich nun das Bild, das wir uns von den Suetons viri illustres machen können, zu den ungleich bekannteren Kaiserbiographien desselben Autors? Vor dem Hintergrund seiner Theorie zweier streng geschiedener biographischer Traditionen hat FRIEDRICH LEO einen markanten Unterschied zwischen beiden Sammelbiographien gesehen, der für ihn vor allem darin bestand, daß Sueton in seinen Literatenviten das alexandrinische Modell in Reinform rezipiert, es jedoch bei der Abfassung der Caesares mit dem peripatetischen Biographietypus kontaminiert habe. ${ }^{81}$ Das Postulat eines derartigen qualitativen Unterschiedes zwischen den beiden Schriften hat jedoch mit der Aufgabe des dahinterstehenden Theoriemodells den Großteil seiner Plausibilität eingebüßt, und daher betont die neuere Forschungsliteratur vor allem die quantitative Differenz. $^{82}$ Dabei wird die zeitliche Priorität von de viris illustribus gegenüber den Kaiserbiographien in der Regel vorausgesetzt, wenn auch nicht selten auf das Fehlen externer Zeugnisse explizit hingewiesen wird. ${ }^{83}$ Trotz aller berechtigten Skepsis wird im folgenden auch hier im Sinne eines gleichsam evolutionistischen Modells für Suetons Schriften ein Übergang vom kleineren und traditionelleren Format der Lebensbeschreibung von Intellektuellen zu den größeren und literarisch ambitionierten Kaiserviten angenommen. ${ }^{84}$

81 Vgl. Leo 1901, 15f.14If. u. 319f.: „Sueton hat dieses Programm discret und verstăndig durchgefuhrt, nirgend auf das Gebiet der Historie übergreifend, in rein gehaltenen, um des Gegenstandes willen leise gesteigertem wissenschaftlichen Stil. Aber es war eine der Geschichte der Gattung widersprechende Bildung, die Übertragung der furr litterarische Personen ausgebildeten und geeigneten Form auf eminent politische Mănner.“

82 Vgl. bereits LEO 1901, 15f:: „Die Caesares beanspruchen eine wirkliche Beschreibung der Persönlichkeit zu geben, die litterarischen vitae geben nur einige Notizen, die dem Leser, der sich den Werken des Mannes năhem will, einen Anhalt und Ausgangspunkt geben; sie verhalten sich zu den Caesares wie das Excerpt zu einem Buche oder die Skizze zu einer Ausfuhrung." u. ferner z.B. WALLACEHADRILL 1983, 59f.66f: „The vast majority of the literary lives were no more than thumb-nail sketches.“, aber auch die Betonung der Unterschiede durch LEWIS 1991, 3666: „As a ,type-series' or $\delta i \alpha \delta o \chi \dot{\eta}$ of sorts, the ,Caesares' might be reckoned comparable, but there significant resemblance apparently ends, for probably their scale, to a large extent their content and structure, and cetainly their motivation, ideology and treatment were very different ...".

83 Ein Anhaltspunkt ergabe sich allenfalls, wenn die Identifikation des Werkes, dessen in seinen Augen zu zogerliche Publikation Plinius bei Sueton anmahnt (Plin. ep. 5,10), mit de viris illustribus stichhaltig wăre (vgl. MACÉ 1900, 66ff., u. dag. LINDSAY 1995b, 75).

84 Vgl. WALLACE-HADRILl 1983, 59f:: „The progression was a natural one in more than one sense. Nepos, and probably Hyginus, had included generals or politicians alongside literary figures in their biographies." Von derselben Beobachtung ausgehend hat BALDWIN 1983, 383f., die Vermutung geăuBert, die Kaiserbiographien könten ein Teil der viri illustres gewesen sein. 
Wie weitreichend die Parallelen des suetonischen Hauptwerkes zu de viris illustribus - vielleicht entgegen dem ersten Eindruck - tatsächlich sind ${ }^{85}$ kann am besten ein Blick auf die gleichfalls als fortlaufende Reihe konzipierten Biographien der römischen Kaiser von Augustus bis Vitellius verdeutlichen, die Plutarch vermutlich in den letzten Jahren Domitians oder unter Nerva geschrieben hat ${ }^{86}$ und von denen sich nur die Lebensbeschreibungen des Galba und Otho erhalten haben. ${ }^{87}$ Für beide Schriften läßt sich also mit einiger Plausibilität der gleiche Entstehungszeitraum ansetzen, und es ergeben sich auch inhaltliche Überschneidungen, die um so auffälliger sind, als uns Nachrichten über an Herrscherdynastien orientierten Reihenbiographien aus der Zeit vor diesen beiden Werken fehlen. ${ }^{88}$ Dennoch lassen sich Gemeinsamkeiten, die über das hinausgehen, was bei der Beschăftigung zweier in der gleichen Zeit schreibender Autoren mit dem gleichen Stoff zu erwarten ist, ${ }^{89}$ ebensowenig aufzeigen wie eindeutige Bezugnahmen des einen auf den anderen oder vice versa. ${ }^{90}$

85 Formale Übereinstimmungen zwischen Nepos und den Caesares wurden bereits mehrfach konstatiert (vgl. z.B. SCHMIDT 1891, 14ff., u. STEIDLE 1951, 145ff.), ohne jedoch die vermittelnde Funktion der suetonischen viri illustres gebührend zu berücksichtigen.

86 Die Priorităt der Kaiserviten Plutarchs sowohl gegenüber suetonischen Caesares als auch gegenüber den plutarchischen Parallelbiographien stellt die unstrittige communis opinio dar (vgl. z.B. BOWERSOCK 1998, 196). Eine genauere Datierung wurde von JOSEPH GEIGER angestrebt, der vor dem Hintergrund der programmatischen Bezugnahme Trajans auf Caesar dessen Fehlen bei Plutarch als Argument für eine frühere Entstehungszeit gewinnt (vgl. GEIGER 1975 u. 2002). Wahrend dieser terminus ante quem weitgehende Zustimmung gefunden hat, gilt das fur den von GEIGER gleichfalls vertretenen Ausschluß der Herrschaft Domitians als aus politischen Grunden ungeeignete Abfassungszeit und die daraus resultierende Datierung in die Regierung Nervas nur bedingt (vgl. zustimmend SYME 1980a, 106f.110f., sowie dag. JONES 1971, 72f., u. BOWERSOCK 1998, 197ff.).

87 Es existiert außerdem jeweils ein Fragment aus der Biographie des Tiberius sowie des Nero und von derjenigen des Augustus läßt sich eine ungefähre Vorstellung aus anderen plutarchischen Schriften gewinnen (vgl. JONES 1971, 79f.).

88 Der oft angeführte Kopenhagener Papyrus (P. Haun. 6) enthalt wenig mehr als ein Namensregister (vgl. Gallo 1975, 57ff., u. BowERSOCK 1998, 193f., sowie dag. Geiger 1981, 86 Anm. 5, mit Beispielen für hellenistische Reihenbiographien, die anhand des jeweiligen Herrschaftsgebietes organisiert sind, u. LEO 1901, 142, der die über die $\delta\llcorner\alpha \delta \propto \chi \dot{\eta}$ der Schulhaupter zusammengehaltenen philosophischen Sammelbiographien als Vergleich heranzieht).

89 Die altere Literatur zur Quellenfrage faßt JONES 1971, 74ff., zusammen, der sich zugleich von der lange Zeit vorherrschenden Sichtweise absetzt, daß Plutarchs Biographien im wesentlichen auf einen unbekannte, aber bedeutenden lateinischen Historiker des 1. Jh. zuruckgehen (vgl. v.a. SYME 1958a, 180ff.674ff., u. SYME 1980a, 105ff.).

90 Vgl. Gugel 1977, 145f., u. Bowersock 1998, 194f., sowie dag. BaLDWIN 1983, 87ff.530ff., der eine Korrektur des von Plutarch gezeichneten Bildes durch Sueton vermutet. Eine mögliche Bezugnahme liegt allerdings vor, wenn Sueton in der Othovita seinen eigenen Vater als Augenzeugen anführt (vgl. Suet. Otho 10,1), da Plutarch ebenfalls in der Biographie Othos seinen Patron Mestrius Florus erwăhnt (vgl. Plut. Otho 14,2 u. ferner BALDWIN 1983, 544). Zur Bedeutung mundlicher Quellen bei Plutarch vgl. allg. THEANDER 1959 u. JONES 1971, 75f. 
Plutarchs Kaiserviten wird in der Forschung mehrheitlich der biographische Charakter abgesprochen und statt dessen ihre Nahe zur Geschichtsschreibung betont. ${ }^{91}$ Dieser Eindruck entsteht einerseits durch die Entscheidung Plutarchs, die Lebensläufe der drei letztlich gescheiterten Herrscher des Vierkaiserjahres in enger Verbindung zu schildern und auf diese Weise eine chronologisch mehr oder weniger durchgängige Erzăhlung zu schaffen, innerhalb derer ein Teil der biographischen Informationen zu den einzelnen Kaisern an ihrem historischen Ort und nicht in der eigentlichen Vita der jeweiligen Person ihren Platz finden. ${ }^{92}$ Andererseits betrachtet er die Regierungen der sich in schneller Reihenfolge ablösenden Herrscher, wie er in dem der Darstellung des Vierkaiserjahres vorangestellten Proömium erläutert, unter dem gemeinsamen Aspekt des schädlichen Einflusses, den das Militär in dieser Zeit auf die Geschicke des römischen Staates ausgeübt hat. Als kongruent mit diesem eher historiographischen als genuin biographischen Interesse erweist sich ferner die Bedeutung, die Plutarch im Unterschied zu Sueton den Personen im Umfeld der Herrscher einräumt, und die weitgehende Ausblendung des vorherigen Lebens seiner Protagonisten. ${ }^{93}$

Diese Beobachtungen sind zwar zumindest für den erhaltenen, allerdings möglicherweise nicht charakteristischen Teil der Kaiserbiographien, ${ }^{94}$ zutreffend. Plutarch selbst jedoch setzt auch seine Kaiserviten wie später die Parallelbiographien deutlich von der Geschichtsschreibung ab:

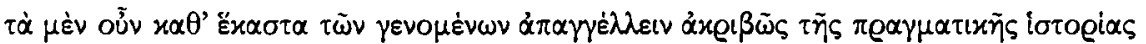

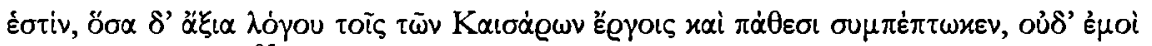

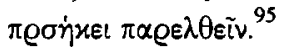

Gerade weil es sich bei dieser Abgrenzung um einen Topos innerhalb der biographischen Literatur der Antike handelt, ${ }^{96}$ wird deutlich, daß Plutarch sich auch bei der Be-

91 Vgl. z.B. Leo 1901, 156; SYME 1980a, 104, u. mit weiterer Literatur Braun 1992, 102 Anm. 24.

92 Dies gilt vor allem für die Einfuhrung Othos, die in der Galbavita erfolgt (vgl. Plut. Galba 19-20 u. ferner GEORGIADOU 1988, 354). Die Herausgeber des Teubnertextes verweisen zudem auf die in einigen Handschriften fehlende Trennung der beiden im Rahmen des Moralia-corpus uberlieferten Biographien (vgl. LINDSKOG / ZIEGLER 1973, xiv-xv).

93 Vgl. BRAUN 1992. 95f. 102, u. ASH 1997, 189f.

94 Der Gedanke, daß es sich bei den Biographien Galbas und Othos innerhalb der Kaiserviten Plutarchs um Ausnahmen gehandelt habe, wird vor allem von ASH 1997, 190ff., stark gemacht.

95 Vgl. Plut. Galba 2,5 („Die Einzelheiten der Reihe nach und detailliert zu schildern stellt die Aufgabe eines Geschichtswerkes dar, doch alles, was den Kaisern aufgrund ihrer Handlungen oder Erfahrungen zugestoßen ist und eine Erwahnnung verdient, darf auch ich nicht ubergehen.") sowie ferner Plut.

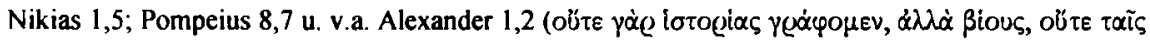

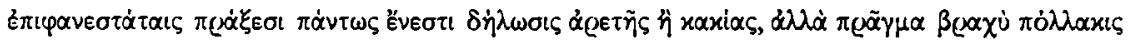

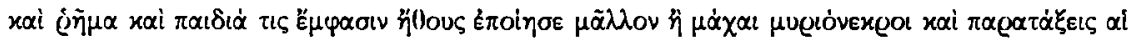
$\mu$ 취 besprochen von FRAZIER 1999, 17ff., u. DUFF 1999, 14ff., wobei letzterer sie allerdings eng auf ihren jeweiligen Kontext bezogen wissen will. 
handlung des Vierkaiserjahres nicht als Historiker verstanden wissen wollte. ${ }^{97}$ Ebenso wie in seinem späteren Hauptwerk liegt trotz der im Proömium aufgeworfenen Problematik des Militärs und seines Einflusses auf die Ernennung der Kaiser der Akzent im eigentlichen Text dann auch doch recht eindeutig auf der Charakterschilderung der beiden Herrscher und somit auf der moralischen Unterweisung. ${ }^{98}$

Mit dem Anspruch der Vermittlung eines moralischen Nutzens bewegt sich Plutarch zwar in der Nähe zur sogenannten moralischen Geschichtsschreibung, mit der beispielsweise Theopomp oder Ephoros in der intensiv geführten historiographischen Debatte der hellenistischen Zeit eine dritte Position zwischen der $\tau \dot{Q} \varrho \psi \iota \varsigma$ Herodots und der $\dot{\omega} \varphi \dot{e} \lambda_{\epsilon \in \iota} \alpha$ des Thukydides bezogen hatten und deren Selbstverständnis sich mit den

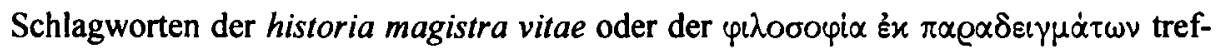
fend umschreiben läßt. ${ }^{99}$ Doch machen diese intentionalen Übereinstimmung Plutarch nicht zwingend zum Historiker, da moralphilosophische Zielsetzungen auch innerhalb der Biographie auf eine reiche Tradition zurückblicken können. Allerdings sind wir, um eine Vorstellung von der Form solcher Lebensbeschreibungen zu gewinnen, im wesentlichen auf Plutarchs Biographien angewiesen, so daß es schwierig abzuschätzen ist, wie groß ihre Abweichung von diesem biographischen Modell und damit ihre Năhe zur Geschichtsschreibung tatsăchlich waren.

In der Darstellungstechnik und der inhaltlichen Schwerpunktsetzung ist die Distanz zu den Parallelbiographien jedenfalls nicht allzu groß. Fundamental unterscheidet sich dagegen diese Form der Biographie in ihrer narrativen Strategie und damit ihrer Funktionalität von derjenigen des suetonischen Typs. Plutarch versucht den Spagat zwischen einer ästhetisch befriedigenden Präsentation des Materials und der inhaltlichen Fokussierung auf das Individuum, indem er einzelne, in sich geschlossene Abschnitte, die zwischen knapp skizzierten Anekdoten und ausführlicheren historiographischen Erzählungen changieren, narrativ verbindet und grosso modo chronologisch präsentiert. ${ }^{100}$ Sueton dagegen verzichtet zumeist, wenn auch nicht immer, auf diese Gratwanderung und stellt den informativen Charakter seines Textes eindeutig in

96 Vgl. Pol. 10,21,8; Cic. fam. 5,12,2-7 u. Nep. Pelop. 16,1,1 sowie ferner JONES 1971, 73.

97 Vgl. dag. die von GEORGIADOU 1988, v.a. 350f., vertretene Interpretation, daB Plutarch im Galbapro-

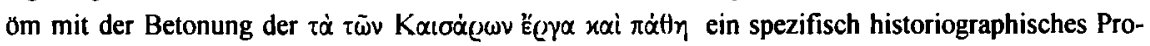
gramm vertritt, das sich deutlich von demjenigen der Parallelbiographien unterscheide.

98 In den Kaiserviten zeigt sich dieses vorwiegend moralische Interesse vor allem an der außerst vorteilhaften Charakterschilderung der Protagonisten (vgl. JONES 1971, 73f.80).

99 Vgl. Cic. de or. 2,36 u. Ps.-Dion. Hal. rhet. 11,2 sowie ferner z.B. Walbank 1990, 255, u. Pownall 2004).

100 Auf den ersten Blick haben knappe Anekdoten (wie das klassische Apophthegma Plut. Caesar 11,3-4) einerseits und umfangreiche Exkurse (wie die historiographisch geschilderte Schlacht von Pharsalos: Plut. Caesar 39-46) andererseits nicht viel gemeinsam, doch sind es solche Einheiten von unterschiedlicher Lange und Gestaltung, die von Plutarch mit knappen Überleitungen und unter Beachtung einer ungefăhren Chronologie aneinandergereiht werden und dann das Ganze einer Biographien ergeben. 
den Vordergrund, indem er dem Leser eine einfache Orientierung und die ausgewählte Lektüre einzelner Passagen ermöglicht. ${ }^{101}$ In diesem Punkt, und nicht in einer rein chronologischen Erzählweise hier und einer ausschließlich thematischen Präsentation des Materials dort, besteht der eigentliche Unterschied zwischen den beiden Biographen. Denn Sueton gliedert sein Material an den Stellen, an denen eine solche Anordnung sinnvoll erscheint, ebenso chronologisch wie sich Plutarch nicht scheut, thematische Einheiten zu bilden, um bestimmte, fur den jeweiligen Charakter entscheidende Aspekte zu verdeutlichen. ${ }^{102}$

Diese stark divergierenden Strategien in der Prăsentation des Materials werfen die Frage nach der Darstellungsabsicht und dem jeweiligen Publikum sowie dessen Interessen bei der Lektüre biographischer Literatur auf. Plutarchs Wirkungsabsicht läßt sich eindrucksvoll unter Verweis auf sein Selbstzeugnis im Proömium der Vita des Aemilius Paulus mit der Vermittlung ethisch-moralischer Lehren und Vorbilder umreißen. ${ }^{103}$ Dementsprechend dienen die von ihm geschilderten Anekdoten auch vorrangig der Charakterschilderung oder wurden ihres exemplarischen Charakters wegen ausgewählt. ${ }^{104}$ Für Sueton hingegen ist die kohärente Darstellung des jeweiligen Charakters nicht das zentrale Anliegen, ${ }^{105}$ ein Umstand, der ihm in der Forschung vielfach

101 Ein prominentes Beispiel für den Wechsel zwischen primăr informativen und stärker erzahlenden Passagen bietet die Caesarvita, die damit jedoch zugleich innerhalb der suetonischen Biographien eine gewisse Sonderstellung einnimmt. Der erhaltene Text beginnt mit Schilderung der Karriere Caesars bis zur Prătur in ,chronologischen Rubriken', denen als Stichwort die Bezeichnung der jeweiligen Stufe des cursus honorum vorangestellt ist (vgl. Suet. lul. 2-17 u. ferner SCHERBERICH 1995, 21, zu ahnlichen Phänomenen in der Claudiusvita), um dann von der Bewerbung um den Konsulat bis zur Überquerung des Rubikon die von Sueton offenbar als entscheidend bewertete Phase in der literarisch anspruchsvolleren Form einer zusammenhängenden, der Geschichtsschreibung verwandten Erzahlung zu bieten (18-33), die schließlich wieder in eine thematische Prasentation des eigentlichen Burgerkrieges und der sich anschließenden Regierung Caesars ubergeht (34-75), ein Wechsel der von Sueton explizit markiert wird (34,1: ordo et summa rerum, quas deinde gessit, sic se habet). Die Ermordung Caesars geht zwar aus der rubrizierenden Aufzahlung seiner vitia hervor, ist selbst aber wiederum in anspruchsvollerer Manier ausgefürt (76-87), wobei neben dem Vorbild der Sterbeszenen in der Historiographie auch an den EinfluB der exitus illustrium virorum-Literatur zu denken ist.

102 Vgl. z.B. Plut. Caesar 15-17 oder Plut. Cato minor 2-3 sowie ferner WEIZSÄCKER 1931, 81f.; STEIDLE 195I, 13ff.150ff.; GEIGER 1988, 250ff., u. STADTER 1996.

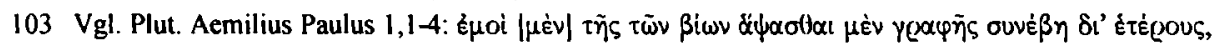

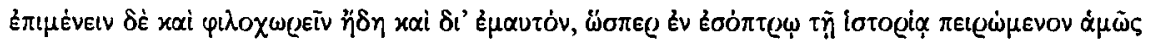

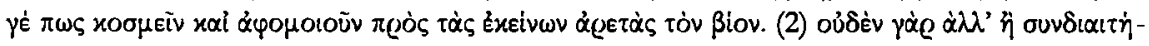

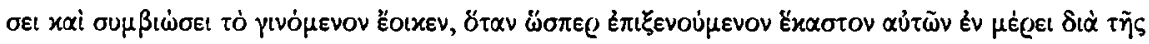

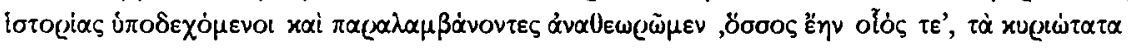

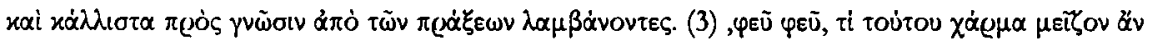

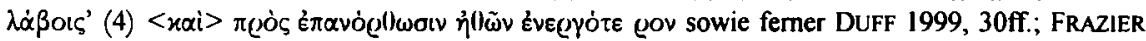
1999, 43ff., u. LAMBERTON 2001, 73 f.

$104 \mathrm{Vgl}$. BECK 1998, v.a. $41 \mathrm{ff}$.

105 Vgl. dag. 2.B. MOUCHOVÁ 1968, 106, u. GUGEL 1977, 149 ff. 
zum Vorwurf gemacht wurde. ${ }^{106}$ Es ist allerdings fraglich, ob sich daraus Hinweise auf die jeweilige Leserschaft gewinnen lassen. Die wichtigste Einschränkung des Rezipientenkreises der suetonischen Biographien ist wohl ihre Abfassung in lateinischer Sprache, deren Beherrschung man im griechischen Reichsteil auch unter den Gebildeten nur bedingt voraussetzen konnte, wie Plutarchs Eingestăndnis seiner anfänglich eher bescheidenen Lateinkenntnisse eindrucksvoll illustriert. ${ }^{107}$

Dennoch handelt es sich bei der Aufteilung nach Sprachen wohl doch um ein zu simples Schema. Und auch die Beobachtung, daß Plutarch Ereignisse der römischen Geschichte und lateinische termini technici meist erklärt, ${ }^{108}$ griechische aber voraussetzt, kann nicht uneingeschränkt als Argument dafür herangezogen werden, daß er von einem rein griechischen Publikum ausgeht. ${ }^{109}$ Denn ein Blick auf die von MARTIN HOSE herausgearbeiteten historischen Inhalte der antiken Schulbildung verdeutlicht, ${ }^{110}$ daß Plutarch auch bei seinen römischen Lesern Kenntnisse der klassischen griechischen Geschichte voraussetzen konnte. Eine Differenzierung des jeweiligen Publikums kann also nur entlang seiner vermuteten Interessen sinnvoll vorgenommen werden, die sich jedoch nicht empirisch verifizieren lassen. Auf diese Weise ergeben sich jedoch die Bilder des ,typischen Plutarchlesers', der stärker an moralphilosophischen Fragestellungen interessiert ist, einerseits und des ,typischen Suetonlesers', der eher den Erwerb biographisch geordneten historischen Faktenwissens beabsichtigt, andererseits zeichnen, die beide eine gewisse Plausibilität für sich verbuchen können.

Zusammenfassend läßt sich festhalten, daß die einzige Übeinstimmung zwischen den Kaiserbiographien Plutarchs und denen Suetons darin besteht, daß sie beide eine - im übrigen nicht identische - Reihe römischer Herrscher in chronologischer Ordnung behandeln. Weder die Form der Präsentation noch die vom Autor verfolgte Intention zeigen größere Übereinstimmungen. Auch das von beiden jeweils angesprochene Publikum dürfte nicht identisch gewesen sein, so daß auch eine Bezugnahme des späteren auf den früheren zwingend erforderlich war. Trotz des auffälligen Befundes, daß die Gattung der dynastisch geordneten Herrscherbiographie innerhalb weniger Jahrzehnte offenbar zweimal erfunden wurde, ${ }^{111}$ kann man sich der pointierten Formulierung RONALD SYMEs anschließen, mit der er den Vorbildcharakter Plutarchs

106 Vgl. die von STEIDLE 1951, 1f., zusammengestellte Literatur.

$107 \mathrm{Vgl}$. Plut. Demosthenes 2,2.

$108 \mathrm{Vgl}$. Duff 1999, $301 \mathrm{ff}$.

109 Vgl. v.a. STADTER 2002

$110 \mathrm{Vgl}$. HOSE 1994, 5ff.

111 Eine andere Erklärung schlagt BOWERSOCK 1998, 204ff,, vor, der die plutarchischen Kaiserviten in die letzten Jahre Domitians datiert und vermutet, daß sie durch den Kontext ihrer Entstehung korrumpiert und somit der allgemeinen damnatio memoriae dieser Zeit zum Opfer gefallen seien. 
für Sueton bestreitet: „He merely preceded, he did not show the way. Suetonius had already written De viris illustribus."112

b) Die Datierung der Caesares und die Reihenfolge ihrer Abfassung

Auch wenn hier mit der überwiegenden Mehrheit der Forschungsliteratur von einer zeitlichen Priorität der Schrift de viris illustribus gegenuber den Kaiserbiographien ausgegangen wird, ist daran zu erinnern, daß uns gesicherte Kenntnisse hieruber nicht zur Verfügung stehen. ${ }^{113}$ Ebenso verfugen wir über keinerlei externe Zeugnisse zur Abfassung oder Publikation der Caesares sowohl in ihrer Gesamtheit als auch hinsichtlich einzelner Viten, mit Ausnahme der Nachricht, daß die gemeinsam mit dem Anfang der Caesarvita verlorene praefatio eine Widmung an Septicius Clarus enthielt. ${ }^{114}$ Daher wird in der Regel diese Information in Kombination mit einer in der Hadriansbiographie der historia Augusta enthaltenen Notiz, daß Septicius gemeinsam mit Sueton vermutlich $122 \mathrm{n}$. Chr. nach einem gesellschaftlichen Fauxpas gegenüber der Kaiserin ihrer Posten als praefectus praetorii beziehungsweise ab epistulis enthoben worden seien, ${ }^{15}$ zur Datierung der Kaiserbiographien oder zumindest des zuerst veröffentlichten Teils herangezogen.

Doch weist diese Argumentation eine Reihe von Schwachstellen auf. Bereits das factum brutum der lediglich in der historia Augusta überlieferten Absetzung der beiden Beamten wurde verschiedentlich in Zweifel gezogen. Handelt es sich bei der historia Augusta als solcher ja bekanntermaßen schon um keine sonderlich zuverlässige Quelle, so ist in diesem Fall deswegen besondere Vorsicht geboten, weil Sueton zu den erklärten Vorbildern ihres Verfassers zăhlt: Die für Sueton letztlich vorteilhafte Anekdote einer ungerechten Behandlung durch den Kaiser büßt daher zusätzlich an Glaubwürdigkeit ein. ${ }^{16}$ Ferner ist die Datierung dieser Angelegenheit nur aus ihrer

112 Vgl. SYME 1980a, 110. Dabei erwagt er die Moglichkeit, daß sich die beiden Autoren zumindest indirekt kannten: Unter den Adressaten der Briefe des jungeren Plinius, der Suetons literarischer Patron war, befinden sich mit Sosius Senecio und Minucius Fundanus auch zwei Förderer Plutarchs (vgl. SYME 1980a, 111, u. ferner GeIGER 1988, 248).

113 S.o. S. $238 f$.

$114 \mathrm{Vgl.} \mathrm{Lyd.} \mathrm{mag.} \mathrm{2,6} \mathrm{u.} \mathrm{ferner} \mathrm{MORGAN} 1986$.

$115 \mathrm{Vgl}$. SHA Hadr. 11,3: Septicio Claro praefecto praetorii et Suetonio Tranquillo epistularum magistro multisque aliis, quod apud Sabinam uxorem in [i]us[s] eius familiarius se tunc egerant, quam reverentia domus aulicae postulabat, successores dedit, uxorem etiam ut morosam et asperam dimissurus, ut ipse dicebat, si privatus fuisset.

116 Den alteren Forschungsstand fassen LAMBRECHT 1984, 23, und BENEDIKTSON 1993, 382f., zusammen, die neuesten Beitrage stammen von LINDSAY 1994, der sich für die Authentizităt der historia Augusta-Nachricht ausspricht, und BALDWIN 1997, der noch einmal die Argumente der Skeptiker anfürt, zugleich jedoch darauf verweist, daß auch er die Authentizităt prinzipiell furr moglich hălt. 
Plazierung innerhalb der Hadriansvita möglich, so daß auch die Angabe des Jahres $122 \mathrm{n}$. Chr. nur bedingte Gültigkeit für sich beanspruchen kann. ${ }^{117}$ Doch auch wenn mit der Mehrheit der Forschungsliteratur von der Authentizităt dieser Nachricht ausgegangen wird, so bleibt es doch reine Spekulation, daß Septicius Clarus, zu dessen weitgespanntem Freundeskreis unter anderem der jüngere Plinius gehørte, wegen dieses Vorfalls nicht nur seinen Posten verloren hat, sondern auch noch in einem solchen $\mathrm{Maße}$ in Ungnade gefallen ist, daß es für seinen langjăhrigen Protegé Sueton undenkbar geworden wäre, ihn zum Widmungsträger der Kaiserbiographien machen. ${ }^{118}$

Als größter Unsicherheitsfaktor in diesem Zusammenhang erweist sich jedoch, daß wir nicht wissen, auf welche Teile der Sammlung sich die Widmung an Septicius Clarus erstreckt hat. Unter den verschiedenen Vorschlägen nehmen neben der Annahme einer geschlossenen Publikation aller zwölf Viten vor $122 \mathrm{n} . \mathrm{Chr} .{ }^{119}$ diejenigen einen prominenten Platz ein, die Suetons Verwendung von Originaldokumenten und seine Kenntnis von Eigennamen, deren Häufigkeit im Laufe der Reihe der Caesares abnimmt, mit dem Verlust des Postens als ab epistulis und damit des Zugangs zu den kaiserlichen Archiven in Zusammenhang bringen. ${ }^{120}$ Allerdings konnten in neueren Untersuchungen zur biographischen Technik Suetons diese Unterschiede, die sich zu einem Großteil auf die Verwendung oder Nichtverwendung der möglicherweise schon publiziert vorliegenden Augustusbriefen beschrănken, ${ }^{121}$ uberzeugend auch auf andere Weise erklärt werden. ${ }^{122}$

117 Zwar wird unmittelbar zuvor Hadrians auf $122 \mathrm{n}$. Chr. datierbare Britannienreise geschildert, doch steht auch der Aussagewert der Einreihung an dieser Stelle angesichts der generellen Unzuverlassigkeit der hisloria Augusta zur Debatte. So haben sich CROOK 1956/7 u. GASCOU 1978 mit guten Grunden fur 128 ausgesprochen, wăhrend ALFÖLDY 1979 u. SYME 1980b, 68f., weiterhin 122 favorisieren.

118 Vgl. ferner BALDWIN 1997, der die Moglichkeit einer Aussohnung Hadrians mit Sueton zu einem späteren Zeitpunkt erwagt

119 Vgl. Z.B. BALDWIN 1975a, 69; CizeK 1977, 189ff;; AlFOldy 1979, 253; LAMBRECHT 1984, 23; SCHERBERICH 1995, 13, u. FLACH 1998, $189 f$.

$120 \mathrm{Vgl}$. v.a. TOWNEND 1959, 286ff. Der Einschnitt wird allerdings unterschiedlich angesetzt. Waren fur TOWNEND 1959, 288, nur die Caesar- und Augustusbiographie wahrend der Amtszeit als ab epistulis entstanden, so sah SYME 1958a, 501.780, die Zasur zwischen Nero und Galba, und zuletzt sprach sich ABRAMENKO 1994, 86ff., fur einen Einschnitt zwischen Vespasian und Titus aus, weil er in den Biographien der Flavier eine zunehmend kritische Haltung dem Kaiserhaus gegenuber erkennt und diese mit der Absetzung Suetons in Verbindung bringt (eine alternative Erklärung der hier besonders relevanten Stelle Suet. Dom. 8,2 bieten Pailler / SABLAYrolles 1994, 38f.).

121 Die Frage, ob Sueton die Augustusbriefe in publizierter Form vorlagen (eine spătere Edition bezeugt Gell. 15,7,3), wird kontrovers diskutiert (vgl. bejahend z.B. MALCOVATI 1977 u. BALDWN 1983, 47f. 155 sowie dag. TOWNEND 1959, 286f.); eine interessante Position wird von WALLACE-HADRLL 1983, 94f., vertreten: „Suetonius produces his quotations with the air of one who is certainly not handling well-known material. ... The error is to reduce the issue to black-and-white alternatives: either the letters were published or they were in secret imperial archives. But the fluid conditions of the ancient book-trade allow for grey areas. A text might enjoy limited circulation or limited availability 
Angesichts dieses wenig ermutigenden Befundes sind wir also bei dem Versuch, die Entstehungszeit der Kaiserbiographien genauer einzugrenzen, auf den Text selbst angewiesen. Da dieser jedoch datierbare Bezüge auf die Gegenwart des Autors nicht in der gewünschten Zahl und Exaktheit enthält, ${ }^{123}$ geraten hier vor allem die Unterschiede zwischen den ersten und zweiten sechs Biographien in den Blickpunkt. Diese weichen nicht nur in ihrer Länge, sondern zum Teil auch in ihrer Struktur deutlich voneinander ab, wenn Aussagen über den letzten Punkt auch durch den stark individuellen Charakter der einzelnen suetonischen Biographien erschwert werden. Diese Beobachtungen hatte GLEN BOWERSOCK in einem bereits 1969 erschienen Aufsatz zum Anlaß genommen, die Abfassung der zweiten sechs Kaiserviten als zeitlich früher gegenüber der ersten Hexade mit den Lebensläufen der julisch-claudischen Herrscher anzusetzen und sie in trajanische Zeit zu datieren. ${ }^{124}$ Weniger an der absoluten Datierung in trajanische Zeit, die ohnehin Spekulation bleiben muß, als vielmehr an der Umkehrung der relativen Chronologie in den suetonischen Caesares hat sich unmittelbar Widerspruch entzündet, der vor allem von KEITH BRADLEY formuliert wurde und der rasch zur communis opinio der Forschung avancierte. ${ }^{125}$ Allerdings stellte BRADLEY selbst ausdrücklich fest, daß auch er keine definitiven Argumente für die von ihm vertretene Sichtweise präsentieren könne, sondern sie ihm aufgrund der angeführten Gründen lediglich plausibler erscheine. ${ }^{126}$

Tatsächlich erweist sich der Gedanke, daß Sueton die letzten sechs Viten zuerst geschrieben, wenn auch nicht notwendigerweise bereits veröffentlicht hat, ${ }^{127}$ aus einer Reihe von Gründen als erwägenswert. Daß eine streng chronologische Vorgehensweise für die Behandlung der Geschichte des Prinzipats nicht die einzig denkbare Mög-

without being formally 'published'. ... Certainly Augustus was known as a letter-writer to a limited number of cognoscenti before Suetonius."

122 Vgl. v.a. CONINCK 1983 sowie ferner z.B. BALDWIN 1983,180f., u. HURLEY 2001, 8f.

123 Von SYME 1958a, 780, war der Versuch unternommen worden, aus der Erwathnung der $126 \mathrm{n}$. Chr. gestorbenen Domitia Longina (Suet. Tit. 10,2) einen Anhaltspunkt zu gewinnen, da Sueton von ihr wie von einer Verstorbenen zu sprechen scheint (vgl. dag. jedoch BALDWIN 1983, 46).

$124 \mathrm{Vgl}$. BOWERSOCK 1969b. Zur geringeren Überzeugungskraft der Untersuchungen des Wortgebrauchs vgl. BRADLEY 1973, 259f., u. BALDWIN 1983, 468ff.

125 Vgl. BrADLEY 1973. Die Möglichkeit einer Zustimmung zum Vorschlag BOWERsocKs wurde jedoch verschiedentlich erwogen: vgl. BALDWIN 1983, 49.181f.296.545f., u. FUHRMANN 1999, 331.

126 Vgl. BRADLEY 1973, v.a. 261: „But there is no proof for either view.” u. ferner die Einschatzung von BOWERSOCKs Vorsto B durch SYME 1980a, 117: „The notion is ingenious. It provokes thought but it fails to convince." Die Unsicherheit uber diesen Punkt ist unter anderem auf eine auffallige Eigenheit der Kaiserbiographien zurückzuführen: Sueton verzichtet weitgehend auf Querverweise zwischen den einzelnen Viten, zu denen sich eigentlich angesichts der sich vielfach überlappenden Lebenszeiten der Dargestellten reichlich Gelegenheit geboten hătte; s.u. S. 282f.

127 Vgl. BaLDWIN 1983, 181f. Anm. 202, und die von WallaCe-HadRILl 1983, 1, betonte Mőglichkeit einer zunăchst nur in Form einer Rezitation erfolgten Veroffentlichung. 
lichkeit darstellt hat, kann bereits ein Seitenblick auf die Reihenfolge der Entstehung der taciteischen Historien und Annalen verdeutlichen. Im Gegenteil läßt sich sogar argumentieren, da $\beta$ in der Wahrnehmung der frühen Adoptivkaiserzeit die als eigene Gegenwart empfundene Epoche mit den sich überschlagenden Ereignissen des Vierkaiserjahres begonnen hat. ${ }^{128}$ Bei historischer Literatur im Rom der Republik wie der frühen Kaiserzeit handelt es sich jedoch in ihrer überwiegenden Mehrheit - Livius bildet die prominenteste Ausnahme - um Zeitgeschichtsschreibung. In der Regel wird erst in einem zweiten Schritt die fernere Vergangenheit, die vom Autor nicht mehr selbst erlebt wurde und die möglicherweise zudem bereits von einem Vorgänger kompetent dargestellt worden war, in den Blick genommen.

Weitere Argumente dafür, sich die Entstehung der suetonischen Kaiserbiographien von der zweiten Hexade her vorzustellen, ergeben sich aus der Struktur der Viten selbst. Zunächst ist hier noch einmal auf ihre auffallige Kürze zurückzukommen, die weder mit der geringen objektiven Bedeutung der dargestellten Herrscher, wie sich vor allem bei Domitian zeigt, noch mit der fehlenden subjektiven Wertschätzung durch den Autor, in der Titus bekanntermaßen sehr weit oben rangiert, zu erklären ist. ${ }^{129}$ Vielmehr bietet sich ein Vergleich mit den Kurzbiographien aus der Sammlung de viris illustribus an, deren umfangreichere Stücke durchaus den Umfang der Othooder der Titusbiographie erreichen können. Eine Parallele zu Suetons Sammelbiographien ergibt sich auch aus der heute weitgehend anerkannten Zusammenfassung der Biographien der drei Bürgerkriegskaiser sowie der drei Flavier zu je einem Buch, die von ISAAC CASAUBONUS in seiner Genueser Edition von 1595 aufgrund der in der Suda enthaltenen Nachricht, daß Sueton Kaiserbiographien in acht Büchern geschrieben habe, vorgenommenen wurde. ${ }^{130}$

In der Diskussion wurden darüber hinaus zahlreiche Unterschiede im Aufbau der einzelnen Viten bislang nicht hinreichend berlicksichtigt. ${ }^{131}$ Diese lassen erst bei einer

$128 \mathrm{DaB}$ die Ereignisse der Jahre 68 und $69 \mathrm{n}$. Chr., die Tacitus zu einem longus et unus annus zusammenfaßt (dial. 17,3), als Fluchtpunkt im historischen Horizont der Zeitgenossen figurierten, zeigt auch die Nachricht bei Flavius Josephus (bell. lud. 4,496), diese seien bereits von zahlreichen Autoren dargestellt worden. Einige wenige Beispiele sind in Form knapper Testimonien noch greifbar: So schrieb Pompeius Planta, der unter Vespasian und Trajan hohe Ämter in der Provinzverwaltung bekleidete, über die Schlacht von Betriacum (vgl. Schol. ad Iuv. 2,99) und der als Unterredner im dialogus de oratoribus bekannte Vipstanius Messalla über die Belagerung Cremonas (vgl. Tac. hist. 3,25,2).

$129 \mathrm{Vgl}$. dag. den jedoch allenfalls auf die drei Kaiser des Jahres 69 zutreffenden Einwand von BRADLEY 1973, 262: „It needs to be reemphasized that the content of a Suetonian life was influenced partly by the amount of information available to the author, partly by the length of time spent by the subject in public life, partly by the length of subject's life. These basic facts are perhaps sometimes neglected."

130 Vgl. die praefatio in der Edition von IHM 1908, viii.

131 BOWERSOCK 1969b, 121f., hat zum einen auf die Plazierung der Rubrik zu den artes liberales, die in der Domitiansvita erstmals nach den Informationen zur außeren Erscheinung und damit an der Stelle behandelt wird, an der sie sich auch bei den julisch-claudischen Kaisem regelmäßig wiederfindet, und 
,Inversion' der Entstehungszeit der beiden Hexaden eine folgerichtige Entwicklung erkennen, die von dem kleinen Format der Stücke aus de viris illustribus über die in vielerlei Hinsicht stark experimentellen sechs Kaiserviten der zweiten Hälfte hin zu den kunstvoll angelegten und weitaus umfangreicheren Biographien der julisch-claudischen Dynastie reicht. ${ }^{132}$ Die Besonderheiten der zweiten Hexade zeigen sich dabei sowohl auf der Makroebene, beispielsweise im durchgängig chronologischen Aufbau der Othovita ${ }^{133}$ und in der stark an ein Enkomion erinnernden Gliederung der Titusbiographie, ${ }^{134}$ als auch auf der Ebene von Detailbeobachtungen, wie dem weitgehenden Fehlen expliziter Verweise innerhalb einer Vita ${ }^{135}$ oder der noch nicht standardisierten Verwendung einzelner Kategorien ${ }^{136}$ beziehungsweise deren Plazierung in der jeweiligen Lebensbeschreibung. ${ }^{137}$ Behălt man dagegen die herkőmmliche Chronologie bei, so bleibt man als Erklärung für diese Phänomene, die dann nur als ,Verfall' der suetonischen Darstellungskunst gedeutet werden können, auf die problematische These eines Zusammenhangs mit Suetons Zugang zu den kaiserlichen Archiven angewiesen. ${ }^{138}$

zum anderen auf den in der ersten Hexade bei negativ bewerten Kaisern charakteristischen zweigliedrigen Aufbau verwiesen, der bei Domitian noch entwickelt wird (vgl. dag. BRADLEY 1973, 261).

$132 \mathrm{Vgl}$. BALDWIN 1983, 296: „Also, the possibility that the last six vitae were composed first, short and experimental in the manner of the De viris illustribus, and that the more elaborate came later, had better to be remembered." Der - allerdings nicht in vergleichbaren Relationen - nachlassende Umfang der Biographien in der Reihe von Augustus bis Nero erklärt sich moglicherweise aus der Bedeutung der beiden ersten Herrscher fur die Etablierung der neuen Staatsform (vgl. GuUA 1995, 54lf., u. SALLMANN / SCHMIDT 1997a, 49), sowie aus Suetons spezifischen Interessen, die hier wie auch in de viris illustribus einen Schwerpunkt in der spaten Republik und der augusteischen Zeit aufweisen (vgl. WALLACE-HADRILL 1983, 2.50ff., der ferner vermutet, Sueton habe zunachst nur die beiden ersten Biographien konzipiert und sei erst durch deren Erfolg zu einer Fortsetzung veranlaßt worden).

133 Vgl. STEIDLE 1951, 105

134 Vgl. LEO 1901, $9 \mathrm{f}$.

135 Einem einzigen Beispiel aus der zweiten Hexade (Vit 18) stehen neun Beispiele in den ersten sechs Biographien gegenuber (vgl. Aug. 90; Tib. 70,5; Cal. 8,6.32,3.35,2; Claud. 29,1.35,1.36,2 u. Nero 22,5 sowie ferner MouCHOvÁ 1968, 65).

136 So werden beispielsweise die von Kaisern veranstalteten spectacula erstmals in der Domitiansvita als eigenstăndiger Punkt in Form einer Rubrik behandelt (vgl. Suet. Dom. 4,1-2 u. ferner Vesp. 19,1 u. Tit. 7,3.8,2), wăhrend dieses Vorgehen spater zur Regel wird (vgl. Suet. Iul. 39; Aug. 43-45; Tib. 7,1.47; Cal. 18-20; Claud. 21 u. Nero 11-13).

137 In der zweiten Hexade steht die Rubrik, Äußeres' lediglich in der Vespasiansvita vor der exitus-Schilderung und bildet mit den ubrigen, privaten' Eigenschaften einen thematischen Komplex (vgl. Suet. Vesp. 20), wie es in den Biographien der julisch-claudischen Kaiser mit Ausnahme der Nerovita zu Regel wird (vgl. Suet. Iul. 45; Aug. 79-80; Tib. 68; Cal. 50 u. Claud. 30-31 sowie Nero 51).

138 Die vorgeschlagenen Erklărungen operieren zumeist mit dem Verlust des Interesses am Gegenstand oder einer Abneigung gegen die Monarchie als Institution nach seiner Entlassung als ab epistulis (vgl. Z.B. TOWNEND 1967, 90f.; SYME 1980a, 118ff., u. LINDSAY 1995, 3). 
Aber auch die Schwierigkeiten des hier vertretenen Vorschlages zur relativen Chronologie der Kaiserviten sollen nicht verschwiegen werden. Der Anfang der Galbabiographie weist mit den lapidaren Worten progenies Caesarum in Nerone defecit nur minimale Spuren eines Proömium auf, ${ }^{139}$ wenn auch zu bedenken ist, daß die folgende Zusammenstellung der sich auf den Dynastiewechsel beziehenden Prodigien diese Funktion wenigstens zum Teil erfulltt ${ }^{140}$ und Sueton generell auf eine historische Einordnung der von ihm geschilderten Lebensläufe verzichtet. Gleichwohl ist es nur schwer vorstellbar, daß dem Werk nicht eine allgemeine praefatio, die wahrscheinlich auch eine Dedikationsadresse beinhaltete, vorangestellt gewesen sein sollte. Die Lösung dieses Problems kann einerseits in dem bereits angedeuteten Unterschied zwischen Abfassung und Publikation bestehen, andererseits aber auch in der Möglichkeit einer Überarbeitung der älteren zweiten Hälfte nach Fertigstellung der ersten Hexade. Beide Erklärungen sind freilich gleichermaßen spekulativ.

Festzuhalten bleibt jedoch, daß gute Argumente für eine Inversion der beiden Hexaden innerhalb der suetonischen Kaiserbiographien in Hinsicht auf ihre relative Chronologie sprechen, während für die traditionelle Reihung im wesentlichen nur ihre Übereinstimmung mit der historischen Abfolge der römischen Herrscher und der Befund der einzigen für die Überlieferung des Textes ins Mittelalter verantwortliche Handschrift spricht. Dabei ist allerdings in Rechnung zu stellen, daß auch die Anordnung der Biographien in der Handschriftentradition durch eine gezielte Angleichung an die historische Reihung entstanden sein kann, die von einem späteren Bearbeiter oder im Rahmen einer zweiten Auflage bereits von Sueton selbst vorgenommen worden sein könnte. ${ }^{141}$ Aus diesen Gründen wird dem weiteren Verlauf dieser Untersuchung die Annahme zugrunde gelegt, daß Sueton nach der Arbeit an de viris illustribus mit den Biographien des Vierkaiserjahres und der Flavier begonnen hat und erst dann in einem zweiten Schritt zu den Herrschern aus der julisch-claudischen Dynastie übergangen ist.

Für den Versuch einer absoluten Datierung ist mit dieser Festlegung der relativen Chronologie freilich wenig gewonnen. Weil der Verlust des Postens ab epistulis als

139 Vgl. Suet. Galba 1 („Die Dynastie der Caesaren endete mit Nero.”). Fraglich scheint allerdings, ob diese Worte zwingend als unmittelbare Anknupfung an die Nerovita zu verstehen sind (vgl. BRADLEY 1973, 257f.: „Galba 1 does make an effective transition from Nero 57, a description of public and private reactions to Nero's death, to the year of the four emperors; but it does not make a successful introduction to the events of $68 / 69$ alone.")

$140 \mathrm{Vgl}$. GUGEL 1977, 28ff.60ff. 152.

141 In diesem Zusammenhang sei ein erneuter Verweis auf die Überlieferungsgeschichte der beiden taciteischen Großwerke gestattet, die offenbar bereits Hieronymus in einer Ausgabe vorlagen, die sich an der Chronologie der behandelten Ereignisse und nicht der Reihenfolge der Entstehung orientierte (vgl. Hier. comm. in Zachariam 3,14: Cornelius quoque Tacitus, qui post Augustum usque ad mortem Domitiani vitas Caesarum triginta volumimibus exaravit u. ferner V. ALBRECHT 1992, II 903). 
Erklärung für die nachlassende Qualităt nicht mehr benötigt wird, kann er auch als Datierungshilfe nicht mehr herangezogen werden. ${ }^{142}$ Damit und unter der Voraussetzung, daß eine Widmung an Septicius Clarus auch denkbar erscheint, wenn dieser nicht mehr als praefectus praetorii fungiert, fältt der einzige auswertbare Hinweis auf eine Abfassungszeit fort. Denkbar ist daher jeder beliebige Zeitpunkt nach dem Ende der Korrespondenz mit Plinius durch dessen Tod im zweiten Jahrzehnt des 2. Jh. $\mathbf{n}$. Chr. bis zu Suetons eigenem Ableben, über das wir allerdings keinerlei Kenntnis haben. ${ }^{143}$ Gleichwohl läßt die hier vertretene Sichtweise einer literarischen Entwicklung, die über die antiquarische Schriftstellerei und die den Literaten und Intellektuellen gewidmeten Kurzbiographien hin zu den Lebensbeschreibungen der römischen Kaiser verläuft, eine etwas spätere Abfassungszeit, ungefăhr in den spăten zwanziger oder dreißiger Jahren des 2. Jh. n. Chr., wahrscheinlich werden.

c) Die Konzeption der Caesares: Der Inhalt und seine Vermittlung

Die Wahrnehmung der suetonischen Caesares in der modernen Forschung läßt sich auch als eine Folge enttäuschter Erwartungen begreifen, die zumeist daraus resultierten, daß an Suetons Werk Vorstellungen herangetragen wurden, die von den jeweiligen Interpreten allgemein und überzeitlich mit der Gattung der Biographie verbunden wurden. So lastete man es Sueton beispielsweise an, daß er im Gegensatz zu Plutarch nicht die Schilderung eines Charakters als moralisches Phänomen und ethisches Exempel angestrebt habe. ${ }^{144}$ Diese Beobachtung trifft sicher etwas Richtiges, wie sich bereits an der Entscheidung für die vorrangige Verwendung eines Rubrikenschemas ablesen läßt, in dem die Informationen aus verschiedenen Lebensabschnitten thematisch und nicht unter Beachtung der individuellen Chronologie zusammengefaßt werden, so daß eine charakterliche Entwicklung nur sehr eingeschränkt zum Ausdruck kommen kann. Zu einem negativen Werturteil kann eine solche Feststellung jedoch erst vor dem Hintergrund einer spezifischen, in diesem Fall vor allem an Plutarch orientieren Erwartungshaltung gegenüber antiken Biographien werden.

Vielleicht als Reaktion auf die Enttäuschung, daß Sueton offenbar nicht primär an der Individualität der von ihm dargestellten Personen interessiert ist, wurde die Intention seines Werkes vielfach in der Propagierung eines überindividuellen Herrscherideals gesehen, in dem die Vorstellungen des Autors und seiner Rezipienten, in denen

$142 \mathrm{Zu}$ einer möglichen hadrianfeindlichen Tendenz der Flavierbiographien im Zusammenhang mit der Demission Suetons vgl. CARNEY 1968 u. ABRAMENKO 1994.

143 Vgl. MACÉ 1900, 226ff., u. BALDWIN 1983, 46ff.

$144 \mathrm{Vgl}$. die von STEIDLE 1951, If., zusammengestellte Literatur, sowie dag. z.B. MOUCHOVÁ 1968, 106, u. GUGEL 1977, 149ff. 
man in diesem Zusammenhang zumeist die römischen Ritter und kaiserlichen Verwaltungsbeamten erblickt, ${ }^{145}$ von einem idealen Herrscher literarisch Gestalt gewonnen hätten. ${ }^{146}$ Die Kaiserbiographien Suetons werden in diesem Deutungsansatz daher bis zu einem gewissen Grad als funktionales Äquivalent zur Gattung des mittelalterlichen und frühneuzeitlichen Fürstenspiegel angesehen. ${ }^{147}$ Eine wichtiges Argument stellen in diesem Zusammenhang die einzelnen Kategorien dar, die vor dem Hintergrund der am Kaiserhof in vielfalltigen Formen kursierenden Tugendkatalogen ${ }^{148}$ als gesellschaftlich vorgeprägtes, der Evaluation des jeweiligen Herrschers dienendes Schema verstanden werden, ${ }^{149}$ das Sueton bei der Abfassung seiner Biographien mehr oder weniger zwangslăufig übernommen habe. ${ }^{150}$ Dabei wird allerdings dem flexiblen Charakter des jeweils in hohem Maße auf die einzelne Person zugeschnitten Rubrikenschemas keine hinreichend Beachtung geschenkt.

Dabei wird insbesondere der Panegyricus des jüngeren Plinius, die wahrscheinlich deutlich erweiterte schriftliche Fassung seiner $100 \mathrm{n}$. Chr. vor Trajan gehaltenen gratiarum actio, ${ }^{151}$ als zeitgenössische Parallele herangezogen. ${ }^{152}$ Doch kann gerade der Vergleich mit der Pliniusrede den divergenten Charakter des suetonischen Ansatzes verdeutlichen. Denn trotz der in beiden Texten vorrangig verwendeten thematischen Gliederung lassen sich signifikante kompositorische Unterschiede aufzeigen. ${ }^{153}$ Vor allem verbietet aber die fundamental verschiedene Kommunikationssituation eine engere Parallelisierung. Denn auch in der überarbeiteten Fassung bleibt der okkasionelle Rahmen der vom amtierenden Konsul gehaltenen Dankesrede für die Rezeption des Panegyricus konstitutiv. Während auf diese Weise für Plinius der Kaiser als

$145 \mathrm{Vgl}$. v.a. WALLACE-HADRILL 1983, 157: „Suetonius writes from the point of view of the subject anxious about his neck, his pocket, his standing, and his comfort. It follows that it is the presence or absence of vice that most concerns him. The virtues are largedly negative ones." Zur Diskussion des Adressatenkreises s.u. S. $321 \mathrm{ff}$.

146 Vgl. WitTKe 1974, 47f.; CizeK 1977, 154ff.; GasCOU 1984, 711ff.; Wallace-HadRILL 1983, I42ff., LEWIS 1991, 3628.3649ff.; BRADLEY 1991,3713ff., u. GIUA 1995, 541 ff.

147 Zur Gattung des Fürstenspiegels und ihrer Bedeutung für die antike Literatur vgl. SCHULTE 2001, v.a. 16ff., unter dessen Definition eines Furstenspiegel Suetons Kaiserbiographien nicht fallen.

I48 Vgl. Wallace-Hadrill 1983, 145ff., u. ferner BRAdLEy 1991, 3719f., zur Rolle der hadrianischen Münzemissionen.

149 Vgl. z.B. WALLACE-HADRILL 1983, 143f.: „What he does is to measure each Caesar against a set scale of criteria. Each virtue/vice category applies as it were a litmus test. A good emperor will show up positively on the tests of clemency, civility liberality and continence, a tyrant negatively on the same tests."

150 Vgl. v.a. BRADLEY 1991, 3714f.3721ff.

151 Vgl. Plin. ep. 3,13 u. 3,18. Die Deutung des Panegyricus als antiker Furstenspiegel ist allerdings nicht unumstritten (vgl. bejahend HADOT 1972, 601f., u. dag. die Skepsis bei SCHULTE 2001, 218ff.).

152 Vgl. WaLlaCe-HaDrill 1983, 144.155, u. BRADLEY 1991, $3717 \mathrm{ff}$.

153 Vgl, z.B. LEWIS 1991, 3628. 
direkter Adressat fungiert, wendet sich Sueton formal an seinen Widmungsträger Septicius Clarus. Den Kaiserviten fehlt darüber hinaus sowohl der explizite didaktische Anspruch, der im Panegyricus deutlich hervortritt, ${ }^{154}$ als auch das bei Plinius naturgemäß prominente laudatorische Element. Die weitgehende Abwesenheit des letzteren stellt im übrigen auch den wichtigsten Unterschied der suetonischen Biographien zum häufig mit Blick auf die Rubrikengliederung als Modell ins Spiel gebrachten Enkomion dar. ${ }^{155}$

Dennoch trifft der Vergleich mit panegyrischen und enkomiastischen Texten insofern etwas Richtiges, wenn mit ihm auf die Existenz paränetischer Momente in den Kaiserbiographien hingewiesen werden soll. Ein Modellcharakter sowohl der positiv gezeichneten Herrscher wie - im abschreckenden Sinne - auch der negativ aufgefaßten ist nicht zu leugnen, doch dürfte sich dieser nicht exklusiv auf den Kaiser, sondern vielmehr - wie gerade die Betonung ,privater' Eigenschaften nahelegt ${ }^{156}$ - auf die Leserschaft im allgemeinen erstreckt haben. ${ }^{157}$ Dieser didaktische Impuls hat jedoch einen entschieden anderen Charakter als die moralpadagogische Intention, wie sie etwa in den Parallelbiographien Plutarchs deutlich zutage tritt. Eher bietet sich ein Vergleich mit der parănetischen Empfehlung eines bestimmten Lebensstiles an, wie wir sie in den plinianischen Porträtbriefen oder in einigen Kapiteln der gellianischen noctes Atticae kennengelernt haben. Dieses protreptische Moment verbindet die Kaiserbiographien im übrigen erneut eng mit den viri illustres, denn den dort porträtierten Intellektuellen dürfte im gesellschaftlichen Kontext der Bildungskultur des 2. Jh. $\mathbf{n}$. Chr. eine ähnliche Vorbildfunktion zugekommen sein.

Andererseits kann aber keinesfalls die Rede davon sein, daß Sueton die moralische Bewertung der von ihm portrătierten Herrscher allein dem Leser überließe. ${ }^{158}$

154 Vgl. z.B. Plin. paneg. 73,6 und femer seine eigenen Aussagen zur Intention des Panegyricus: primum ut imperatori nostro virtutes suae veris laudibus commendarentur, deinde ut futuri principes non quasi a magistro, sed tamen sub exemplo praemonerentur, qua potissimum via possent ad eandem gloriam niti (Plin. ep. 3,18,2).

155 Vgl. v.a. STEIDLE 1951, 129ff., sowie dag. LEWIS 1991, 3665f., u. ZIMMERMANN 1999, 44f., der die Sonderstellung der Biographien Suetons und Plutarchs gegenuber dem panegyrischen Charakter der ubrigen biographischen und zeitgeschichtlichen Produktion der Zeit betont.

$156 \mathrm{Vgl}$. insbesondere Suet. Vesp. 21 u. Aug. $78 \mathrm{mit}$ der Beschreibung eines typischen Tagesablaufes.

157 Vgl. WallaCE-HADRILL 1983, S. 179f. „It was a commonplace of ancient thought and of imperial panegyric that the ruler set an example which his subjects almost inevitably followed, and the proper way to rule was not simply by imposing laws, but by setting the right example."

$158 \mathrm{Vgl}$. dag. TOWNEND 1967, 92: „He leaves it open to us to judge for ourselves, in a way that the eloquence of Tacitus seldom permits, as he constrains our agreement by the subtely and force of his language. ... With Suetonius, the opposite is rather apparent: that he never makes up his mind about the nature of his subject, nor seeks to give a consistent account,... He allows us to construct our own figures from his materials, and we feel that the results are real." 
Wenn er direkte auktoriale Kommentare auch nur sparsam einsetzt, ${ }^{159}$ so charakterisiert er seine Personen doch in hinreichender Deutlichkeit durch die Auswahl und Anordnung der über sie berichteten Fakten. Hinter diese von WOLF STEIDLE erstmals prominent vertretene Einsicht kann es kein Zurück geben. ${ }^{160}$ Und doch sollte darüber hinaus bedacht werden, daß die Fakten auch bereits per se und gleichsam durch Sueton hindurch charakterisierend wirken, vielleicht in stärkerem Maße als es im Einzelfall seinen Intentionen entsprach. ${ }^{161}$ Häufig scheint sich Sueton auf eine partielle Meinungsbildung über den Charakter seiner Caesares zu beschränken, wodurch er sich ebenso von der Biographie plutarchischer Prägung ${ }^{162}$ wie von der prononciert senatorischen Geschichtsschreibung eines Tacitus ${ }^{163}$ unterscheidet. Wenn man Sueton jedoch deswegen zubilligen wollte, er sei es, der in Wirklichkeit sine ira et studio schreibe, ${ }^{164}$ wäre man selbst Opfer der subtilen Leserführung des Biographen geworden, der es auch gerade unter dem Mantel einer ,objectivité affectée ${ }^{165}$ verstanden hat, seine Perspektive auf die ersten zwölf römischen Herrscher der Nachwelt zu vermitteln. ${ }^{166}$

159 Vgl. z.B. Suet. Iul. 76,1; Cal. 22,1; Nero 19,3 u. Vesp. 1,1 sowie ferner EKTOR 1980, 318f.; BRADLEY 1991, 3703, u. SCHERBERICH 1995, 21.

160 Vgl. v.a. SteidLE 1951, 102ff., der als erster Suetons ,Prinzip der Charakterisierung durch Fakten' betont hat, sowie femer CIZEK 1977, 65ff.; GASCOU 1984, 688ff;; BRADLEY 1991, 3702f.; LEWIS 1991, 3653, u. v. ALBRECHT 1992, Il 1116: „Suetons Bewertung der Fakten kommt indirekt in der Anordnung des Stoffes zum Ausdruck, wobei die synchrone Sicht gegenuber der diachronen uberwiegt. Einzelzuge werden in Gradationen angeordnet und wirken so auf den Leser: Als geschickter Psychologe suggeriert der Biograph Urteile, statt sie auszusprechen. So laßt er dem Leser den Schein der Freiheit."

161 Vgl. SHOTTER 1993, 11: ,... true to his original profession, Suetonius was a cold and unemotianal cataloguer of his subjects' characteritics. Even the most commonly-heard criticism - his fondness for a lewd or outrageous anecdote - can be described to his conviction that he should not suppress anything that he read or heard; a caveat of 'it is said that ...' may have been sufficient for conscience. The fact remains, however, that whatever his overall intentions, Suetonius nearly always wrote down the worst version of an incident that he knew."

$162 \mathrm{Vgl}$. SHOTTER 3993, 12: „Suetonius remained external to his subjects, making no general estimate of character and omitting the philosophical or moral reflections we might have expected from Plutarch. There is in fact what amounts to a refusal to enter into a character's thoughts: indeed it is probably this cold recital which lacks an attempt to comprehend that makes Suetonius often appear hostile, despite the fact that in essence there is little he says ... that is not mentioned in other sources."

$163 \mathrm{Vgl}$. SONNABEND 2002, $176 \mathrm{f}$.

164 Vgl. Tac. ann. 1,1,4 sowie ferner EKTOR 1980 u. BENEDIKTSON 1993, 377.

165 Vgl. GasCOU 1984, 675ff.

166 Vgl. WALLACE-HADRILL 1983, 149f: ,In that he documents both virtues and vices with characteristic scholarly impartiality, Suetonius differs from both the panegyrist and writer of invective. But one point he does hold in common with them is that the function of virtues is to generate popularity, of vices to induce hatred." 
In gleicher Weise liegt es auf der Hand, daß sich allein aus der Reihung von in ăhnlichen Kategorien beschriebenen Personen für den Leser die Mőglichkeit einer vergleichenden Bewertung nach moralischen, aber auch realpolitischen Gesichtspunkten ergibt. Bei der Beantwortung der Frage, inwieweit hierin eine wesentliche Intention des Autors besteht, ist jedoch Vorsicht geboten. ${ }^{167}$ Denn Sueton legt schon bei der Thematisierung von inhaltlichen Bezügen innerhalb einer Biographie eine auffällige Zurückhaltung an den Tag, explizite Querverweise zwischen den Biographien fehlen dagegen vollstăndig. ${ }^{168}$ Wenn in der Forschungsliteratur dennoch die Bezogenheit der einzelnen Biographien aufeinander vorausgesetzt wird, ${ }^{169}$ so geschieht dies lediglich auf der Grundlage impliziter Bezugnahmen, deren jeweilige Interpretation jedoch den Schluß auf eine generelle Tendenz des gezielten Verweisens zwischen den Biographien nicht zuläßt. ${ }^{170}$ Die Option einer vergleichenden Betrachtung der einzelnen Herrscher für den Leser soll hiermit ebensowenig ausgeschlossen werden wie die Möglichkeit, daß derartige Überlegungen auch für den Verfasser eine - wenn auch untergeordnete - Rolle gespielt haben können. Es dürfte jedoch angesichts des Verzichts auf jede Form der Explizierung einer solchen Intention von Seiten des Autors zu weit führen, in der Konzeption seiner Biographien ,geschichtsphilosophische Ziele" und den Versuch, „das Phänomen des Prinzipats als in der Kaiserperson individualisierte Reichsgeschichte zu deuten," zu erblicken. ${ }^{\text {71 }}$

Im Vordergrund steht für Sueton, so die im folgenden zu untermauernde These, weder eine Art nachträglicher Evaluation der ersten zwölf principes noch die Würdigung der einzelnen Machthaber aus einer moralphilosophischen Perspektive, wenngleich vom Autor natürlich bewußt ein bestimmtes Bild der historischen Persönlichkeiten tradiert wird, sondern die Vermittlung von Wissen über die Caesares mit Blick auf die spezifischen Bedürfnisse und Interessen der Bildungskultur des 2. Jh. n. Chr. Suetons primäre Intentionen bei der Abfassung der Kaiserviten lassen sich mit den Schlagwörtern der Information und Unterhaltung seiner Leser skizzieren, zu denen als

167 Vgl. v. AlareCht 1992, Il 1109: „Ein wichtiges Problem, das noch der konsequenten Untersuchung harr, ist die Bezogenheit der verschiedenen Lebensbeschreibungen aufeinander."

$168 \mathrm{Vgl}$. MOUCHOVÁ 1968, 65.

169 Vgl. z.B. LEO 1901, 142; STEIDLE 1951, 73, u. GUGEL 1977, 143: „Zuletzt aber hat sich gezeigt, daß Suetons Viten nicht bloß für sich allein gesehen werden düfen, sondern immer in ihrer Bezogenheit auf die anderen Viten. Suetons Biographiensammlung ist als Einheit konzipiert, der einzelne Kaiser nur ein Mosaikstein im Gesamtgefuge, nach den Grundsătzen der Übereinstimmung und des Gegensatzes charakterisiert und daher nicht völlig zu verstehen, ohne in Beziehung zu den anderen zu setzen."

$170 \mathrm{Vgl}$. die Diskussion der betreffenden Stellen bei MOUCHOVÁ 1968, 65ff., die sich kritisch mit den von STEIDLE 1951, 73, fur die These einer zusammenhangenden Komposition in Anspruch genommen Berichten über den Tod des Tiberius auseinandersetzt (vgl. Suet. Tib. 73,3-4 u. Cal. 12,4).

171 Vgl. LAMBreCHT 1984, 25ff.; BradLey 1991, 3720ff.; SALLMANN / SCHMIDT 1997a, 47, u. fur die Zitate SALLMANN 2001, 1085 
drittes Element die Belehrung in Form der Tradierung von Modellen bestimmter Verhaltensweisen tritt. Gerade hier zeigt sich die große Nahe, die die Caesares trotz ihrer traditionellen biographischen Form in funktionaler Hinsicht zu einem Werk wie den gellianischen noctes Atticae aufweisen. Dabei wird wie von Gellius so auch von Sueton beim Aspekt der Unterhaltung der Akzent nicht ausschließlich auf die delectatio des Lesers beim Akt der Lektüre gelegt, sondern beide Autoren berücksichtigen darüber hinaus auch die Eignung der von ihnen dargebotenen Informationen zur aktiven Verwendung durch den Rezipienten im Rahmen der, Salonkultur' des 2. Jh. n. Chr.

Suetons Kaiserbiographien weisen also nicht nur, wie schon lange beobachtet wurde, in der literarischen Technik, ${ }^{172}$ sondern auch in der intentionalen Motivierung ein große Nähe zu de viris illustribus auf. ${ }^{173}$ Dies zeigt sich bereits in der vorwiegenden Verwendung einer wissenschaftlich-nüchternen Diktion, ${ }^{174}$ die Quintilians Klassizismus näher steht als dem zeitgenössischen Archaismus. ${ }^{75}$ Mit der Bereitschaft zur Aufnahme von in ihrem Wortlaut unveränderten Zitaten und von unübersetzten griechischen oder umgangssprachlichen termini bewegt sich Sueton außerdem in größerer Nähe zur Fachschriftstellerei ${ }^{176}$ als zu den elaborierten Stilprinzipien der Historiographie. ${ }^{177}$ Der Anspruch der Utilităt wird aber vor allem in der Organisation des Textes der Kaiserviten deutlich, der auch demjenigen Leser vielfältige Orientierungshilfen gibt, der keine durchgängige Lektüre des gesamten Werkes beabsichtigt, sondern daran interessiert ist, bestimmte Passagen gezielt lesen oder schnell nachschlagen zu können.

172 S.o. S. $239 \mathrm{ff}$.

$173 \mathrm{Vgl}$. DiHLE 1987, 64ff., der Sueton allerdings zugleich in die Nahe der Geschichtsschreibung ruckt; zu den Unterschieden zwischen der zeitgenossischen Historiographie und Sueton s.u. S. $271 \mathrm{ff}$.

174 Vgl. z.B. LeO 1901, 144; WALLACE-HADRILl 1983, 203f., u. SCHERBERICH 1995, $21 \mathrm{ff}$.

I75 Vgl. z.B. Cizek 1977, 14ff., u. ShOtTER 1993, 35ff., sowie dag. SAllmanN / SCHMIDT 1997a, 49: „Suetons scheinbar sachlicher Stil, rhetorisch aber gewollter Duktus kann sich neben der pathetischen Dramatik und der berühmten $\delta \varepsilon t v o \dot{t} \eta\rceil s$ des Tacitus behaupten. Anders als in den zwanglos skizzierten Viri illustres (...) bewegt sich Suetons Sprache hier mit gepflegter Schlichtheit zwischen prätentiossen Purismen und blühendem Modernismus auf der Linie des quintilianischen Stilideals, ohne die eigene Zeit und des beginnenden Archaismus zu verleugnen ...". Gegen die Berechtigung des Begriffes Archaismus hat sich SCHINDEL 1994, v.a. 341, ausgesprochen, der das Phanomen als „Ausdruck eines ,Historismus"“ versteht, ,einer Verstărkung der geschichtlichen Dimension im Bewußtsein einer Epoche, die aufgrund inneren und außeren Friedens Muße für die Vergangenheit findet."

176 Zur charakteristischen Stilistik lateinischer Fachtexte vgl. FÖGEN 2003.

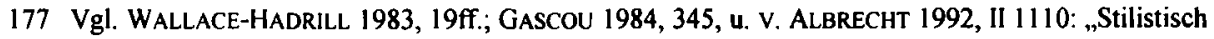
gehört er in die Năhe der Fachschriftsteller. Sueton gehört zu den Autoren, die das mot juste suchen; er strebt nicht nach rhetorischem Pomp, sondern nach căsarischer elegantia, allerdings ohne Purismus.", sowie dag. STEIDLE 1952, 125f., der vor dem Hintergrund seiner These eines starken Einflusses autochthon rómischer Vorbilder eine Năhe zum Sprachduktus republikanischer res gestae sieht. Zum Prosarhythmus vgl. MACÉ 1900, 379ff.; D'ANNA 1954, 211 ff., u. SCHERBERICH 1995, $27 \mathrm{ff}$. 
Daher wiederholen die Caesares auf der Ebene der zwölf Einzelviten großformatig die Katalogstruktur von de viris illustribus, weisen aber zugleich eine differenzierte und zu einem hohen Prozentsatz rekurrente Binnengliederung auf, deren Orientierungsfunktion für den Leser noch auf verschiedene Weise verstärkt wird. So läßt sich etwa eine beträchtliche Ausweitung in der Verwendung von Prăskripten beobachten. Während bei Nepos und in den suetonischen viri illustres lediglich der Name des Porträtierten im Nominativ syntaktisch verbunden oder unverbunden dem eigentlichen Text vorangestellt wird, ${ }^{178}$ findet sich dieses Gliederungsprinzip in den Kaiserbiographien auch vor den einzelnen Rubriken innerhalb der jeweiligen Biographie. Die syntaktische Anbindung an den folgenden Text ist dabei zur ausnahmslosen Regel geworden, ein stilistischer Vorteil, der mit dem Verzicht auf die ausschließliche Verwendung des Nominativs erkauft wurde. Die Verwandtschaft der bei sehr vielen Rubriken in den Caesares zu beobachtenden Eigenheit, daß ein inhaltlicher Schlüsselbegriff an den Anfang gerückt wird, ${ }^{179}$ mit den Präskripten der Kurzbiographien wird dann noch deutlicher, wenn man sich beides mit den Mitteln der antiken Textgestaltung - sei es durch Rubrizierung, sei es in der Form einer ëx $\theta \varepsilon \sigma \iota \varsigma-{ }^{180}$ hervorgehoben denkt. $^{181}$

Die vom Autor angelegte textimmanente Gliederung nachzuvollziehen, wird heute dadurch erschwert, daß die modernen Suetonausgaben die in der Handschriftentradition und frühen Drucken des 15. Jh. aufgekommene und von ERASMUS in seiner Baseler Edition von 1518 übernommene Kapitelzählung fortführen, obwohl von CARL LUDWIG ROTH bereits 1858 auf die inhaltlich wesentlich adäquatere Gliederung des Haupttextzeugen, des am Ende des 9. Jh. im Martinskloster von Tours entstandenen und heute in Paris befindlichen codex Memmianus, ${ }^{182}$ hingewiesen wurde:

„Sed nolui tamen nescius esses, lector benevole, reperisse me in Memmiano codice aliam capitum divisionem tam commodam tamque luculentam, ut ipsius Tranquilli manu instituta esse videatur. “183

178 S.o. S. 243 f.

179 Vgl. NisSEN 1886, 497f; SCHMiDT 1891, 32; LUCK 1964, 231; MouCHOVÁ 1968, 45; WITTKE 1974, 46f. mit Anm. 121, u. CizEK 1977, 53.

180 Vgl. SCHRÖDER 1999, 103 f.

181 Vgl. WALLACE-HADRILL 1983, 13.

$182 \mathrm{Zu}$ Datierung, Beschreibung und Namensgebung der Handschrift vgl. die praefationes in den Editionen von RoTH 1858, xx-xxiii, u. IHM 1907, vii-x. Die von RICHARD BENTLEY vertretene These, daB alle erhaltenen Suetonhandschriften auf den codex Memmianus als Archetypen zuruckgingen, kann als widerlegt gelten (vgl. ROTH 1858, xxiii-iv, u. IHM 1907, xi-xii).

183 Vgl. ROTH 1858, xii-xiii („Ich mochte aber den geneigten Leser nicht daruber in Unkenntnis lassen, $\mathrm{da}$ B ich im codex Memmianus eine andere Kapiteleinteilung gefunden habe, die so zweckmaßig und uberzeugend ist, da $B$ es den Anschein hat, Sueton habe sie selbst vorgenommen."). Zwar hatte auch ERASMus den codex Memmianus, der ihm von seinem Schuler und Freund LORD WILliam BLOUNT 
Zwar behielt ROTH aus Gründen der Praktikabilităt die von ihm für irreversibel gehaltene Erasmuszählung bei, stellt ihr aber die Einteilung des codex Memmianus konkurrierend zur Seite, indem er sie in der Abschnittgliederung des Textes nachbildete. ${ }^{184}$

Der Herausgeber der heute maßgeblichen Edition, MAXIMILIAN IHM, übernahm diesen geglückten Kunstgriff und begründete seine Entscheidung auch in der praefatio seiner 1907 erschienen editio maior. ${ }^{185} \mathrm{Da}$ der betreffende Passus jedoch in der editio minor, die seit 1908 in zahlreichen Neuauflagen erschienen ist und wesentlich größere Verbreitung gefunden hat, den Kürzungen in der praefatio zum Opfer gefallen ist, konnte sich die Kapiteleinteilung des codex Memmianus, trotz ihrer bequemen Zugänglichkeit und verschiedener Versuche, ihr unter Hinweis auf ihre mögliche Authentizität mehr Bedeutung beizumessen, ${ }^{186}$ in der wissenschaftlichen Öffentlichkeit gegenüber der Erasmuszählung kaum Gehör verschaffen. Ob die Einteilung wirklich auf Sueton zurückgeht, kann anhand einer Handschrift aus dem 9. Jh. naturgemäß nicht definitiv beantwortet werden. Da sich jedoch an zahlreichen Punkten Überein-

MOUNTJOY zugănglich gemacht worden war, herangezogen, doch beschrankt er sich in seiner Verwendung auf Fragen der Textablieferung, wie auch die Widmungsepistel an die sächsischen Fürsten Friedrich und Georg zeigt, in der er als einzige Handschrift der codex Memmianus Erwăhnung findet: „Ac Suetonium quidem nescio quo deo prospicio, et antehac non ita passim depravatum, nunc eruditorum meaque opera purum, ni fallor, et integrum habemus, suffragante mihi ad hoc negocii, pervetusto quodam codice, quem e bibliotheca monasterii, apud Nervios olim, nunc Tornacenses, vulgato cognomine divi Martini, nobis exhibuit nobilissimus ille Gulielmus Montioius, qui id temporis regias vices ea in urbe gerebat.").

184 Es ist allerdings auf von beiden Herausgebern vorgenommene Verănderungen hinzuweisen, die sie in den praefationes zwar summarisch als Korrekturen rechtfertigen, an den einzeinen Stellen aber nicht nachgewiesen haben. So lassen sich etwa in der nach dem Ausweis des codex Memmianus aus 62 Absătzen bestehenden Caesarbiographie 9 und in den 72 Absătzen der Tiberiusbiographie 12 Abweichungen zu dem von IHM gedruckten Text nachweisen. Die prozentuale Hăufigkeit der Abweichungen ist im übrigen in den kurzeren Biographien der zweiten Hexade geringer. In der Vitelliusvita sind die von IHM gewăhlten Einteilungen in allen 14 Fallen mit dem codex Memmianus identisch.

185 Vgl. Інм 1907, xxviii: „De capitum distinctione, quam supra tetigi, Rothio adsentiendum fuit, qui etsi ordinem numerandique morem a scribis saeculi XV inductum et ab Erasmo in editione Basileensi sanctum quamuis non raro incommodiorem mutare noluit, tamen capitum diuisionem qualis in Memmiano perbene instituta deprehenditur, lectori uersiculorum initiis reductis indicandam censuit, paucis tantummodo aliter administratis quae necessario refingenda erant."

186 Vgl. FUNAIOLI 1931, 612f: „Die gewöhnliche Kapitelanordnung unserer Ausgaben datiert endgültig von Erasmus (ed. Basel 1518); der Memmianus hat eine andere, wahrscheinlich die ursprungliche.", u. LuCK 1965, 231: „Der Aufbau wäre einfach genug, wird aber durch die herkommliche Kapiteleinteilung, die auf die Basler Ausgabe des Erasmus von 1518 zuruckgeht, verwischt und uberdeckt und ist deshalb noch nie in allen Einzelheiten richtig angegeben worden. Manche Zusammenhange versteht erst, wer die Gliederung in Kapitel und Abschnitte, die unsere Aufgaben aufweisen, einfach ignoriert. ... Es würde sich ein Philologe wirkliche Verdienste erwerben, wenn er auf Grund der Spuren im Codex Memmianus, der Haupthandschrift der ,Caesares', eine neue, verstăndigere Gliederung aller Kaiser-Viten entwerfen könnte." 
stimmungen mit der immanenten Gliederung des Textes ergeben, kann zumindest der oben wiedergegeben Einschätzung ROTHS beigepflichtet werden.

Da der Umfang der Rubriken in den Caesares denjenigen der Mehrzahl der in de viris illustribus versammelten Porträts deutlich überschreitet, schien es Sueton offenbar darüber hinaus ratsam, eine weitere Gliederungshilfe, deren er sich zuvor in seinen antiquarischen Schriften bedient hatte, auf die Biographie zu übertragen. ${ }^{187}$ In diesen Făllen faßt Sueton in einem einleitenden Satz bereits die Punkte zusammen, die er im weiteren Verlauf der Rubrik sukzessive behandeln will. ${ }^{188}$ Wegen der Analogie zu der aus der Rhetorik bekannten Strategie hat sich für diese Erweiterung des Prăskriptes, mit der Sueton ein weiteres Gliederungsmittel für den umfangreicheren Text der Kaiserbiographien gewinnt, die Bezeichnung als divisio oder partitio eingebürgert. $^{189}$

Mit der Gliederung der einzelnen Rubriken mit Hilfe von Präskripten und divisiones $^{190}$ nähern sich Suetons Kaiserbiographien ebenso wie mit ihrem systematischen Aufbau im Großen, der zunächst durch die einzelnen Kaiser, dann durch die grosso modo vergleichbare Reihenfolge der Kategorien bestimmt ist, den Strukturprinzipien der Fachschriftstellerei an. ${ }^{191}$ Dennoch unterscheiden sie sich vor allem durch die Variationen, die im Aufbau der einzelnen Biographien zu beobachten sind, und durch die einzelnen aufwendiger gestalteten Passagen, wie sie sich häufig etwa im Zusammenhang mit der Schilderung der Todesumstände eines Kaisers finden, deutlich von der Form einer klassischen $\tau \dot{\chi} \chi \nu \eta$, die ausschließlich der Vermittlung des Lernstoffes eines bestimmten Faches dient.

Ein Vergleich bietet sich jedoch mit jener Gruppe von Schriften an, deren Autoren ihr Augenmerk weniger auf die Vermittlung des gesamten für ein bestimmtes Ge-

187 Vgl. TOWNEND 1967, 84, der auf ein Fragment aus Suetons liber de genere vestium verweist (Frg. 168 REIFFERSCHEID). Vergleichbare Gliederungen finden sich bereits in den fruhsten griechischen Beispielen fur Enkomien (vgl. z.B. Isokr. Euag. 22) und in einigen Nepos-Viten (s.o. S. 243f.).

$188 \mathrm{Vgl}$. z.B. Suet. Nero 19,1: peregrinationes duas omnino suscepit: Alexandrinam et Achaicam. Auf die Defizite dieses Gliederungsprinzips hat TOWNEND 1967, 85f., hingewiesen: „At all events, having adopted divisio in order to make clear the scheme of his arrangement per species, he soon begins to use it more and more, until it becomes a positive mannerism and often tends to confuse the reader instead of assisting him. This is largely because once he has announced the topics to be dealt with he is lieky to proceed from one to the next without repeating the key word or marking the transition in any way. ... Often, indeed, it is extremely difficult even for the reader with his eye open for this particular feature of arrangement, to decide how the material is intended to be classified."

189 Vgl. Cic. Brut. 302; div. in Caec. 45; inv. 1,31 u. TOWNEND 1967, 84ff.

190 Vgl. TOWNEND 1967, 86, zur divisio: "No other feature, perhaps, displays so clearly the method of the grammaticus turned biographer."

191 Vgl. dag. WALLACE-HADRILL 1983, 22: „Suetonius' natural affinities are with the abundant technical literature of the early empire - Vitruvius on architecture, Frontinus on aqueducts, Celsus on medicine, the jurists, physiognomists, agronomists, metricians and grammarians." 
biet einschlägigen Fachwissens denn vielmehr auf die für die Allgemeinbildung relevanten Informationen gelegt haben. ${ }^{192}$ Bücher dieser Art sind seit dem sich in der späten Republik vollziehenden Paradigmenwandel in der gesellschaftichen Verankerung gerade von historischem Wissen in reicher Zahl entstanden. In einen funktionellen Zusammenhang mit Sueton lassen sich von den uns erhaltenen Werken vor allem die Exempelsammlung des Valerius Maximus ${ }^{193}$ und der Geschichtsabriß des Velleius Paterculus, ${ }^{194}$ die beide in tiberianischer Zeit entstanden sind, stellen. ${ }^{195}$

Zu solchen Schriften, die primär der Vermittlung historischen Wissens dienen, weisen die Kaiserbiographien auch in der Präsentation des Materials eine Reihe von Gemeinsamkeiten auf. Das gilt zunächst fur die Tendenz zur Erzăhlung in abgeschlossenen Kleinformen, die durch die Gattung des exemplum bei Valerius Maximus evident ist, aber auch bei Velleius Paterculus in Form der ,unit composition', eines Kompositionsprinzip, in dem aus der parataktischen Reihung kleiner Einheiten the-

192 Zur Unterscheidung zwischen dem auf praktische Verwendbarkeit zielenden Fachbuch und dem der Befriedigung der curiositas dienenden Sachbuch vgl. FuHRMANN 1974, 181 ff., u. v. ALBRECHT 1992, I 450ff., der den Unterschied zwischen „bohrenden Einzeluntersuchungen“ und "lesbaren Gesamtdarstellungen“ vor allem im Bemuhen um eine „ansprechende literarische Gestaltung“ erblickt. Es wäre gleichwohl zu erwagen, ob nicht auf weite Strecken des suetonischen Werks die von STEINMETZ 1982, 291f., für den literaturkritischen Umgang mit Fachprosa aufgestellten Regeln anzuwenden sind: „Es ist ein Kennzeichen fachwissenschaftlicher Veroffentlichungen, daß sie nicht Literatur im Sinne von Kunstprosa oder auch nur von gefalliger Unterhaltung sein wollen. Sie stehen außerhalb einer irgendwie asthetisch bestimmten Zielsetzung, sie wollen den Leser informieren und sonst nichts. Sie beanspruchen, sachlich Richtiges vorzubringen, und wollen folglich nach den Kriterien sachlich richtig und sachlich falsch beurteilt werden. Aber, wenn man einmal von der philologischen Arbeit der Edition moglichst authentischer Texte absieht, so können fachwissenschaftliche Werke auch Gegenstand philologischer Untersuchung und asthetisch-philologischen Kriterien beurteilt werden, und zwar in dreierlei Weise. Denn da ein fachwissenschaftlicher Text den Leser sachlich informieren will, kann erstens gefragt werden, welche Darstellungsformen die jeweilige Fachwissenschaft entwickelt hat, ob diese Formen fur die genannten $Z$ wecke geeignet sind und wie geschickt oder ungeschickt diese Formen gehandhabt werden; zweitens kann gefragt werden, ob der darzustellende Stoff sachgerecht und das Fassungsvermogen des Lesers berücksichtigend gegliedert, daß heißt aber auch geordnet und geistig bewaltigt ist; und schließlich kann drittens gefragt werden, ob die Sprache so durchgearbeitet ist, daß sie dem doppelten Anspruch der Sachlichkeit und der Deutlichkeit gerecht wird, das aber heißt, ob sie hinsichtlich des Stoffes angemessen, also sachgema $B$ ist und ob sie hinsichtlich des Lesers auf die Verstandlichkeit achtet. So besehen hat wissenschaftliche Literatur stets eine fachliche und eine didaktische Komponente."

193 Vgl. Val. Max. 1 praef. 1 (quae apud alios latius diffusa sunt, quam ut breviter cognosci possint, ab illustribus electa auctoribus digerere ..., ut documenta sumere volentibus longae inquisitionis labor absit) sowie ferner z.B. HONSTETTER 1977, 7 ff.; BLOOMER 1992, IIff.; SKIDMORE 1996, 103ff., u. WARDLE 1998, 6ff.

194 Vgl. z.B. WOODMAN 1975; STARR 1981 u. SCHMITZER 2000, $287 f f$.

195 Ausführlicher s.o. S. 6f. 
matisch zusammengehörige Gruppen gebildet werden, eine wichtige Rolle spielt. ${ }^{196}$ In ähnlicher Weise stellt die Gruppierung kleiner Informationseinheiten zu Rubriken das Grundprinzip der suetonischen Biographie dar, das jedoch jederzeit und in fließenden Übergängen zu größeren und erzăhlerisch ambitionierteren Einheiten ausgebaut werden kann.

Der Übergang von einer stärker narrativ gestalten und daher auch primär chronologisch geordneten Passage zu einem Abschnitt mit vorwiegend thematischer Gliederung wird von Sueton in der Augustusvita explizit gemacht: proposita vitae eius velut summa parte $<s>$ singillatim neque per tempora sed per species exequar, quo distinctius demonstrari cognoscique possint.$^{197}$ Der Wechsel zwischen den beiden zentralen Darstellungsmodi der narratio und des Rubrikenschemas, die von Sueton hier mit den Schlagworten einer Gliederung per tempora beziehungsweise per species bezeichnet werden, ist allgemein charakteristisch für seine biographische Technik. ${ }^{198} \mathrm{Da}$ eine Gliederung nach thematischen Rubriken zur Folge hat, daß in den entsprechenden Teilen der Biographie die Kongruenz in der zeitlichen Ordnung von Geschichte und Erzählung aufgehoben wird, läßt sie sich aus narratologischer Perspektive als eine Reihe von Analepsen beziehungsweise Prolepsen beschreiben. ${ }^{199}$

Mit der optionalen Verwendung von narratio oder Rubrik als Phänomen der Makroebene korrespondiert der Wechsel zwischen unterschiedlich ,intensiven' Darstellungsformen bei der Gestaltung der kleineren Einheiten. Denn diese erhalten ihre charakteristische Struktur durch das Nebeneinander von einerseits vorwiegend informativen und andererseits stärker narrativ angelegten Partien, die sich hinsichtlich der erzählerischen Dichte deutlich voneinander unterschieden. Dieser Wechsel läßt sich in narratologischer Terminologie als ein Zusammenspiel von summary und Szene be-

196 Vgl. StaRR 1980. Die Orientierungsfunktion der Kapiteluberschriften bei Valerius Maximus, deren Echtheit neuerdings zu recht wieder diskutiert wird (vgl. BLOOMER 1992, 17f.27f.), ubernimmt bei Velleius der stereotype Beginn der einzelnen thematischen Abschnitte mit einer Datierung, die neben der Angabe des chronologischen Verhaltnisses zum letzten berichteten Ereignis meist die Nennung eines bekannten Namens oder Ereignisses beinhaltet.

197 Vgl. Suet. Aug. 9,1 („Nachdem ich bis jetzt gleichsam eine Übersicht uber sein Leben vorgelegt habe, werde ich die einzelnen Teile nun nicht nach chronologischen, sondern nach thematischen Gesichtspunkten durchgehen, damit auf diese Weise die Darstellung und das Verständnis klarer wird.").

198 Zur Rubrik bei Sueton vgl. DELLA CORTE 1958, 204: „Ogni rubrica rappresenta un complesso, che annovera tutto quanto interessa, senza tenere conto del tempo in cui il fatto è avvenuto.“; MouCHOVÁ 1968, 17: „In den beschreibenden Partien fasst Sueton in ein Ganzes, das gewöhnlich als Rubrik bezeichnet wird, solche Tatsachen zusammen, die aus verschiedenen Zeitabschnitten des Lebens des betreffenden Kaisers stammen, miteinander aber verwandt sind und sich auf ein und dasselbe Thema beziehen."; CIZEK 1977, 52ff., u. GASCOU 1984, 390ff.

$199 \mathrm{Vgl}$. GENETTE 1998 [1972/1983], $21 \mathrm{ff}$. 
greifen, da in den stärker narrativen Partien das Erzähltempo im Verhältnis zur gesamten Lebensschilderung deutlich verlangsamt wird. ${ }^{200}$

Den für Suetons biographische Technik charakteristischen Wechsel zwischen diesen beiden Darstellungsformen kann bereits der uns erhaltene Anfang der Caesarvita eindrucksvoll verdeutlichen. Denn dieser Abschnitt erhält sein spezifisches Relief dadurch, daß die Ebene einer beinahe fachwissenschaftlichen Informationsvermittlung immer wieder durch narrativ anspruchsvoll gestaltete Passagen aufgelockert wird: Zunächst erhalten wir - beginnend mit der auch in anderen Biographien als Einleitung ăhnlicher Rubriken fungierenden Angabe zum Verlust des Vaters ${ }^{201}$ - auf engstem Raum und syntaktisch dicht verwoben ${ }^{202}$ eine Füle von Einzelinformationen zu verschiedenen Ereignissen in diesem Lebensabschnitt:

annum agens sextum decimum patrem amisit; sequentibusque consulibus flamen Dialis destinatus dimissa Cossutia, quae familia equestri sed admodum dives praetextato desponsata fuerat, Corneliam Cinnae quater consulis filiam duxit uxorem, ex qua illi mox Iulia nata est; neque ut repudiaret compelli a dictatore Sulla ullo modo potuit. ${ }^{203}$

An die letzte Information knüpft sich nun ein doppelter ,Exkurs', der den Reigen der nüchternen Fakten zunächst mit einer miniaturhaften historisch-biographischen Erzählung unterbricht:

quare et sacerdotio et uxoris dote et gentilicis hereditatibus multatus diversarum partium habebatur, ut etiam discedere e medio et quamquam morbo quartanae adgravante prope per singulas noctes commutare latebras cogeretur seque ab inquisitoribus pecunia redimeret, donec per virgines Vestales perque Mamercum Aemilium et Aurelium Cottam propinquos et adfines suos veniam impetrauit. ${ }^{204}$

$200 \mathrm{Vgl}$. GENETTE 1998 [1972/1983], $61 \mathrm{ff}$.

$201 \mathrm{Vgl}$. Suet. Aug. 8,1 u. Nero 6,3. Alternativ konnen ăhnlich gelagerte Rubriken auch mit dem Verweis auf das Anlegen der toga virilis eingeleitet werden: vgl. Suet. Galba 4,3; Vesp. 2,2 u. ferner Tib. 7,1.

202 Die Zusammenstellung ganz unterschiedlicher Inhalten in einer syntaktischen Einheit steht bei Sueton gleichberechtigt neben der parataktischen Reihung (vgl. SCHERBERICH 1995, 2lf.).

$203 \mathrm{Vgl}$. Suet. Iul. 1,1 („Als er fünfzehn war, verlor er seinen Vater; im folgenden Jahr wurde er zum Jupiterpriester gewahit und heiratete, nachdem er die Verbindung mit Cossutia gelost hatte, eine Frau aus dem Ritterstand, die aber hinreichend vermögend war und mit der er noch als Kind verlobt worden war, die Tochter des vierfachen Konsuls Cinna, die bald darauf Julia zur Welt brachte; von Sulla konnte er auf keine Weise dazu gebracht werden, sich von ihr scheiden zu lassen.").

204 Vgl. Suet. Iul. 1,2 („Daher wurde er seiner Priesterstelle, der Mitgift seiner Frau und der Erbschaft seiner Familie beraubt und zudem als Anhănger der gegnerischen Seite betrachtet, so daß er sogar untertauchen mußte und, obwohl er an viertägigen Wechselfieber litt und dieses sich verschlimmerte, gezwungen war, beinahe jede Nacht sein Quartier zu wechseln und sich von seinen Verfolgern freizukaufen, bis er schließlich durch die Fürsprache der Vestalischen Jungfrauen sowie des Mamercus Aemilius und des Aurelius Cotta, Freunde und Verwandte von ihm, eine Begnadigung erreichen konnte."). 
Auf die Schilderung dieser Episode folgt nun noch die ebenso detaillierte Wiedergabe der wegen ihres pointierten Charakters möglicherweise den Lesern als Zitat geläufigen Reaktion Sullas:

satis constat Sullam, cum deprecantibus amicissimis et ornatissimis viris aliquamdiu denegasset atque illi pertinaciter conenderent, expugnatum tandem proclamasse sive divinitus sive aliqua coniectura: vincerent ac sibi haberent, dum modo scirent eum, quem incolumem tanto opere cuperent, quandoque optimatium partibus, quas se cum simul defendissent, exitio futurum; nam Caesari multos Marios inesse. ${ }^{205}$

Wie das ausgewählte Beispiel zeigt, können diese narrativen ,Erweiterungen' hinsichtlich ihrer jeweiligen Ausgestaltung signifikante Unterschiede aufweisen. Ließe sich im ersten Fall die These vertreten, daß es sich um ein, wenn auch sehr kurzes und biographisch auf die Person Caesars zentriertes Stück dramatischer Historiographie handelt, deren Einfluß auf Sueton sonst insbesondere in der Gestaltung der Sterbeszenen spürbar ist, kann der zweite Teil als Apophthegma klassifiziert werden, das ebenso auf die Information des Lesers über die historische Situation wie auf seine Unterhaltung zielt. Eine in diese Richtung weisende Gestaltung der facta et dicta seiner Protagonisten findet bei Sueton weitaus häufiger statt als die Funktionalisierung zum exemplum, da die für die Definition des exemplum zentralen normativen Aspekte ${ }^{206}$

$205 \mathrm{Vgl}$. Suet. lul. 1,3 („Es ist hinlanglich bekannt, daB Sulla, nachdem er die Bitten der mit ihm eng befreundeten und uberaus angesehenen Männer lange Zeit abgelehnt hatte, jene sie aber dennoch hartnăckig fortsetzten, schließlich nachgab und dabei - sei es aufgrund göttlicher Eingebung, sei es weil er eine Vermutung hatte - ausrief: Sie soliten ihren Sieg haben und ihn dazu, solange sie nur wußten, $\mathrm{da} ß$ derjenige, dessen Rettung sie nun mit aller Macht erstreben, dereinst der Sache der Optimaten, die sie gemeinsam mit ihm verteidigt hătten, ihr Ende bereiten werde; denn in Caesar stecke mehr als ein Marius."). Zur Begründung, warum die Sueton gerade diese Episode in detaillierter Form darstellt, wurde auf Plutarch verwiesen, der gleichfalls die Konfrontation mit Sulla und das sich anschließende Seerăuberabenteuer ausführlicher schildert (Plut. Caesar 1-2), und die Vermutung ins Feld gefuhrt, daß beide Autoren hier von einer gemeinsame Quelle abhăngig sind (vgl. zusammenfassend STEIDLE 195I, 13ff.). Doch lassen sich auch daruber hinaus gehende Grunde fur eine ausfuhrliche Behandlung dieser Stelle plausibel machen: Denn neben dem Beitrag zur Charakterschilderung, den beide Episoden fraglos leisten und der fur Plutarch im Vordergrund gestanden haben dürfte, läßt sich für Sueton vermuten, daß er gerade die Bekanntheit des Sulla-Diktums zum Anlaß genommen hat, um seinen Lesern auf diese Weise zugleich die ihnen vielleicht nicht prassente situative Einbindung dieses geflugelten Wortes zu bieten. Ein ăhnlicher Fall liegt möglicherweise in der Vitelliusvita vor: s.u. S. 279.

206 Vgl. STIERLE 1973, 357: „Das Exemplum konstituiert sich aus den drei Momenten Situation - Entscheidung - Ausgang der Situation. ... Sofern gegebene Situation und Exemplum durch Isomorphie verbunden sind, läßt sich der Ausgang des Exemplums begreifen als Vorgriff auf den Ausgang der eigenen Situation. Das Exemplum zeigt, wohin es fuhren muß, wenn man sich einer gegebenen Situation so oder so entscheidet. In dieser Isomorphie liegt das uberredende, zur Handlung oder zur Unterlassung auffordernde Moment des Exemplums." u. ferner v. Moos 1988, 69ff. 
sich in den Kaiserbiographien nur am Rande konstatieren lassen. ${ }^{207}$ Zwar weist die Darstellung seiner Figuren hin und wieder einen paränetischen Zug auf, doch unterscheidet sich diese Protreptik deutlich von den moraldidaktischen Zielsetzungen der antiken Historiographie ${ }^{208}$ oder der Biographie à la Plutarch. ${ }^{209}$

Das von Sueton in seinen Kaiserbiographien umgesetzte Konzept läßt sich also als ein Wechselspiel zwischen einem faktenorientierten Grundgerüst von Informationen auf der einen Seite und an ausgewählten Stellen eingestreuten, stilistisch aufwendiger gestalteten Erzählpartien auf der anderen Seite beschreiben. Mit beidem, sowohl mit der über weite Strecken sachlichen und nüchternen Diktion als auch mit der Präsentation historischen Wissens in Form von kleinen, hăufig anekdotisch zugespitzten narrationes unterscheidet sich Sueton von der traditionellen Geschichtsschreibung und ihren literarischen Ansprüchen, die sich nicht zuletzt auch die stilistische Homogenität des Gesamtwerkes umfaßten.

Die Beantwortung der Frage, warum Sueton dieser literarischen Technik den Vorzug gegeben hat, obwohl er damit eine Reihe von Defiziten in Kauf nahm, die ihm vor allem im Vergleich mit der Historiographie immer wieder angekreidet wurden, ${ }^{210}$ wurde durch die von ANDREW WALLACE-HADRILL vorgeschlagene Interpretation in ein neues Licht gerückt, der es plausibel machen konnte, daß den Kaiserbiographien das Konzept einer ,not-history' zugrunde liegt. ${ }^{211}$ Dieses ,mirror-image of history' läßt sich auf der stilistischen Ebene ${ }^{212}$ ebenso nachweisen wie in der Anordnung des Stoffes in Rubriken und dem damit einhergehenden Verzicht auf eine Glie-

207 Auch die in der rhetorischen Verwendung des Exempels dominierende argumentative Dimension ist für Sueton nicht zentral (vgl. allg. v. MOOS 1988, 48ff; CHAPLIN 2000, 1ff., u. WITTCHOW 2001, 37ff., der das Exempel ,vornehmlich in seiner Ausprăgung als kleine Erzăhlung mit Zeigegestus“" (S. 13) auffaßt und daher den Begriff mit dem der Anekdote weitgehend synonym verwendet (S. 13.19), zugleich aber mit seinen Hinweis auf die Narrativitat als „eine Moglichkeit des exemplum“, doch „eine Notwendigkeit der Anekdote“" (S. 31.72f.372) einen entscheidenden Unterschied benennt).

208 Vgl. z.B. Pol. 6,54,3; Sempronius Asellio Frg. 2 HRR (= Gell. 5,18,9); Sall. lug. 4,5; Liv. praef. 10; Tac. hist. 1,3 u. ann. 4,33 mit FORNARA 1983, 84ff.112ff., sowie ferner speziell zur normativen Funktion des historischen exemplum in der romischen Republik MUTSCHLER 2000a; MUTSCHLER 2000b; STEMMLER $2000 \mathrm{u}$. STEMMLeR 2001.

209 Vgl. WaLLACE-HADRILl 1983, 23f., u. BradLEY 1991, 3713f., sowie dag. GaSCOU 1984, 430ff.

210 Vgl. z.B. FLACH 1972, v.a. 285 : „Zieht man Bilanz, kommt eine stattliche Zahl bezeichnender Manngel zusammen ... Die hervorstechendsten sind: Verstoße gegen die Chronologie, Verallgemeinerungen, Unterdrückung wichtiger Varianten, Vernachlässigung des historischen Kontextes, Ungenauigkeit in der Zuweisung der Verantwortung, Zerreißung von Zusammengehörigkeiten, Fehleinordnung oder willkürliche Zurechtbiegung einzelner Fakten, fehlende Geschlossenheit." (vgl. ferner FLACH 1998, 175ff.)

211 Vgl. WALLACE-HADRILL 1983, 8ff., u. ferner unabhangig GASCOU 1984, 344f.

212 Vgl. WaLlaCE-HadriLL 1983, 19ff. 
derung anhand der Chronologie, ${ }^{213}$ wie sie in der antiken Geschichtsschreibung die Regel ist, ${ }^{214}$ oder in der weitgehenden Ausblendung politisch-militärischer zugunsten privat-persönlicher Aspekte. ${ }^{215}$ Darüber hinaus ist auf die fundamentalen Differenzen in intentionaler Hinsicht zu verweisen, so etwa auf das Fehlen einer explizit gemachten didaktischen Zielsetzung. ${ }^{216}$

Sueton wird zwar mit dieser Hinwendung zu den kleineren Formen der narrativen Präsentation nicht eigentlich beabsichtigt haben, ein Alternativmodell zur Historiographie im Allgemeinen zu etablieren, wie die Analogie mit der Rolle des anekdotischen Erzählens als ,la petite histoire' zur Überwindung des historistischen ,grand récit' in den postmodernen Ansätzen der Geschichtswissenschaft nahelegen könnte. ${ }^{217}$ Doch ist bereits verschiedentlich beobachtet worden, daß die Vermeidung einer zu großen Nähe zur Historiographie als Reaktion auf die wenige Jahre zuvor erschienen Geschichtswerke des Tacitus zu verstehen ist ${ }^{218}$ und insofern doch eine Alternative zur ,klassischen' antiken Geschichtsschreibung formuliert. In diesem Zusammenhang ist auch nicht irrelevant, daß Suetons Ansatz in der Folgezeit Modellcharakter gewinnt und sich in der späteren Kaiserzeit gegenüber dem noch einmal bewußt und spürbar

213 Vgl. WALLACE-HADRILl 1983, 10ff., der jedoch zugleich auf Ausnahmen wie die exitus-Szenen der Kaiser und die erste Hălfte der Caesarvita hinweist. Das Rubrikenschema als solches legt die Vermutung eines wie auch immer gearteten ,Zettelkastens', wie er fur Plinius den Älteren wahrscheinlich ist (vgl. Plin. ep. 3,5,17), nahe (vgl. SCHERBERICH 1995, 24, u. zuruckhaltend WALLACE-HADRILL 1983, 15); doch sollte die Wahl Gliederung nach Rubriken nicht als zwangsläufige Folge der Verwendung eines Zettelkastens, sondern als bewußte Entscheidung Suetons zur Disposition seines Materials verstanden werden.

$214 \mathrm{Zu}$ thematischen Gliederungsprinzipien in der nicht annalistischen Historiographie vgl. JAL 1997.

215 Vgl. WALLACE-HADRILL 1983, 15ff.129ff. Militarische Aktionen erwahnt Sueton nur, wenn sie fur die Person unmittelbar relevant sind (vgl. z.B. Suet. lul. 34-36 u. Aug. 9-18), und fokussiert ihre Darstellung hăufig auf den Aspekt des Umgangs des Kaisers mit den Soldaten (vgl. v.a. Suet. lul. 57-67 u. dag. Plut. Caesar. 18-27). Den aus dieser Schwerpunktsetzung resultierenden kulturgeschichtlichen Wert der suetonischen Kaiserbiographien betont zu recht SONNABEND 2002, $174 \mathrm{ff}$.

216 Vgl. WALLACE-HADRILL 1983, 23f.: „His tone is nothing but didactic. One of the most remarkable features is the rarity with which he intervenes to comment his material. He does not speek in propria persona, except to comment on truth or falsehood. He offers no epigramms or sententiae. He does not even use value-laden adjectives to guide the reader towards approval or disapproval." u. ferner BRADLEY 1991, 3713f., sowie dag. GASCOU 1984, 430ff.

217 Zur Bedeutung der Anekdote innerhalb des unter anderem von STEPHEN GREENBLATT inaugurierten ,New Historicism' vgl. v.a. FINEMAN 1989. Daß sich die antike Historiographie und ihre Verwendung der Anekdote in dieser Diskussion nur bedingt verorten lassen, zeigen SALLER 1980 und insbesondere WITTCHOW 2001, 20ff.

218 Vgl. Z.B. LEO 1901, 1; TOWNEND 1967, 81f; SYME 1980a, 11lf., u. WALLACE-HADRILL 1983, If.9. Von einer Kenntnis der taciteischen Schriften durch Sueton sollte aufgrund der literarischen Kommunikationsbedingungen des 2. Jh. n. Chr. ausgegangen werden (vgl. z.B. CIZEK 1977, 46 Anm. 80, mit der Vermutung, Sueton sei bei Septicius Clarus Zeuge einer Rezitation der Annales geworden). 
bemüht auf republikanische Muster rekurrierenden ${ }^{219}$ taciteischen Konzept letztlich durchsetzt. $^{220}$

$\mathrm{Da} ß$ es indessen nicht Suetons eigentliche Intention war, eine der monarchischen Herrschaftsform adäquate Form der Geschichtsschreibung zu etablieren, ${ }^{221}$ zeigt sich in dem deutlich subsidiären Charakter seiner Kaiserbiographien, mit dem sie sich als ein typisches Werk des 2. Jh. n. Chr. erweisen. Denn die ihnen zugrundeliegende Auswahl und Präsentation der historischen Informationen setzten gerade in ihrem Verzicht auf Vollständigkeit und Systematik die ganz anders gearteten Geschichtswerke des Tacitus und seiner uns nicht erhaltenen Vorlaufer voraus, die dem zeitgenössischen Rezipienten im Gegensatz zum modernen Leser jederzeit zur Verfugung standen. ${ }^{222}$ Sueton intendiert weniger eine Ablösung der traditionellen Geschichts-

219 In der Nachfolge RONALD SYMEs war die Sicht auf Tacitus uberwiegend von Bewunderung gepragt; in den letzten Jahren zeichnet sich jedoch eine kritischere Perspektive ab, in der beispielsweise die der annalistischen Konzeption zugrundeliegenden ,anachronistischen' Zuge deutlicher hervortreten (vgl. z.B. KraUS 2000, 463, u. SONNABEND 2002, 184f., sowie dag. v.a. SyME 1958a, $1144 \mathrm{ff}$.).

220 Die immense Nachwirkung Suetons in den folgenden Jahrhunderten ist verschiedentlich dargestellt (vgl. z.B. LEO 1901, 268ff.; TOWNEND 1967, 96ff.; SALLMANN / SCHMIDT 1997a, 50ff., u. BOWERsock 1998, 206ff.) und in der alteren Forschung mit eindeutiger Parteinahme fur Tacitus in der Regel bedauert worden (vgl. z.B. LEO 1901, 1: „Als Tacitus die Annalen schrieb, arbeitete Sueton an seinen Caesares. Der grosse Schriftsteller erfullt in der alten Kunstform, als Abschluß einer langen Reihe, den Stoff des ersten Jahrhunderts der Monarchie furr immer mit seinem Geiste; der scholasticus findet fur denselben Stoff eine neue Form, eine Form wie sie dem Zeitalter zukam, in dem die lebendigen Krăfte des rơmischen Geistes versiegen wollten. Das Lustrum um 115-120 n. Chr. ist wie die Wasserscheide der römischen Geschichtsschreibung; der Fluss der suetonischen Biographie geht durch die folgenden Jahrhunderte, und Tacitus bleibt in der Vergangenheit." u. SYME 1980a, 125: „History under the Caesars prolonged for a season the tradition of the Republic. Under the benevolent despotism of Trajan it was in danger of becoming obsolete or undesirable. Tacitus by various devices was able to prevent his senatorial annals from degenerating into a sequence of biographies. Suetonius saw what the public wanted. And so, in posterum valescit.").

221 Vgl. dag. z.B. Gugel 1977, 144ff.: „Mit Suetons Caesares ist also die historische Biographie an die Stelle der annalistischen Geschichtsschreibung getreten. Sueton wollte nun gewiB nicht Geschichte

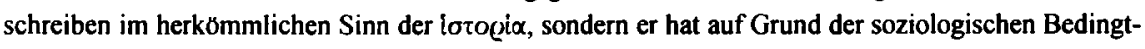
heit die Zeitgeschichte in der ihr jetzt einzig gemaßen Form geboten, und dies nicht als ,Erganzung der Geschichtswerke', , wie das die biographischen Sammelwerke fur fruhere Epochen der Geschichte leisteten' [vgl. LEO 1901, 268 u. 319], sondern, wie wir meinen, durchaus mit dem Anspruch, gleichberechtigt neben die Geschichtswerke zu treten.“ (S. 148); LAMBRECHT 1984, 21.156f.; DiHLE 1987, 42ff.64ff.78ff; Lambrecht 1995, 535f.; SallmanN / SCHMidt 1997a, 46f., u. SAllmanN 2001, 1086: „Daher tritt auch diese ,historisch-private Biographie' gleichberechtigt neben die pragmatische Form der Annalen und Historien, wenn auch mit einer gewissen Verschiebung des Anspruches vom Nutzen zur Unterhaltung."

$222 \mathrm{Vgl}$. TOWNEND 1967, 84: „But if Suetonius irritates modern readers in this way, it is because they are hoping to use him as an historical source, to provide a factual account of the events of such-and-such an emperor's reign. This is not, of course, how Suetonius intended his lifes to be read. He could hardly have dreamed that an age would come when readers lacked even the certain books of Tacitus' An- 
schreibung als vielmehr ihre Ergänzung durch eine Erweiterung des Spektrums derjenigen literarischen Formen, die sich mit der Vermittlung von Vergangenheitswissen beschäftigen. ${ }^{223}$

Entscheidender für die Bevorzugung der kleinen Formen dürfte ohnehin weniger der Gegensatz zur Historiographie gewesen sein als die anderen Vorteile, die mit dieser literarischen Strategie verbunden waren. In ihrer 1968 erschienenen Untersuchung konstatiert BOHUMILA MOUCHOVȦ einen auffalligen Gegensatz zwischen „der Geschicklichkeit Suetons zur wirksamen Bearbeitung kleinerer Einheiten“ und „seiner geringen Fähigkeit, daraus ein einheitliches biographisches Ganzes zu schaffen.“2224 Diese Beobachtung ist von ihr zu recht als grundlegend für die Interpretation der Kaiserviten eingestuft worden, doch gilt es, die ihr innewohnende negative Perspektive zu überwinden, indem man die Ursache weniger in Suetons Unvermögen als in seiner Darstellungsabsicht sucht. Denn daß Sueton zur Gestaltung auch größerer narrativer Komplexe, wie zum Beispiel der Sterbeszene Neros, ${ }^{225}$ durchaus in der Lage war, wird heute niemand mehr ernsthaft bezweifeln. ${ }^{226}$ Eine adäquate Interpretation der Kaiserbiographien muß sich daher von der Frage leiten lassen, welche Gründe Sueton bewogen haben, seinem primär der Vermittlung konkreter Informationen dienenden Text mit einzelnen elaborierten Passagen gleichsam Relief zu verleihen.

Eine ansprechende Gestaltung der kleine erzăhlerischen Formen erhöht zunächst einmal die Lesbarkeit des Textes und leistet auf diese Weise einen wichtigen Beitrag zum unterhaltenden Charakter der Kaiserbiographien. ${ }^{227}$ Die anekdotische Präsentationsweise bringt aber weitere Vorteile mit sich: Das in dieser Form narrativ aufbereitete Wissen eignet sich in hohem Maße zur Memorierung und damit auch zur Wiederverwendung im Kontext der zeitgenössischen Bildungskultur, die in verschiedenen gesellschaftlichen Institutionen dem Einzelnen reichlich Gelegenheit bot, kulturelle Kompetenz zu demonstrieren. Ein Blick in die Literatur, die im 2. Jh. n. Chr. mit der Zielsetzung geschrieben wird, Teilnehmer eines Symposions mit hinreichend Rede-

nals and Histories, not to mention the less brilliant historical works of Aufidius Bassus and the elder Pliny."

$223 \mathrm{Vgl}$. WallaCe-Hadrill 1983, $9 \mathrm{f}$.

$224 \mathrm{Vgl}$. MOUCHOVÁ 1968, 102f. u. 105f.: „Er zeigt seine Kompositionskunst eher in kleineren Einheiten, wo er ein einzelnes Ereignis schildern oder eine bestimmte Eigenschaft des Kaisers dokumentieren kann. Die Zusammenfügung dieser Teile der Biographie zu einem einheitlichen und logisch abgerundeten Ganzen bereitete Sueton aber Schwierigkeiten.“

225 Vgl. Suet. Nero 40-50.

226 Vgl. z.B. TOWNEND 1967, 93ff.; BALDWIN 1983, 509ff; LOUNSBURY 1987, 63ff.; LOUNSBURY 1991, passim, u. ARAND 2002, $115 \mathrm{f}$., sowie dag. MOUCHOVÁ 1968, 59.105.

227 Vgl. MURPHY 1991, 3781: „Undoubtedly the chief reason for the 'Lives' to enduring charm and interest is the Suetonian anecdote. Suetonius' text, in fact, is a veritable cento of anecdotes and surely the vividness and vivacity of the 'Lives' result from his frequent, not to say, constant use of that literary device." 
stoff auszustatten, kann zur Illustration dienen: Auch Athenaios oder Plutarch in seinen $\sigma u \mu \pi \circ \sigma i \alpha x \dot{\alpha}$ bieten ihren Stoff bereits in narrativ aufbereiteter Form, um dem Rezipienten auf diese Weise die ,Nutzanwendung' zu erleichtern. Für Sueton stellte daher sicherlich neben ihrer Lesbarkeit auch die Erzählbarkeit dieser literarischen Kleinformen ein entscheidendes Argument für ihre vielfältige Verwendung dar.

Ausgehend von der Annahme, daß die von Sueton gewählte Präsentationsform eine eng an den Bedürfnissen des 2. Jh. n. Chr. orientierte Vermittlung biographischen Wissens darstellt, deren anekdotische Komponente vor allem auf den doppelten Unterhaltungswert für den primären Akt der Lektüre wie für die sekundäre Anwendung des Materials durch den Leser abzielt, soll nun exemplarisch die Vitelliusvita mit Blick auf ihre Struktur, ihre inhaltlichen Schwerpunkte und die zur Präsentation der ausgewählten Informationen angewandte Technik untersucht werden. Eine vollständige Interpretation dieser Biographie, die alle von philologischer und historischer Seite mit ihr verbundenen Fragestellungen berücksichtigt, kann dabei freilich nicht geleistet werden. Das Augenmerk soll statt dessen zum einen auf den „Dienstleistungen des Autors gegenüber dem Leser، ${ }^{\text {‘228 }}$ liegen, das heißt auf den von ihm zur Gliederung seines Materials verwendeten Strategien wie Rubriken, Präskripte und divisiones. Zum anderen soll der Wechsel zwischen den primär der Informationsvermittlung dienenden Passagen, die in einer sachlich-nüchterner Diktion abgefaßt sind, und den an vielen Stellen eingestreuten aufwendiger gestalteten Passagen im Mittelpunkt des Interesses stehen. $\mathrm{Zu}$ diesem Zweck wurde bewußt eine Biographie ausgewählt, die traditionell zu den kompositorisch eher schwachen Stücken der Kaiserviten gerechnet wird, weil sich gerade hier Suetons spezifische Interessen und Intentionen, die sich von der modernen Erwartungshaltung gegenüber einer literarischen Lebensbeschreibung zum Teil deutlich unterscheiden, besonders gut aufzeigen lassen.

\section{Von Capri zu den scalae Gemoniae: Vitellius' Leben zwischen Rubrik und narratio}

\section{a) Im Schatten der Forschung: Suetons Vitelliusvita}

Da sich das Interesse der Forschung auf die umfangreicheren Biographien der principes aus der julisch-claudischen Dynastie und auf die historisch relevanteren Flavier konzentrierte, standen die drei ,Kurzzeitherrscher' des Vierkaiserjahres lange Zeit im Schatten der wissenschaftlichen Aufmerksamkeit. Erst in den letzten Jahrzehnten des 20. Jh. läßt sich eine verstärkte Beschäftigung mit den drei von Sueton ursprünglich in 
einem Buch zusammengefaßten Biographien beobachten. ${ }^{229}$ In diesen Untersuchungen dominiert die sich aufgrund der Materiallage anbietende Fragestellung eines Vergleiches der suetonischen Viten mit den aus Plutarchs Kaiserbiographien erhaltenen Lebensbeschreibungen Galbas und Othos ${ }^{230}$ sowie insbesondere im Falle des Vitellius, dessen plutarchisches Pendant bekanntlich verloren ist, mit den Berichten in den taciteischen Historien. ${ }^{231}$ Gerade in der Beschäftigung mit Vitellius stand dabei die Frage nach der Glaubwürdigkeit der antiken Quellen, die ein vorwiegend negatives Bild seiner kurzen Regentschaft zeichnen, im Vordergrund. ${ }^{232}$ Dieser Ansatz, der auf einer Linie mit den Tendenzen zu einer positiveren Bewertung auch anderer von den antiken Autoren primär negativ gezeichneter Herrscher liegt, hat gerade für Suetons Vitelliusvita, die von der erfolgreichen ,Geschichtspolitik' der Flavier nicht unbeeinflußt ist, ${ }^{233}$ auch seine unbestrittene Berechtigung.

Der Schwerpunkt der gegenwärtigen Untersuchung soll jedoch weniger auf der propagandistischen Provenienz des Vitelliusbildes liegen, das seine politische Relevanz inzwischen verloren hatte, sondern die Frage in den Vordergrund rücken, welche biographischen Informationen Sueton zur Tradierung auswählt und in welcher Form er diese präsentiert. In diesem Zusammenhang ist zunächst der Aufbau der Biographiengruppe der drei ,Kurzzeitherrscher' im allgemeinen wie der Vitelliusvita im besonderen von Interesse, ein Aspekt, der aufgrund der oben skizzierten Ausrichtung der Forschung sowie wegen der vorherrschenden Meinung, die zweite Hexade der Kaiserbiographien stelle gegenüber der ersten einen literarischen Rückschritt und daher kein lohnendes Untersuchungsobjekt dar, bislang vernachlässigt wurde. ${ }^{234}$ Geht man allerdings statt von einer Degeneration von Suetons biographischer Technik von deren Entwicklung in der zweiten Werkhälfte aus, rücken gerade die Viten der drei Bürgerkriegsherrscher in den Blickpunkt des Interesses, da sie gleichsam das Experimentierfeld für Suetons Strategien der Wissenspräsentation dargestellt haben.

229 S.o. S. 255. Auch in Kommentaren werden die drei Biographien stets gemeinsam behandelt vgl. VENINI 1977; MURSION 1992 U. SHOTTER 1993.

230 Vgl. BaLdWIN 1983, 530ff.; BRAUN 1992 u. BENEDIKTSON 1997.

231 Vgl. BraUn 1990.

232 Vgl. z.B. ENGEL 1977; RICHTER 1992; MURISON 1987; MURISON 1993, 143ff., u. ASH 1999, $95 \mathrm{ff}$.

233 Vgl. allg. Nicols 1978, 95ff., u. FranChET D'ESPÉrEY 1986, 3048ff., sowie zu Vitellius Richter 1992, v.a. 259. Zur Wechselwirkung der flavischen Geschichtspolitik mit der zeitgenðssischen Historiographie vgl. Tac. hist. 2,101,1 (scriptores temporum, qui potiente rerum Flavia domo monumenta belli huiusce composuerunt, curam pacis et amorem rei publicae, corruptas in adulationem causas tradidere) sowie ferner BRACHER 1987 [1948], 88ff., u. BRIESSMANN 1955.

234 Vgl. z.B. die Pauschalurteile von HAENISCH 1937, 65.71, der fur die Biographien des Vierkaiserjahres eine rein chronologische Erzathlweise postuliert, u. dag. STEIDLE 1951, 105f., mit der Beobachtung, „daß Sueton soweit wie moglich die Gruppierung nach Sachgesichtspunkten der chronologischen Erzathlung vorgezogen hat." 
Aus dieser Perspektive erweisen sich auch die Unterschiede zwischen den drei Biographien selbst weniger als Zufall denn als zielgerichtete Entwicklung. Während die Lebensbeschreibungen Galbas und vor allem Othos noch stark chronologisch ausgerichtet sind und allenfalls über ein rudimentäres Rubrikenschema verfügen, bietet die Biographie des Vitellius mit ihrem Wechsel zwischen chronologisch und thematisch organisierten Abschnitten das erste gelungene Beispiel für den spăter charakteristischen Aufbau einer suetonischen Vita. ${ }^{235} \mathrm{Da}$ es inzwischen weitgehend anerkannt ist, daß Sueton diese Grobstruktur flexibler handhabt als früher angenommen, ${ }^{236}$ kann es auch nicht verwundern, daß die Vitelliusvita im Vergleich mit dem von GEOFFREY LEWIS herausgearbeiteten Idealaufbau einer suetonischen Biographie einige signifikante Eigenheiten aufweist. ${ }^{237}$

Neben diesen Phänomenen auf der Ebene der ,Makrostruktur' soll ein besonderes Augenmerk dem uberlegten Wechsel zwischen den beiden unterschiedlichen Schreibstilen gelten. Von diesen ist der eine, der primär auf die Vermittlung möglichst vieler Einzelinformationen zielt, zumeist in den durch thematische Rubriken gegliederten Abschnitten anzutreffen, während der andere, der sich als eine auch stilistisch ambitionierte Form der fortlaufenden narratio begreifen läßt, die chronologisch aufgebauten Passagen dominiert, mit denen sich Sueton daher auch in größerer Năhe zur Historiographie oder zur Biographie plutarchischer Prägung bewegt. Dem Wechsel zwischen diesen beiden für Suetons Caesares charakteristischen Präsentationsformen entspricht auch die Gliederung des folgenden interpretatorischen Durchgangs durch die Vitelliusbiographie, da sich eine Reihe von Beobachtungen jeweils einer der beiden literarischen Techniken zuweisen lassen.

235 Die Unterscheidung zwischen chronologisch-erzahlenden und thematisch gegliederten Passagen innerhalb den Kaiserbiographien geht auf LEO 1901, 2ff., zuruck (vgl. ferner MOUCHOVÁ 1968, 17ff;; CIZEK 1977, 49ff.56ff., u. GASCOU 1984, 349ff.).

236 Vgl. z.B. STEIDLE 1951, 2ff.; LUCK 1964, 230; CizeK 1977, 54ff.; WALLACE-HADRILl 1983, 66ff.; LAMBRECHT 1984, 18; LewIS 1991, 3641; v. AlbreCht 1992, II I 108, u. SALLMANN 2001, 1085, sowie dag. mit Betonung der inflexibilitat des suetonischen Schemas LEO 1901, 2ff., u. FUHRMANN $1999,331$.

237 Vgl. LEWIS 1991, 3641: „Due regard for Suetonius' versatility of variation in working out his themes is, as will appear, of vital importance. In outline, however, the present observation holds good that typically the 'Caesars' are tripartite, offering (1) a chronologically based account of the family background and preimperial career, covering ancestry, parentage, birth and boyhood, the toga virilis and subsequent prima militia (stipendia) and tirocinium fori, honores and under each, the appropriate res gestae, and culminating in accession to power; (2) scrutiny by more or less standard criteria of performance as emperor, for the most part essentially static and proceeding by 'rubrics' or standardised headings; (3) narrative, with omens, of removal from power and death, whetherby violence or illhealth, commonly with an epiloque containing standard documentary data and final honours (if any), and sometimes other addenda." 
b) Im Dunstkreis des Hofes: Das Leben vor dem Antritt der Herrschaft in Rubriken

Die Vitelliusbiographie beginnt mit einem thematisch organisierten Abschnitt, dessen einzelne Rubriken zur Abstammung, Geburt und Jugend des Kaisers sich jedoch häufig sowohl in ihrer Reihung untereinander als auch in ihrer jeweiligen Binnengliederung an der chronologischen Abfolge der Ereignisse orientieren. ${ }^{238}$ Die praktisch alle Kaiserviten eröffnende Rubrik zu den Vorfahren des Portrătierten ${ }^{239}$ ist im Vergleich zur Kürze der gesamten Vita verhältnismäßig umfangreich ausgefallen ${ }^{240}$ und von Sueton zum Teil in Form eines abwägenden in utramque partem disserere gestaltet, ${ }^{241}$ weil die antivitellianische Propaganda diesem im traditionalen Denken der Romer naturgemäß zentralen Punkt offenbar besondere Aufmerksamkeit geschenkt hatte. Die von Sueton gewählte diskursive Darstellungsform zeugt ebenso wie seine explizite Aussage, in der er die von ihm beobachteten Diskrepanzen in Überlieferung auf die adulatores obtrectatoresque imperatoris Vitelli zurückfuhrt, ${ }^{242}$ von einem deutlich

238 Aufgrund dieses ambivalenten Charakters wird die Einleitungspartie einer suetonischen Biographien haufig den chronologischen Teilen zugerechnet (vgl. z.B. LEO 1901, 2; ClZEK 1977, 59ff., u. LEWIS 1991, 3641), doch sind die einzelnen Rubriken in der Vitelliusvita primar thematisch definiert, ihre Übereinstimmungen mit der Chronologie ergeben sich erst sekundar aus der Anordnung gemåß den anthropologischen Gesetzmaßigkeiten.

239 Daß dieser Punkt bei Titus und Domitian fehlt, stellt keine wirkliche Ausnahme dar, weil die Abstammung der Flavier in der Vespasiansvita behandelt wird und die drei Viten ursprunglich ein gemeinsames Buch bildeten (vgl. Suet. Vesp. 1). Daß Sueton dieser Rubrik besondere Bedeutung beimißt, steht sicherlich in Zusammenhang mit dem in Rom vielfach zu beobachtenden Interesse an der Genealogie (vgl. Steidle 1951, 91.111 u. WALLACE-HADRILL 1983, 101ff.), ob der Leser durch diese Rubrik aber angehalten werden soll, ,alles Kommende vor dem Hintergrund der Ahnen sehen“ (vgl. GuGEL 1977,107 , unter Berufung auf Suet. Nero 1,2), erscheint dagegen fraglich.

$240 \mathrm{Vgl}$. dag. die lakonische Kürze bei Tac. hist. 2,50,1: origo illi e municipio Ferentio, pater consularis, avus praetorius sowie ferner HANSLIK 1962, 1706ff., MURISON 1992, 130ff., u. SHOTTER 1993, 31

241 Eine enge Parallele bietet die entsprechende Rubrik der Tiberiusvita, in der Sueton die Geschichte der gens Claudia resümierend zusammenfaßt (vgl. Suet. Tib. 1-2). Zur Bereitschaft Suetons, positive und negative Aspekte nebeneinander zu erwăhnen vgl. LEWIS 1991, 3668f. Als Teil der feindseligen Darstellung des Vitellius wird dieser Abschnitt von BALDWIN 1983, 283, verbucht: „The biography commences with the wanted investigation of imperial ancestors. But the various reports concerning the low origins of Vitellius' first ancestor are soon dropped with the dismissive formula quod discrepat, sit in medio (Vit. 2,1). A marked contrast with the customary dissection of such topics."

$242 \mathrm{Vgl}$. Suet. Vit. I,1: Vitelliorum originem alii aliam et quidem diversissimam tradunt, partim veterem et nobilem. partim vero novam et obscuram atque etiam sordidam; quod ego per adulatores obtrectatoresque imperatoris Vitelli evenisse opinarer, nisi aliquanto prius de familiae condicione variatum esset. u. 2,1: sed quod discrepat, sit in medio sowie ferner dag. MURISON 1992, 134: „Suetonius here affects not to be interested in the minutiae of the sordid origins of the family, but only after he has given us them!". 
höheren Grad an Methodenbewußtsein und reflektiert-kritischem Umgang mit der von ihm vorgefundenen Tradition, als Sueton im allgemeinen zuerkannt wird. ${ }^{243}$

Neben dieser erstaunlich offenen Anordnung, die dem Leser angesichts des kontroversen Materials die Möglichkeit zur Bildung eines eigenen Urteils ermöglichen soll, ist der auffälligste Zug dieses ersten Abschnittes die dichtgedrängte Fülle von Einzelinformationen, die Sueton zu den einzelnen bekannten Vorfahren präsentiert. Vitellius' Vater Lucius spielt in diesem Zusammenhang naturgemäß eine prominente Rolle, doch findet keine markante Absetzung dieser ,Unterrubrik' statt, wie sie in anderen Biographien zu beobachten ist. ${ }^{244}$ Die Art und Weise, in der Sueton in diesem Zusammenhang ein Diktum des Lucius Vitellius anführt, ist jedoch in Hinsicht auf die vermuteten Rezeptionsinteressen seines Publikums aufschlußreich: Nachdem Vitellius' Vater eine kurze Würdigung erhalten hat, geht Sueton von der Behandlung seiner regulären Ämterlaufbahn zu seiner ,Karriere' als Schmeichler verschiedener Kaiser über und erhält auf diese Weise die Möglichkeit, zur Illustration seines mirum in adulando ingenium reiches anekdotischen Material anzubringen. ${ }^{245}$ Darunter befindet sich am Ende der wohl als Klimax konzipierten Reihe folgendes Apophthegma: huius et illa vox est: , saepe facias', cum saeculares ludos edenti Claudio gratularetur. ${ }^{246}$

Die betonte Stellung des Personalpronomens, die Verwendung von ille und der von der klassischen Struktur des Apophthegmas abweichende Aufbau, in dem die hier in Form eines Temporalsatzes gebotene situative Einbindung erst auf das Zitat folgt, legen die Vermutung nahe, daß Sueton von der Bekanntheit des Ausspruches bei seinen Lesern ausging und diese Stelle bewußt auf eine Kontextualisierung des gelauufigen Zitates hin konzipierte, um seinen Lesern auf diese Weise nicht nur das Diktum als solches, sondern zugleich die Kenntnis der ursprünglichen Personenkonstellation und damit des historischen Rahmens zu vermitteln. Darüber hinaus mußten sich auch die von ihm hier versammelten Parallelbeispiele für extreme adulatio dank ihrer Katalogstruktur für eine Anwendung dieser Wissensbestände durch den Rezipienten als hilfreich erweisen, da eine solche thematische Reihung beispielsweise der typischen

$243 \mathrm{Vgl}$. Z.B. FLACH 1998, 177: „In seiner Vita des Vitellius, c. 10,3 und 13,2, gab er selbst die augenfalligsten Verleumdungen als Beweise aus, ohne zu durchschauen, wie einseitig sich die flavische Geschichtsschreibung darauf verlegt hatte, Vespasians Gegenspieler zu einem gefuhllosen Unmenschen und hemmungslosen Vielfraß herabzuwürdigen."

$244 \mathrm{Vgl}$. ahnlich Suet. Galba 3,3-4 u. Vesp. 1,2-4 sowie mit deutlicher Absetzung als ,Unterrubrik' Suet. Otho 1,2; Aug. 3,I u. Tib. 4,I sowie ferner Mouchová 1968, 23.

245 Vgl. Suet. Vit. 2,2-3,1.

246 Vgl. Suet. Vit. 2,5 („Von ihm stammt auch jener Ausspruch: ,Mogest Du sie noch oft feiern!', mit dem er Claudius zur Ausrichtung der [sc. alle hundert Jahre stattfindenden] Sakularspiele beglackwüschte.") sowie ferner allgemein zur ,gradation des effets' bei Sueton vgl. ClzeK 1977, $118 \mathrm{ff}$., u. GASCOU 1984, 697ff. 
Gesprächssituation eines Symposions entgegenkam, in der idealiter von jedem Teilnehmer ein Beitrag zu dem gerade angesprochenen Thema erwartet wurde. ${ }^{247}$

Wie die Anfangsworte der ersten Rubrik - Vitelliorum originem alii aliam et quidem diversissimam tradunt ${ }^{248}$ - den Inhalt des Folgenden getreulich widerspiegeln, so beginnt auch der zweite Abschnitt mit einer einschlägigen Formulierung: A. Vitellius L. filius imperator natus est VIII. Kal. Oct. ${ }^{249} \mathrm{Im}$ Gegensatz jedoch zur von Sueton variabel gestalteten Einleitung der Rubrik zur Abstammung, bedient er sich für diese ,Geburtsnotiz' eines festen Formulars, das mit Ausnahme der unvollständigen Caesarbiographie in allen Kaiserviten anzutreffen ist und mit dem regelmäßig eine Rubrik eröffnet wird, die verschiedene Ereignisse aus der frühen Kindheit umfaßt. Es besteht neben dem formelhaften natus est aus der Nennung des Namens im Nominativ, der Angabe von Tag und Jahr der Geburt ${ }^{250}$ sowie in aller Regel des Geburtsortes. ${ }^{251}$

Eine auf den ersten Blick unauffällige Variation findet sich daruber hinaus in den Biographien der drei Bürgerkriegskaiser: Bei ihnen fügt Sueton zur Namensnennung das in diesem Fall wohl nicht als Teil des Eigennamens verstandene Substantiv imperator hinzu. ${ }^{252}$ Doch gerade daraus ergibt sich ein weiterer Hinweis auf die Herkunft dieses Formulars. Denn mit Angaben zum Namen, der sozialen Stellung und der Herkunft beginnen die Mehrzahl der erhaltenen Kurzbiographien in der Sammlung de viris illustribus, deren im einzelnen variierte Gestaltung den formelhaften Charakter noch erkennen läßt: M. Antonius Gnipho ingenuus in Gallia natus; $<L$. $>$ Ateius Philo-

247 Aus diesem Grund weist auch die zeitgenossische Symposialliteratur in der Regel eine ausgeprägte Katalogstruktur auf (vgl. z.B. Athen. 4,165d-169a; 6,248d-2252f u. 8,338d-347c).

248 Vgl. Suet. Vit. 1,1 („,Über die Herkunft der Vitellier wird gibt es verschiedene, und zwar stark von einander abweichende Berichte.").

249 Vgl. Suet. Vit. 3,2 („Der Kaiser Aulus Vitellius, der Sohn des Lucius, wurde am 24. September geboren.").

250 Gelegentlich gibt Sueton auch die Tageszeit an: vgl. Aug. 5,1; Nero 6,1 u. Vesp. 2,1.

251 Die Nennung des Geburtsortes fehlt außer bei Vitellius nur bei Otho. Bei Tiberius, dessen vermeintlicher Geburtsort zunăchst in indirekter Rede angefuhrt wird (vgl. Suet. Tib. 5,1), und Titus, bei dem zwischen Namen und natus est eine umfangreiche, ihn als amor ac deliciae generis humani preisende Apposition eingeschoben ist (vgl. Suet. Tit. I), lassen sich kleinere Abweichungen von diesem Schema feststellen. Zum umstrittenen Geburtsort Caligulas nimmt Sueton ausfuhrlich Stellung, präsentiert reichlich Quellenmaterial und demonstriert einmal mehr sein MethodenbewuBtsein (vgl. Suet. Cal. 8 sowie ferner z.B. PETER 1897, II 241; FUNAIOLI 1931, 619; STEIDLE 1951, 68, u. FLACH 1998, 176).

$252 \mathrm{Vgl}$. Suet. Galba 4,1 u. Otho 2,1. Ein Blick auf die sonstige Verwendung des Wortes durch Sueton zeigt, da $B$ es als Teil der Kaisertitulatur nur in der Wendung praenomen imperatoris (vgl. Iul. 76,1; Tib. 26,2 u. Claud. 12,1) verwendet wird und es abgesehen von einigen wenigen Fallen, in denen es den Feldherr im engeren Sinne bezeichnet, stets den Charakter der Amtsbezeichnung des Kaisers hat, wie vor allem die hăufige Verbindung mit consalutare belegt (vgl. Nero 8,1.13,2; Galba 10,1; Otho 6,3 u. Vit. 8,1 ). 
logus libertinus Athenis est natus; $Q$. Caecilius Epirota Tusculi natus, libertus At$t i<c i>$ equitis Romani. ${ }^{253}$

Dieser biographische ,Baustein' wurde also von Sueton in seine Kaiserviten integriert, wobei er auf die im neuen Kontext weitgehend funktionslose Angabe der sozialen Stellung als Kaiser bald verzichtete. ${ }^{254}$ Den Formelcharakter dieser ,Geburtsnotiz' als solcher behielt er jedoch in aller Regel bei, weil er mit ihm gerade dem erfahrenen Rezipienten biographischer Literatur einen eindeutigen Lesehinweis auf den folgenden thematischen Komplex geben konnte. Die Funktion dieser rezeptionssteuernden

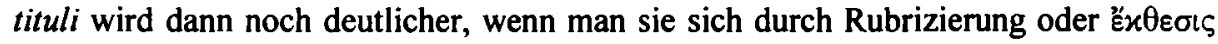
in der antiken Handschrift hervorgehoben denkt: Sie dienen der Orientierung desjenigen, der die Biographie in toto zur Kenntnis nimmt, ermöglichen aber zugleich dem selektiven Leser das gezielte Nachschlagen bestimmter Informationen und erfullen auf diese Weise die Funktionen von Kapitelüberschriften. ${ }^{255} \mathrm{Daß}$ gerade diese Angaben innerhalb der suetonischen Biographie derart prominent plaziert werden, erklärt sich zum einen aus der gesellschaftlichen Bedeutung, die dem Geburtstag als Teil des Kaiserkultes und mit Abstrichen auch dem Geburtsort zugemessenen wurde. ${ }^{256}$ Zum anderen zeigt sich hierin aber auch die allgemeine Relevanz biographischer Basisdaten, die wir bereits im Zusammenhang mit dem synchronistischen Kapitel der noctes Atticae kennengelernt haben. ${ }^{257}$

In der Vitelliusvita folgen auf die ersten als titulus fungierenden Worte zunächst die Nennung eines alternativen Geburtstages und die Angabe des Geburtsjahres über die Namensnennung der Konsuln. An die relativ detaillierte Schilderung des bei der Geburt erstellten Horoskops - Prodigien werden von Sueton häufiger in dieser Rubrik behandelt $-{ }^{258}$ dessen offenbar negativer Inhalt allerdings aus der Reaktion der Eltern

253 Vgl. Suet. gramm. 7,1 („Marcus Antonius Gnipho wurde als freier Mann in Gallien geboren“); 10,1 ("<Lucius> Ateius, ein Freigelassener, wurde in Athen geboren“) u. 16,1 („Quintus Caecilius Epirota wurde in Tusculum geboren und war ein Freigelassener des römischen Ritters Atticus“); ferner s.o. S. $237 \mathrm{ff}$.

254 Als alternative Erklărung für den auffälligen Befund der ausschlieBlichen Kennzeichnung dieser Kaiser als imperator ist eine Anspielung auf die Akklamation durch das Milităr fur die drei Burgerkriegsherrscher denkbar, doch fehien explizite Äußerungen Suetons zur Rolle der Soldaten im Vierkaiserjahr, wie sie Plutarch seiner Galbabiographie vorangestellt hat (vgl. Plut. Galba 1-2).

255 Zur Entwicklung der Kapitelüberschrift vgl. SCHRODER 1999, $125 \mathrm{f}$.

256 Sueton selbst erwahnt, daß das Geburtshaus des Titus noch zu seiner Zeit besichtigt werden konnte (vgl. Suet. Tit. 1) und daB dasjenige des Augustus sogar zu einem sacrarium umgestaltet worden war (vgl. Suet. Aug. 5,1). Auch sein Bemühen, gerade im Zusammenhang mit der Geburt eines Kaisers alternative Daten zu erwăhnen (vgl. Suet. Vit. 3,2; Aug. 5-6 u. Tib. 5) und-wie im Falle der aufwendigen Diskussion von Caligulas Geburtsort (vgl. Suet. Cal. 8) - sorgfaltig gegeneinander abzuwägen, belegt das Interesse Suetons und seiner Leser an Informationen dieser Art (vgl. STEIDLE 1951, 68ff.).

257 S.o. S. $172 \mathrm{ff}$.

258 Vgl. Suet. Galba 4,1-2; Tit. 2 u. Nero 6,1-2. 
erschlossen werden muß, schließt sich ein Komplex an, der Vitellius' Rolle unter den vorherigen Kaisern beleuchtet. Unter den für den Protagonisten wenig vorteilhaften Nachrichten verdient vor allem diejenige, daß er Tiberius auf Capri als Lustknabe zu Diensten gewesen sein soll, Aufmerksamkeit. ${ }^{259}$ Sie ist zum einen wegen der geringen Plausibilităt des Berichteten und der Tatsache von Interesse, daß Sueton hier tatsăchlich Opfer der antivitellianischen Propaganda geworden zu sein scheint, ${ }^{260}$ zum anderen deswegen, weil Suetons Verzicht, diese Stelle zu einem Verweis auf die Tiberiusvita zu nutzen, ein bezeichnendes Licht auf seine biographische Technik wirft. ${ }^{261}$

Im Gegensatz zu Plutarch, der innerhalb seiner Parallelbiographien bereitwillig Querverweise setzt, wenn sich die dargesteliten Ereignisse überschneiden, findet sich bei Sueton keine einzige explizite Bezugnahme auf eine andere Biographie und auch nur eine sehr begrenzte Zahl von internen Verweisen. ${ }^{262}$ Dieser Befund muß um so mehr erstaunen, als sich die Lebenszeiten der dargestellten Personen vielfach überlappen und daher reichlich Gelegenheit zu solchen Verknüpfungen bestanden hätte. ${ }^{263}$ Sueton verzichtet jedoch fast immer darauf, verschiedene Darstellungen ein und desselben Ereignisses zueinander in Beziehung zu setzen, weil ihn ausschließlich die aus der jeweils gewählten Perspektive sichtbare Seite des historischen Geschehens interessiert. So fâllt Suetons Blick bei den Geschehnissen auf Capri einmal nur auf Tiberius und seine moralischen Verfehlungen und bleibt das nächste Mal ausschließlich auf die Rolle des Vitellius in diesem Zusammenhang fokussiert.

Dieses „,fractionnement' des mêmes événements“ läßt sich auch innerhalb ein und derselben Biographie beobachten. ${ }^{264}$ Ein interessantes Beispiel hierfür bietet Neros Griechenlandreise, auf die Sueton zunächst im Zusammenhang mit den positiven oder zumindest neutralen Aspekten seiner Regierung kurz zu sprechen kommt, um Neros Projekte eines Isthmuskanals und einer Militărexpedition ins Kaspische Meer zu erwähnen. ${ }^{265}$ Ein zweites Mal gerät sie im Kontext der negativen Aspekte seiner Herrschaft ins Blickfeld und aus dieser Perspektive rückt das Bild Neros als Sänger und Wagenlenker, dem sich in Griechenland eine vermeintlich ideale Bühne bietet, in

259 Vgl. Suet. Vit. 3,2: pueritiam primamque adulescentiam Capreis egif inter Tiberiana scorta, et ipse perpetuo spint/he]riae cognomine notatus existimatusque corporis gratia initium et causa incrementorum patri fuisse.

260 Vgl. ferner z.B. Cass. Dio 63,4,2 und zur chronologischen Unmoglichkeit MURISON 1987.

261 Das gleiche gilt auch für die übrigen hier versammelten Nachrichten, etwa die Bemerkung, Vitellius sei Claudio per aleae studium familiaris gewesen (vgl. Suet. Claud. 33,2 und zu Suetons Interesse an kaiserlicher Spielleidenschaft femer Aug. 71.83; Cal. 41,2; Nero 30,3 mit WallaCE-HadRlL 1983,

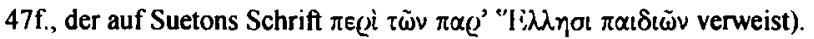

262 Vgl. Mouchoví 1968, 65ff.

263 Für eine Zusammenstellung der in mehreren Viten erwahnten Ereignisse vgl. Gascou 1984, $373 \mathrm{ff}$.

264 Vgl. GASCOU 1984, 348ff., mit zahlreichen Beispielen.

265 Vgl. Suet. Nero 19,2. 
den Vordergrund. ${ }^{266}$ Bei der dritten Erwähnung schließlich dient sie als rein chronologisch-geographischer Referenzrahmen für sein Verhalten nach dem Mord an seiner Mutter. ${ }^{267}$ Die drei Stellen innerhalb der Nerovita werden lediglich mit einem sich auf das factum brutum der Reise beziehenden Querverweis - Achaiam, ut diximus, petit ${ }^{268}$ - miteinander verbunden und stehen ansonsten ebenso isoliert wie die Erwăhnung der Griechenlandreise in der Vespasiansvita: Hier liegt der Fokus ausschließlich auf der Person Vespasians und seines Verhaltens als Mitreisender in der Entourage Neros. ${ }^{269}$

Die Synthetisierung der unterschiedlichen Blickrichtungen zu einem einheitlichen historischen Szenario bleibt dem Leser überlassen oder wird als historisches Hintergrundwissen bei diesem vielmehr vorausgesetzt. Denn gerade in dem Verzicht auf die Erzeugung solcher Synthesen tritt der subsidiäre Charakter der Kaiserbiographien besonders deutlich zutage: Der historische Hintergrund war in Form der taciteischen Geschichtswerke jederzeit abrufbar und mußte von Sueton nicht über interne Verweisen in sein Werk projiziert werden. ${ }^{270}$ Das Unbehagen der modernen Forschung an Suetons Präsentationsweise ist daher auch zu einem Großteil darauf zurückzuführen, daß seine subsidiăr konzipierten Werke heute anstelle der verlorenen historiographischen Literatur als Primärquellen genutzt werden müssen. ${ }^{271}$

Durch die Fokussierung auf die Perspektive der jeweils porträtierten Person tritt das Ereignis natürlich auch in seiner charakterisierenden Funktion plastischer hervor. ${ }^{272}$ Die Beobachtung, daß Sueton seine Protagonisten ,durch Fakten charakterisiere', kann, seit sie von WOLF STEIDLE als zentrales Prinzip seiner Darstellungskunst herausgestellt wurde, als communis opinio der Forschung gelten. ${ }^{273}$ Gleichwohl erschöpft sich die Funktion der dargebotenen Informationen nicht in der Charakterisierung der Protagonisten, deren moralphilosophische Evaluation für Sueton - und hierin unterscheidet er sich deutlich von Plutarch - kein zentrales Anliegen darstellt. Denn der Eindruck, Sueton tradiere lediglich die disiecta membra von Ereignissen, ${ }^{274}$ entsteht nur vor der Folie einer historiographischen Erwartungshaltung. Betrachtet man

$266 \mathrm{Vgl}$. Suet. Nero 22,3-24.

$267 \mathrm{Vgl}$. Suet. Nero 34,4.

$268 \mathrm{Vgl}$. Suet. Nero 22,3 (,er fuhr, wie wir gesagt haben, nach Griechenland”).

$269 \mathrm{Vgl}$. Suet. Vesp. 4,4. Auf ein weiteres illustratives Beispiel fur diese biographische Technik hat WaLlaCE-Hadrill 1983, 13, hingewiesen: Die Verschworung des Varto Murena und Fannius Caepio gegen Augustus wird von Sueton viermal unter verschiedenen Fragehorizonten thematisiert (vgl. Suet Aug. 19,1; 56,4; 66,3 u. Tib. 8), wăhrend der Historiker Cassius Dio einer einmaligen und zusammenhăngenden Prăsentation den Vorzug gibt (vgl. Cass. Dio 54,3).

$270 \mathrm{Vgl}$. WaLLACE-HADRILL 1983, 13.

271 Vgl. z.B. TOWNEND 1967,84 , u. s.o. S. 273f.

272 Vgl. MOUCHOVA 1968, 76f.

273 Vgl. Steidle 1951, 102ff., sowie ferner z.B. Clzek 1977, 65ff. ; Gascou 1984, 688ff;; BradLey 1991, 3702f.; LEWIS 1991, 3653, u. V. ALBRECHT 1992, II 1116.

274 Vgl. BRINGMANN 1971; DÖPP 1972; FLACH 1972 u. FLACH 1998, $189 \mathrm{ff}$. 
die von ihm wiedergegeben Fakten dagegen als Teil einer auf den biographischen Aspekt fokussierten Informationsvermittlung, wirken sie nicht länger isoliert, sondern stellen im Kontext einer Buchgesellschaft, die über verschiedene literarische Medien zur Tradierung historischer Informationen verfugte, eine adäquate Vermittlungsform personenzentrierten Wissens dar.

Geht man von der Kapiteleinteilung des codex Memmianus als wenn auch nicht nachweisbar authentischer, so doch zumindest inhaltlich sinnvoller Gliederung aus, so folgt nun die Rubrik zur Karriere des Vitellius vor seiner Akklamation zum Kaiser. Obwohl dieser thematische Komplex praktisch in allen Kaiserbiographien zu finden ist, unterliegt seine jeweilige Gestalt und vor allem sein Umfang doch je nach den individuellen Gegebenheiten starken Schwankungen und verdeutlicht auf diese Weise eindrucksvoll die Flexibilităt des Rubrikenschemas. ${ }^{275}$ Sueton verwendet für die Einleitung dieses Abschnittes kein festes Formular. Im Falle des Vitellius dient ein Rückbezug auf die voranstehende Erörterung seines Verhaltens unter der Herrschaft seiner Vorgănger als Überleitung, die zugleich den Charakter einer knappen Zusammenfassung hat: trium itaque principum indulgentia non solum honoribus verum et sacerdotiis amplissimis auctus. ${ }^{276}$ Daran schließt sich unmittelbar eine knappe Skizzierung des weiteren Inhaltes an: proconsulatum Africae post haec curamque operum publicorum administravit et voluntate dispari et existimatione, ehe im folgenden die beiden auf diese Weise eingefuhrten Aspekte ausfuhrlicher thematisiert werden. ${ }^{277}$ Für diese von Sueton bereits in seinen antiquarischen Schriften verwendete Form der Textorganisation durch vorweggenommene Gliederungen hat GAVIN TOWNEND unter Verweis auf analoge Strategien der Lesersteuerung in der Rhetorik die treffende Bezeichnung als divisio eingeführt. ${ }^{278}$

275 Wăhrend die Behandlung der frühen Karriere bei den jung an die Macht gelangten principes Augustus und Caligula fortgefallen ist, wird sie bei Tiberius, der den Großteil seines Lebens politisch tattig war, ohne Kaiser zu sein, entsprechend ausfuhrlich abgehandelt (vgl. Suet. Tib. 7-21 sowie ferner Galba 6,1; Otho 4; Vesp. 2,3; Tit. 4,1; Dom. 1-2; Claud. 5-7 u. Nero 7).

$276 \mathrm{Vgl}$. Suet. Vit. 5 („Durch die Gunst dreier Kaiser war er nicht nur mit hohen politischen Ämtern, sondern auch mit bedeutenden Priesterstellen ausgezeichnet worden.").

277 Vgl. Suet. Vit. 5 („Er war als Prokonsul in Afrika tătig und übernahm danach die Verantwortung für die offentlichen Bauten, wobei er beiden Aufgaben mit unterschiedlichem Engagement nachging und seine Leistung daher auch unterschiedliche Bewertungen fand."). Zwar wird die disparate Bewertung, die Vitellius in beiden Funktionen gefunden hat, in der divisio knapp thematisiert, doch zeigt gerade Suetons Verzicht, diesen Gegensatz im folgenden aufzugreifen, daß seine Akzentsetzung auch hier keine primär moralphilosophische ist (vgl. dag. CIZEK 1975, 125f., mit der Vermutung, daß Sueton das Prokonsulat gezielt im Zusammenhang mit den Tempelplunderungen erwahnt, um auch eine der wenigen positiven Nachricht uber Vitellius negativ zu konnotieren).

$278 \mathrm{Vgl}$. TOWNEND 1967, 84ff., der auf ein Fragment aus Suetons liber de genere vestitum verweist (Frg. 168 REIFFERSCHEID), u. S.o. S. 266. 
Mit der Verwendung solcher der Orientierung des Lesers dienenden divisiones bewegt sich Sueton ebenso in der Nähe zur anspruchsvolleren Fachschriftstellerei wie mit der - wenn auch nicht durchgängigen - Wahl von Anfangsworten mit ausgeprägten Signalcharakter für den Inhalt der folgenden Rubrik. ${ }^{279}$ Ein gutes Beispiel fur den Beginn eines thematischen Blockes, der zugleich als titulus fungiert, liegt im nächsten Abschnitt vor, der mit uxorem habuit Petroniam eingeleitet wird und Vitellius' erste Ehe, das gespannte Verhältnis zu seiner Frau, den mutmaßlichen Mord an ihrem gemeinsamen Sohn sowie seine zweite Ehe behandelt. ${ }^{280}$ Dabei entspricht es Suetons allgemeinen Gepflogenheiten, daß er in dieser Rubrik, die er hăufig mit dem vorangestellten Stichwort uxor im Singular einleitet, auch die weiteren Ehen des Kaisers behandelt. ${ }^{281}$ Die mit dem Verzicht auf die Beachtung der Chronologie des Lebenslaufes einhergehende summarische Behandlung des Themenkomplexes ,Familie' an einer einzigen Stelle innerhalb der Biographie macht das Verfahren der Anordnung biographischer Fakten in Rubriken noch einmal besonders augenfälig, ${ }^{282}$ ehe Sueton zur Schilderung der Herrschaftsübernahme durch Vitellius und damit zu einer anderen Präsentationsform übergeht.

Bereits an dem ersten Abschnitt der Vitelliusvita, in dem Sueton die Vorfahren und das Leben des späteren Kaisers vor seiner Thronbesteigung in thematisch geordneten Rubriken präsentiert, lassen sich eine Reihe von Beobachtungen zur biographischen Technik machen, die auch für die anderen Kaiserviten charakteristisch sind. Dies gilt sowohl auf der elementaren Ebene der Verwendung einzelner ,Bausteine' wie beispielsweise des festen Formulars der sogenannten Geburtsnotiz - als auch bei großflächigeren Anordnungsstrategien - wie etwa der Gliederung des Textes durch divisiones oder der Tendenz zur Bildung thematischer Reihen. Aber auch einige Züge, die für die Haltung des Biographen zu den von ihm dargestellten Personen generell von Bedeutung sind, treten schon hier deutlich zutage: Indem er darauf verzichtet, die einzelnen von ihm dargebotenen Informationen auch über den jeweiligen Abschnitt hinaus zueinander in Bezug zu setzen, läßt er zwar einerseits der charakterisierenden Wirkung der Fakten freien Lauf. Er steht aber auf der anderen Seite auch, wie vor

279 Die Anfangsworte einiger Abschnitte der Vitelliusvita enthalten vor diesem funktionalen Hintergrund nebensăchliche Informationen (vgl. z.B. Suet. Vit. 7,1: a Galba in inferiorem Germaniam contra opinionem missus est $\mathrm{u}$. 14,1: pronus vero ad cuiuscumque et quacumque de causa necem atque supplicium), doch nimmt die Tendenz zum primär informativen Charakter des Eingangspassus im Laufe der Zeit zu, wie vor allem das Beispiel der Claudiusvita zeigt (vgl. SCHMIDT 1891, 32f.).

280 Vgl. Suet. Vit. 6 u. zur historischen Glaubwurdigkeit MURISON 1993, 150ff.

281 Vgl. Suet. Galba 3,4; Vesp. 3; Tit. 4,2; Tib. 7,2-3; Claud. 26-27 u. Nero 35,1-3 sowie ferner MouCHOVÁ 1968, 28ff.

282 Das Thema eignet sich fur eine separate Behandlung naturlich in besonderem Maße, wie auch die Bereitschaft Plutarchs zeigt, an dieser Stelle gelegentlich von seinem primar chronologisch organisierten Schema abzuweichen (vgl. z.B. Plut. Cato minor 24-25). 
allem sein Umgang mit der Überlieferung zu den Vorfahren des Vitellius veranschaulicht, seinen Quellen nicht kritiklos gegenüber und wählt die von ihm wiedergegebenen Wissensbestände daher durchaus gezielt aus.

c) ,Einmal Germanien und zurück': Der Weg auf den Thron als narratio

Im Anfangsteil der Biographie steht für Sueton die Vermittlung einzelner Fakten im Vordergrund. Diese werden zwar in einer Reihenfolge präsentiert, die sich grob an der natürlichen Chronologie der anthropologischen Gesetzmäßigkeiten eines Lebenslaufes orientiert, für deren konkrete Anordnung und Wahrnehmung sich jedoch das Rubrikenschema und das mit ihm verbundene thematische Organisationsprinzip als ausschlaggebend erwiesen hat. Daran schließt sich in der Lebensbeschreibung des Vitellius ein zweiter Abschnitt an, in dem die einzelnen biographischen Fakten in einem kohärenten chronologischen Zusammenhang dargeboten und in Anlehnung an historiographische Darstellungstechniken erzählt werden.

Sueton stellt erneut eine zentrale Information an den Anfang und läßt mit der Mitteilung, daß Vitellius von Galba mit der Verwaltung der machtpolitisch bedeutsamen Provinz Germania inferior betraut wurde, die Erzählung derjenigen Ereignisse beginnen, an deren Ende Vitellius als neuer Kaiser in Rom eintrifft. Auch innerhalb dieser prinzipiell als fortlaufende narratio konzipierten Passage lassen sich inhaltliche Zäsuren nachweisen, sie sind jedoch weniger deutlich ausgeprägt als im thematisch gegliederten ersten Teil. Nimmt man erneut die Kapiteleinteilung des codex Memmianus zum Ausgangspunkt, so ergibt sich ein erster Abschnitt, der die für Vitellius wenig vorteilhafte Behandlung der Hintergründe seiner Berufung zum Statthalter in Germanien und einen Bericht über seine finanziellen Schwierigkeiten vor dem Antritt dieses Amtes enthält. ${ }^{283}$ Mit der Ankunft in Germanien setzt sodann die zweite Phase der Erzählung ein, deren Relevanz für die weitere Entwicklung von Sueton im Einleitungssatz sogleich deutlich hervorgehoben wird:

advenientem male animatus erga principem exercitus pronusque ad res novas libens ac supinis manibus excepit velut dono deum oblatum, ter consulis filium, aetate integra, facili ac prodigo animo. ${ }^{284}$

Die sich anschließende Schilderung ist mit anekdotischem Material stark angereichert und führt den stilistisch deutlich gehobenen Ton des Einleitungssatzes fort. ${ }^{25}$ Sie

$283 \mathrm{Vgl}$. Suet. Vit. 7,1-2.

284 Vgl. Suet. Vit. 7,3 („Den Ankommenden empfing das Heer, das gegen den Kaiser eingestellt und zu einem Aufstand bereit war, freudig und mit offenen Armen, wie ein Geschenk der Gotter, da er der Sohn eines dreifachen Konsuls war, im besten Alter stand und als umgänglich und großzugig galt."). 
dient dem Zweck, Vitellius' Anbiedern bei den Soldaten und damit seine aktive Beteiligung an der weiteren Entwicklung zu verdeutlichen. ${ }^{286}$ Sueton läßt sodann unmittelbar die Ausrufung des Vitellius zum Imperator folgen. In einer stark auf den Protagonisten fokussierten Perspektive wird der Leser Zeuge, ${ }^{287}$ wie dieser von einer impulsiv bis irrational handelnden Soldateska zur Unzeit, nämlich bereits am Abend, aus seinem Schlafgemach fortgerissen und ita ut erat in veste domestica zum Kaiser proklamiert wird. ${ }^{288}$ Es schließt sich die Schilderung der improvisierten Prozession durch die Straßen der Colonia Agrippinensis an, während deren er das Schwert Caesars in Händen hält, das von einer anonym bleibenden Person aus dem Marsheiligtum entwendet und ihm dargeboten wurde. ${ }^{289}$ Darauf folgt die Erwähnung des aus Suetons Sicht offenbar mißglückten Versuchs des Vitellius, den Brand seines Hauptquartiers in der gleichen Nacht als positives Vorzeichen zu interpretieren. ${ }^{290}$ Die Erzählung des zentralen Ereignisses seiner Proklamation gehört mit ihrem plastischen, dem Prinzip

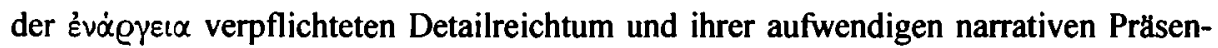
tation, die eine Beeinflussung durch die tragische Geschichtsschreibung vermuten lassen, sowie mit der ironisch-distanzierten Brechung des Geschehens zu den literarisch ambitioniertesten Passagen in der Biographie des Vitellius wie den Kaiserviten insgesamt. ${ }^{291}$

Sueton verläßt im folgenden die Nahperspektive, die er in der Schilderung der $a c$ clamatio-Szene eingenommen hatte, und nimmt statt dessen die Aufstandsbewegung als Ganzes in den Blick, wenn auch Vitellius weiterhin logisches wie zumeist auch grammatisches Subjekt der Handlung bleibt. Nach einer kurzer Mitteilung über den von Vitellius angenommenen Germanicus-Namen ${ }^{292}$ und über die strategischen Ent-

285 So gehơrt beispielsweise die religiöse Dignităt evozierende Wendung supinis manibus sonst eher der Dichtersprache an (vgl. z.B. Verg. Aen. 4, 203 u. Ov. met. 8,679).

286 Vgl. Suet. Vit. 7,3-8,1. Tacitus dagegen zeigt Vitellius in einer wesentlich passiveren Rolle (vgl. v.a. Tac. hist. 1,50-52 u. ferner ASH 1999, 105ff.).

$287 \mathrm{Vgl}$. dag. Tac. hist. 1,55-57.

288 Vgl. Suet. Vit. 8,1 (,so wie er war, in den Kleidem, die er zu Hause trug“) u. ferner MURISON 1992, 150 , der wohl zu recht vermutet, daß die Spontaneităt der Akklamation inszeniert war.

$289 \mathrm{Vgl}$. LOUNSBURY 1987, 99f.: „For it becomes clear that the mere detail can be so disposed as to carry an emotional impact: porrectum sibi a quodam is properly casual for this casual, comic principate."

290 Die Schilderung einer mißglückten acclamatio muß auf Suetons primäre Leser durch den Kontrast zu den ihnen aus den verschiedenen Medien der kaiserlichen Selbstdarstellung vertrauten Pråsentationen dieses Ereignisses noch weitaus eindringlicher gewirkt haben. DaB Sueton verschiedene Stellen der Vita bewuBt als Gegensatz zur zeitgenössischen Wahrnehmung solcher ,emblematic scenes' gestaltet hat, um damit Vitellius' fehlende Eignung zu unterstreichen, hat BURKE 1998 etwa fur die Schilderung des iter (vgl. Suet. Vit. 10,2) und des adventus in Rom (vgl. Suet. Vit. 11,1) plausibel gemacht.

$291 \mathrm{Vgl}$. LOUNSBURY 1987, 99f.

292 Vgl. Suet. Vit. 8,2 u. zur Ablehnung des Augustus-Titels ferner TIMONEN 1993, 138. 
scheidungen, die er nach der Nachricht von Galbas Tod getroffenen hat, ${ }^{293}$ geht Sueton ausführlicher auf weitere Prodigien ein, die dem neuen Thronprătendenten zuteil wurden, ${ }^{294}$ ohne diese - wie an anderen Stellen ${ }^{295}$ in einer eigenstăndigen Rubrik zu versammeln. ${ }^{296} \mathrm{Er}$ setzt sich allerdings auch hier partiell uber die chronologische Ordnung der Erzählung hinweg, da das letzte, mit mox Viennae datierte Prodigium wohl erst nach dem Eintreffen der Nachricht vom Tod Othos bei Vitellius anzusetzen ist, auf die Sueton jedoch erst im Anschluß eingeht. ${ }^{297}$ Gleichwohl gelingt es ihm, in der Aufzählung der Vorzeichen untereinander die zeitliche Abfolge zu beachten, ${ }^{298}$ ohne deswegen auf den Effekt einer inhaltlichen Klimax verzichten zu müssen. ${ }^{299}$

Die wiedergegebenen Vorzeichen beziehen sich hier wie auch sonst in den Kaiserbiographien beinahe ausschließlich auf die Übernahme oder den Verlust der Herrschaft. ${ }^{300}$ Als singulär erweist sich hingegen die an dieser Stelle gegebene Deutung der Prodigien, die explizit auf später von Sueton behandelte Ereignisse vorausweist: quibus ostentis par respondit exitus; nam confirmatum per legatos suos imperium per

293 Vgl. Suet. Vit. 9 u. ferner Tac. hist. 1,51-70. Bei Tacitus erhalt Vitellius die Nachricht von Galbas Tod erst auf dem Marsch (vgl. Tac. hist. 1,64,I u. ferner MURISON 1992, 151).

294 Vgl. Suet. Vit. 9. Zum Brand des Hauptquartiers tritt noch der Tag der acclamatio hinzu, wenn man der von Gugel 1977, 65, vertretenen Deutung folgt, daß die Information, die Ausrufung sei neque diei neque temporis ratione habita erfolgt, als Hinweis darauf zu verstehen ist, daß die acclamatio an einem zweiten Tag im Monat und damit an einem Ungluckstag stattgefunden hat (an einem dies postriduanus; vgl. Gell. 5,17 u. Macr. sat. 1,16,21 sowie ferner RüPKE 1995, 563ff.). Ob Sueton allerdings angesichts der sich in diesem Jahr überschlagenden Ereignisse das doch sehr spezielle Faktenwissen, daB Vitellius am 2. Januar zum Kaiser ausgerufen wurde (wahrend der Abfall von Galba bereits am 1. Januar erfolgte: vgl. Tac. hist. 1,55,3-57,1 u. ferner MURISON 1993, 82), bei seinen Lesern voraussetzen konnte, erscheint zumindest fraglich.

295 Vgl. die Zusammenstellung bei GUGEL 1997, 28 f.

296 Vgl. ferner Suet. Vit. 11,2;13,3 u. 14,4 mit der Erwăhnung weiterer Vorzeichen.

297 Vgl. MURISON 1993, 143ff.

298 Vgl. MOUCHOVÁ 1968, 34, die der Stelle allerdings den Charakter einer Rubrik zuspricht.

299 Vgl. GUGEL 1977, 65, u. ferner allg. GASCOU 1984, 400: „Lorsqu'il veut illustrer un trait de charactère ou un aspect quelconque de l'activité d'un César, Suétone se contente souvent d'énumérations vagues, sans références aux dates, et en adoptant parfois une disposition 'impressioniste' plutôt que chronologique, d'où un fourmillement de faits qu'on ne sait comment situer dans le temps."

$300 \mathrm{Vgl}$. WALLACE-HADRILL 1983, 191f. Zur von Sueton selten kommentierten Reaktion der betroffenen Personen auf die Vorzeichen vgl. Suet. Iul. 59.81 u. Otho 8,5 sowie ferner DELLA CORTE 1958, 53ff., gegen dessen These, Sueton bewerte die Kaiser danach, ob sie den Prodigien die ihnen zukommende Bedeutung beimessen oder nicht, sich mit guten Grunden MOUCHOVÁ 1968, 37ff., ausgesprochen hat. Zur Funktion der Vorzeichen in Suetons biographischer Technik vgl. ferner GUGEL 1977, 28: „Die Untersuchung aller in den Kaiserviten Suetons vorkommenden Vorzeichen labt nirgends ihre blo $B$ dem Zufall uberlassene Verwendung erkennen, noch werden sie aus bloßem Sammeleifer oder einer ubertriebenen, kleinlichen Liebe zum historischen Detail in den Lebenslauf eingefugt; vielmehr sind sie ein Mittel biographischer Technik, die erzăhlte Handlung oder die beabsichtigte Charakterisierung wirkungsvoll zu unterstreichen oder entscheidende Einschnitte im Leben der Kaiser zu markieren.“ 
se retinere non potuit. ${ }^{301}$ Sueton greift diese Deutung zudem nach Vitellius' Tod noch einmal auf und bestätigt sie auch rückblickend ausdrücklich. ${ }^{302}$ Diese doppelte Bezugnahme zweier Stellen aufeinander stellt den einzigen Fall eines explizit markierten internen Querverweises innerhalb der zweiten Hexade der Kaiserbiographien dar ${ }^{303}$ und unterstreicht damit den experimentellen Charakter der Vitelliusvita.

Den nächsten deutlicheren Einschnitt bildet die Nachricht von Othos Tod, an die sich die Erwähnung der beiden einzigen als positiv bewerteten Maßnahmen der Regierung des Vitellius anschließt. Bei diesem von Sueton hier scheinbar chronologisch eingeordneten Abschnitt handelt es sich allerdings eher um die Behandlung der oftmals vom Streben nach Popularităt getragenen initia imperii eines neuen Herrschers, für die Sueton in den späteren Biographien eine eigene Rubrik entwickelt, die dann an die Spitze des die Herrschaft per species darstellenden Teiles tritt. ${ }^{304}$ Denn zumindest die zweite Regierungshandlung, die Sueton nach der Entlassung der Prătorianerkohorten anführt und die in der Bestrafung derjenigen Personen bestand, die im Zusammenhang mit der Ausschaltung Galbas bei Otho um eine Belohung nachgefragt haben, ist mit großer Sicherheit erst nach dem Eintreffen des Vitellius in Rom anzusiedeln. ${ }^{305}$ Der Abschnitt endet mit der expliziten Bemerkung egregie prorsus atque magnifice et ut summi principis spem ostenderet, nisi cetera magis ex natura et priore vita sua quam ex imperii maiestate gesisset. ${ }^{306}$ Durch dieses Fazit wird der hier im chronologischen Zusammenhang dargebotene, aber vorwiegend thematisch organisierte Textteil zur später in Rubriken erfolgenden Behandlung der Herrschaft des Vitellius in Bezug gesetzt, in der keine weiteren positiven Aspekte mehr thematisiert werden. ${ }^{307}$

$\mathrm{Da} ß$ die Chronologie der Ereignisse jedoch weiterhin die Grundlage der Darstellung bildet, unterstreicht Sueton dadurch, daß er mit dem Anschluß namque itinere incohato einen engen zeitlichen Bezug zu der folgenden Schilderung von Vitellius' Marsch nach Rom, seinem Besuch des Schlachtfeldes von Betriacum und seines Einzuges in der Hauptstadt herstellt. Es sind nicht zuletzt diese drei Episoden, aus denen sich ein wenig vorteilhaftes Bild des Vitellius bei Sueton ergibt. Wird schon das Ver-

301 Vgl. Suet. Vit. 9 (,Mit diesen Vorzeichen stimmte sein Ende aberein; denn die Herrschaft, die seine Offiziere für ihn errungen hatten, konnte er aus eigener Kraft nicht verteidigen.").

$302 \mathrm{Vgl}$. Suet. Vit. 18 u. ferner GaSCOU 1984, 358.

303 Vgl. MOuCHOVÁ 1968, 65, mit neun Beispielen aus der ersten Hexade.

304 Vgl. Suet. Dom. 3; Tib. 22-25; Cal. 13-16; Claud. 11-13 u. Nero 9 sowie ferner WITTKE 1974, 46ff.

305 Vgl. MURISON 1992, 155.

306 Vgl. Suet. Vit. 10,1 („Er hatte ganz und gar vortrefflich und großartig reagiert und gab Anlaß zu der Hoffnung, er werde sich als ausgezeichneter Kaiser erweisen, wenn er sich nicht in seinen weiteren Entscheidungen mehr nach an seiner Veranlagung und nach an seinem fruheren Lebensstil orientiert hătte denn an der Würde seines Amtes.").

307 Vgl. dag. STEIDLE 1951, 105, der Suet. Vit. 10-11 als die initia imperii versteht und den thematischen Teil bereits hier beginnen laßt. 
halten seiner Soldaten auf ihrem weiteren Vormarsch explizit als ritu triumphantium und damit als einem neuen Herrscher wenig angemessen bezeichnet, ${ }^{308}$ so leistet insbesondere die Darstellung von Vitellius' Besuch des Schlachtfeldes von Betriacum, dem Ort der Niederlage Othos, einen entscheidenden Beitrag zur negativen Charakterisierung des Protagonisten.

Vor allem das dictum des Vitellius optime olere occisum hostem et melius civem, das Sueton als seine Reaktion auf das Zurückschaudern einiger seiner Begleiter angesichts des Verwesungsgeruches der zahllosen Leichen - die Schlacht lag zu dem Zeitpunkt seines Besuches über vier Wochen zurück - wiedergibt, ${ }^{309}$ dürfte in den Ohren seiner zeitgenössischen Leser wenig Sympathie für den letzten Bürgerkriegsherrscher hervorgerufen haben. Gerade die überaus desavouierende Wirkung des mit Alliteration und paralleler Konstruktion überraschend kunstvoll gestalteten Apophthegmas legt allerdings den Verdacht nahe, daß Sueton kein authentisches Zitat, sondern eine auf genau diese Wirkung berechnete Fiktion der flavischen Seite wiedergibt. ${ }^{310} \mathrm{Da}$ es sich hier aber um eine der wenigen Stellen handelt, an denen die vorwiegend distanziert-abwägende Darstellung von auktorial geäußerter Entrüstung durchbrochen wird - Sueton läßt Vitellius die Worte detestabili voce sprechen -,, ${ }^{311}$ drängt sich über das letztlich nicht zu lösende Problem der historischen Authentizität ${ }^{312}$ hinaus die Frage nach der Intentionalităt des an dieser Stelle wie in der gesamten Biographie gezeichneten Vitelliusbildes auf.

$308 \mathrm{Vgl}$. Suet. Vit. 10,2 sowie ferner zur Parallelúberlieferung MURISON 1993, 145f., u. zum Charakter als ,emblematic scene' BURKE 1998.

$309 \mathrm{Vgl}$. Suet.Vit. 10,3 (,ein erschlagener Feind rieche sehr gut, noch besser aber ein erschlagener Mitbürger").

$310 \mathrm{Vgl}$. FLACH 1998, 177

311 Vgl. LOUNSBURY 1987, 102: „Suetonius did not seek to impose his ethos on his material after the appreciable fashion of Tacitus. This is not to maintain that he made, in the narrative, no explicit comment upon the deeds and traits of his characters. Sometimes he is even indignant, as at the the exquisite harshness of Tiberius toward his exiled wife (Tib. 50,1), or the brutal loutishness of Vitellius visiting the battlefield at Bedriacum, .... Yet, these are exceptional cases. He aims for a concretion of effect, an impassive, imperturbable gaze, to which he matches his chill Latinity and through which the audience are induced to adopt an equal vision. They are asked, not to apprehend emotionally and by intellect what he means them to apprehend, but to see the same." Das Adjektiv detestabilis dient Sueton sonst nur noch je einmal zur Charakterisierung des Tiberius (vgl. Suet. Tib. 63,1), von Neros Vater (vgl. Suet. Nero 5,1) und von Nero selbst (vgl. Suet. Nero 6,1).

312 Tacitus, der kein freundlicheres Bild des Besuches zeichnet, erwahnt das Diktum nicht, allerdings ist seine Schilderung recht knapp und verfolgt eine andere Zielsetzung (vgl. Tac. hist. 2,70,1 u. ferner MORGAN 1992, 29: „Though Tacitus appears anyway to have disinclined simply to bow to convention, to the extent that he makes one oblique reference to the smell of victory, his aim is not to disgust his audience with the specific details of the emperor's conduct at the site or his comments on this unpleasantness. Rather, he was seeking to bring out the horrors of the scene as a whole, playing Vitellius off against the other participants, military and civilian, living and dead."). 
Hat Sueton mit der Tradierung einer Information wie dieser bewußt einen Akt der damnatio durch memoria vorgenommen, wie mit Blick auf die ,Fliegenfänger-Anekdote' in der Domitiansvita von FRANK WITTCHOW pointiert formuliert wurde? $?^{313}$ Der Gedanke an eine gleichsam negative Kommemoration liegt im Falle des Vitellius aufgrund der Dichte, in der Sueton hier unvorteilhafte Einzelheiten tradiert, ${ }^{314}$ natürlich besonders nahe. Zudem läuft eine gegenteilige Deutung Gefahr, in Sueton mit Teilen der älteren Literatur einen epigonalen ,Kopisten' zu erblicken, der in blinder Abhängigkeit von seinen Quellen steht. Eine solche Sichtweise würde jedoch seinem an verschiedenen Stellen greifbaren kritischen Urteilsvermögen ${ }^{315}$ nicht gerecht werden. Zudem berücksichtigt eine solche Deutung nicht in hinreichendem Maße, daß Sueton sich über die Vorgänge des Vierkaiserjahres, an denen sein Vater unmittelbaren Anteil hatte, ${ }^{316}$ auf vielfältige Weise, unter anderem mittels mündlicher Überlieferung, informieren konnte und daher keinesfalls gezwungen war, ein von anderen präfiguriertes Vitelliusbild unhinterfragt zu übernehmen. ${ }^{317}$

Ob Sueton allerdings wirklich mit dem Anspruch auftrat, in Konkurrenz zu einer vom Senat ausgesprochenen damnatio memoriae zu treten, ${ }^{318}$ ob er und eine explizit geschichtspolitische Zielsetzung in der Art verfolgte, daß die Biographien der negativ bewerteten Kaiser eine gezielte Verurteilung mit Blick auf die Nachwelt darstellen sollen, erscheint gleichwohl fraglich. Denn vor dem Hintergrund dieser Intention erscheint Suetons Vorgehen schon in der Vitelliusvita wenig konsequent: Sein reflektierter Umgang mit der Überlieferung zur Herkunft der Vitellier ${ }^{319}$ wäre in dieser Interpretation ebenso ein Fremdkörper wie die Tradierung solcher Informationen, die

313 Vgl. Suet. Dom. 3,1: inter initia principatus cotidie secretum sibi horarum sumere solebat nec quicquam amplius quam muscas captare ac stilo praeacuto configere, ut cuidam interroganti, essetne quis intus cum Caesare, non absurde responsum sit a Vibio Crispo, ne muscam quidem mit WiTTCHOW 2001, 348f.358: „Für Sueton ist eine Anekdote wie um den Fliegenfanger Domitian eine Weise, wie Senatoren statt einer damnatio memoriae eine damnatio durch memoria an einem Kaiser vornehmen können. Das ist eine andere Strategie, mit dem ailgegenwärtigen Kaiser umzugehen, als sie Tacitus verfolgt hat, aber sie gehört in die gleichen Kommunikationsbedingungen." sowie ferner STEIDLE 1951, 94, U. LAMBRECHT 1995, 519.

314 Vgl. z.B. CIZEK 1977, 152f.23I ff., u. BALDWIN 1983, $283 \mathrm{ff}$.

315 Vgl. z.B. Suet. Cal. 8.

316 Vgl. Suet. Otho 10,1 (interfuit huic bello pater meus Suetonius Laetus, tertiae decimae legionis tribunus angusticlavius). Suetons Vater durfte allerdings wegen seiner Nahe zu Otho gerade fur Vitellius keine allzu objektive Quelle gewesen sein (vgl. BALDWIN 1983, 285).

317 Vgl. Gascou 1984, 335ff.457, sowie speziell zur Darstellung der Bürgerkriegsherrscher MURIsON 1992, xiiff., u. SHOTTER 1993, 33ff. Die wenigen positiven Nachrichten ober Vitellius (vgl. RiCHTER 1992, v.a. 233f.) werden von MURISON 1992, I52ff., zusammengefaBt.

318 Eine damnatio memoria muB in einer Gesellschaft mit dem Komplexitatsgrad der rómischen Kaiserzeit weitgehend wirkungslos bleiben. $\mathrm{Zu}$ den Auswirkungen der über Domitian verhangten damnatio memoriae vgl. PaILLER/SABLAYROLLES 1994.

319 Vgl. Suet. Vit. 1,1 u. s.o. S. $278 f f$. 
für die Bewertung des Vitellius als neutral oder gar positiv einzustufen sind. ${ }^{320} \mathrm{Im}$ Gegensatz zu Plutarchs moralphilosophisch begründeter Zielsetzung einer ethischen Evaluation der von ihm dargestellten Personen erfolgt bei Sueton eine Meinungsbildung über den ,Charakter' seiner Caesares häufig nur partiell, ohne daß die Synthese der einzelnen Züge zu einem homogenen Ganzen angestrebt wird. ${ }^{321}$

Auch wenn der Entwurf eines geschlossenen Charakterbildes nicht Suetons primäres Ziel darstellt, geben seine Kaiserviten - wie jede andere literarische Lebensbeschreibung auch - natürlich gleichwohl Auskunft über die Wertmaßstäbe ihres Autors und seiner Gesellschaft, ${ }^{322}$ weswegen sie in den letzten Jahren auch zu recht als Quelle furr diese Fragestellungen herangezogen wurden ${ }^{323}$ In besonderem Maße gilt dies für Stellen wie die vorliegende, an denen die Leser durch das sorgfältige Arrangement und eine der seltenen auktorialen Bewertungen zur Bewertung der gegebenen Informationen nachdrücklich aufgefordert werden. Hier berührt sich seine Intention mit der sonst eher innerhalb der antiken Historiographie anzutreffenden Absicht, das Bild seiner Zeitgenossen wie das kommender Generationen von den dargestellten Personen aktiv zu beeinflussen. ${ }^{324}$ Angesichts der vor diesem Hintergrund wenig konsequenten Gestaltung der Kaiserbiographien, der sparsamen Verwendung auktorialer Kommentierung, ${ }^{325}$ des Fehlens einschlägiger programmatischer Aussagen ${ }^{326}$ sowie des betont subsidiären Charakters des Werkes, das erst durch die Zufalle der Überlieferungsgeschichte zur beinahe alleinigen Quelle über die romische Kaiserzeit wurde, ist es allerdings wenig wahrscheinlich, daß die damnatio durch memoria Suetons primäre Wirkungsabsicht darstellte. ${ }^{327}$

$320 \mathrm{Vgl}$. Suet. Vit. 5 u. 10,1. Derartige Zuge fehlen in den von Josephus (bell. Jud. 4,588-96) und Philostrat (Ap. 5,29-43) gezeichneten Vitelliusbildern vollstandig.

321 Vgl. SHOTTER 1993, 12: „Suetonius remained external to his subjects, making no general estimate of character and omitting the philosophical or moral reflections we might have expected from Plutarch. There is in fact what amounts to a refusal to enter into a character's thoughts: indeed it is probably this cold recital which lacks an attempt to comprehend that makes Suetonius often appear hostile, despite the fact that in essence there is little he says ... that is not mentioned in other sources." $u$. dag. GASCOU 1984, 675ff., für den es sich um eine ,objectivité affectée' handelt.

322 Vgl. v.a. SWain 1997.

323 Vgl. z.B. NeWBOLd 1997 u. PICCIRILLI 1998.

324 Vgl. POMEROY 1991, viii: „Commendation or condemnation, commiseration or exaltation, all suggest that the historian feels that his own efforts are achieving something important, even that he is contributing in his own way to the process of history-making ... What is clear is that the historians of the ancient world claim a power in their societies which is beyond the dreams or - probably - the wishes of a modern historical writer." u. ferner z.B. MARINCOLA 1997, $158 \mathrm{ff}$.

325 Vgl. z.B. Suet. lul. 76,1; Cal. 22,1; Nero 19,3 u. Vesp. 1,1 sowie ferner EKTOR 1980, 318f;; BRADLEY 1991, 3703, u. SCHERBERICH 1995, 21.

326 Auch unter diesem Aspekt erweist sich der Verlust der praefatio als bedauerlich.

$327 \mathrm{DaB}$ die Kaiserbiographien gleichwohl in der Wahmehmungskategorie einer damnatio durch memoria rezipiert werden konnten, zeigt wohl am eindrucksvollsten eine in der historia Augusta uberlieferte 
Sueton schildert im folgenden Vitellius' ebenfalls noch auf dem Schlachtfeld von Betriacum geảußerten Sarkasmus gegenuber Otho und thematisiert den angesichts der Bürgerkriegsumstände unangemessen triumphalen Einzug in Rom. ${ }^{328}$ Auch wenn die Tendenz, die den wiedergegebenen Fakten innewohnt, auch hier durchgängig antivitellianisch ist, legt doch die Beibehaltung der chronologischen Abfolge und der damit einhergehende Verzicht auf eine Anordnung des Materials in Form einer inhaltlichen Klimax die Vermutung nahe, daß die Stigmatisierung des letzten Bürgerkriegskaisers als Tyrann für ihn nicht das einzige Anliegen darstellt. ${ }^{329}$ Vieimehr könnten die hier mitgeteilten Informationen auch dazu dienen, am Beispiel des Vitellius ein negatives Rollenmodell von allgemein für einen römischen Befehlshaber inakzeptablen Verhaltensweisen zu geben. Eine solche Funktionalisierung wäre jedenfalls der potentiellen Lebenswirklichkeit eines größeren Teils von Suetons zeitgenőssischen Lesern kommensurabel gewesen und dürfte daher auch ihr Interesse gefunden haben.

Mit dem adventus des neuen Herrschers in der Hauptstadt des imperium Romanum endet der chronologisch organisierte Abschnitt, der den Leser Vitellius' Weg von Rom nach Germanien und von dort auf den Kaiserthron mitverfolgen ließ. Die hier angewandte narrative Technik unterscheidet sich von derjenigen der Historiographie lediglich in der extremen Fokussierung auf den Protagonisten, die sich am deutlichsten daran ablesen läßt, daß der Leser vom entscheidenden Waffengang erst gemeinsam mit Vitellius hört und auch den Ort des Geschehens nicht vor dem Protagonisten betritt, wăhrend die Schilderung der Schlacht von Betriacum in der Vita des persőnlich anwesenden Otho erfolgt. ${ }^{330}$ Mit weiten Teilen der kaiserzeitlichen Geschichtsschreibung hat Sueton auch die auf évógyeı der Darstellung und Dramatisierung des Geschehens zielende Detailfülle gemeinsam, wie sie vor allem in der Schilderung von Vitellius' acclamatio zutage tritt. ${ }^{331}$ Indem sich Sueton in den chronologischen Partien an die Erzählstrategien der Historiographie, zumal ihrer ,tragischen' Variante, ${ }^{332}$ anlehnt, artikuliert er zugleich einen deutlich gesteigerten literarischen Anspruch.

Geschichte: Commodus laßt einen Leser der suetonischen Caligulavita den Lowen vorwerfen, angeblich weil er sich Caligula wegen ihres gemeinsamen Geburtstag verbunden fuhlte. Wahrscheinlicher ist, daß er in der literarischen Stigmatisierung des Vorgängers eine Gefahr auch fur seinen eigenen Nachruhm erblickte; eine Sorge, die sich mit seiner Darstellung in der historia Augusta als berechtigt enwiesen hat: eum etiam, qui Tranquilli librum vitam Caligulae continentem legerat, feris obici iussit, quia eundem diem natalis habuerat, quem et Caligula (vgl. SHA Comm. 10,2 mit STEIDLE 195I, 9).

328 Vgl. Suet. Vit. 10,3-11,1 u. ferner zum adventus als ,emblematic scene' BURKE 1998.

329 Vgl. dag. z.B. CizEK 1977, 23 I ff., u. SCHEID 1984, 178f. mit Anm. 3, die auf. die zahlreichen Parallelen der suetonischen Biographie zum klassischen Muster einer Tyrannendarstellung verweisen.

330 Vgl. Suet. Otho 9,2. Ein weiteres Beispiel fur das Fehlen von Querverweisen in Suetons Kaiserviten.

331 Einen Unterschied zur mit den „grands événements“" befaßten Historiographie erblickt GaSCOU 1984, $414 \mathrm{ff}$, in der Vielzahl der angefuhrten Details.

332 Die durch ULLMAN 1942 angeregte intensive Beschaftigung mit der tragischen Geschichtsschreibung (vgl. z.B. ZeGERS 1959; WALBANK 1960 u. BRINK 1960) hat in jüngerer Zeit an Scharfe verloren, da 
Dabei wird an einigen Besonderheiten dieses Abschnittes - wie vor allem der die weitere Handlung vorwegnehmenden Bestätigung eines Prodigiums - erneut der experimentelle Charakter der Vitelliusvita deutlich. Denn wăhrend die Darstellung Galbas und vor allem diejenige Othos noch einen fast durchgängig chronologischen Aufbau zeigen, ${ }^{333}$ haben wir mit der Lebensbeschreibung des Vitellius das erste Beispiel für die konsequente Anwendung der Variation zwischen der Präsentation von Informationen in Form von Rubriken und der Verwendung einer literarisch ambitionierten narratio vorliegen. Daß sich dieses Darstellungsprinzip an zahlreichen anderen Stellen der Kaiserviten beobachten läßt, ${ }^{334}$ zeigt nicht nur, daß es sich um wichtiges Merkmal der biographischen Technik Suetons handelt, sondern stellt auch ein wichtiges Argument für die zeitliche Priorität der Entstehung der zweiten Hexade der Caesares dar. Mit dem Wechsel des literarischen Stils geht zugleich eine gewisse Akzentverschiebung zwischen den Polen der utilitas und delectatio zugunsten des zweiten Aspektes einher, ohne daß allerdings der informative Charakter des Textes völlig aufgeben würde.

d) sed vel praecipue luxuriae saevitiaeque deditus:

Die Ausübung der Herrschaft in Rubriken

Um die nur wenige Monate umfassende Herrschaft des Vitellius darzustellen, wechselt Sueton erneut die literarische Technik und greift wieder auf ein primär thematisch organisiertes Rubrikenschema zurück, wenn auch angesichts der Kürze des behandelten Zeitraumes die Abgrenzung von einer chronologischen Anlage nicht immer leicht

deutlich geworden ist, daB es sich dabei nicht um ein ausformuliertes historiographisches Programm handelt (so schon SCHWARTZ 1905), sondern vielmehr um eine fur die hellenistische Zeit allgemein charakteristische Entwicklung: Die verănderte politische Situation fuhrte zu einer anderen Wahmehmung von Geschichte, da diese von Produzenten wie Rezipienten historiographischer Literatur zunehmend weniger gestaltet als vielmehr erlitten wurde. Die neue Perspektive auf historisches Geschehen zeigt sich in der Betonung des Waltens der rúx $\eta$ in der Neuen Komödie oder in der Fokussierung der

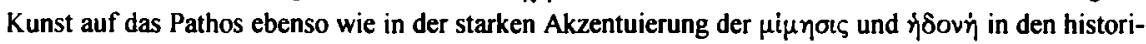
schen Werken (vgl. FORNARA 1983, 124ff.; GeNITLI / CERRI 1988, 43f.; MALITZ 1990, 335f.; LENDLE 1992, 184ff., u. LUCE 1998 [1997], 163ff.). Aufgrund der vergleichbaren Rahmenbedingungen laßt sich eine analoge Ausrichtung der historiographischen Produktion der romischen Kaiserzeit vermuten.

333 Vgl. STEIDle 1951, 105.

334 Anspruchsvoll gestaltete Passagen kommen in Form abgeschlossener Erzăhlungen mit meist anekdotischem Charakter allerdings auch in den thematischen Abschnitten vor (vgl. LoUNSBURY 1987, 99f:: „Such abrupt diminutions of narrative concentration vary again and again the stream of happenings."), gleichwohl erscheint aufgrund der Unterschiede in Quantitat und Qualitat eine Betonung der Differenz zwischen thematischen und chronologischen Blocken sinnvoll. 
fällt. ${ }^{335}$ Den Auftakt bildet eine Rubrik mit unterschiedlichen Tabuverletzungen des neuen Herrschers, deren Inhalt im Einleitungssatz treffend zusammengefaßt und zugleich auf das Fazit des chronologischen Teiles bezogen wird: magis deinde ac magis omni divino humanoque iure neglecto. ${ }^{336}$

Im Einzelnen findet sich hier zunächst eine Übersicht über die von Vitellius als Kaiser bekleideten honores, die Sueton in anderen Biographien zu einer eigenständigen Rubrik zusammenfaßt. ${ }^{377}$ Hier jedoch stehen diese Angaben ganz unter dem Aspekt des Tabubruches und sollen vor allem den Umstand betonen, daß Vitellius diese Ämter an einem dies ater, dem Jahrestag der Niederlage an der Allia, ${ }^{338}$ übernommen hat. ${ }^{339}$ Das zweite in dieser Rubrik besprochene $\sigma x \alpha \nu \delta \alpha \lambda$ ov stellt die auf dem Marsfeld abgehaltene Totenfeier fur Nero dar, deren Behandlung Sueton explizit als symbolisch für die generelle Regierungspraxis des Vitellius verstanden wissen will: et ne cui dubium foret, quod exemplar regendae rei publicae eligeret. ${ }^{340} \mathrm{Daß}$ er an dieser Stelle eine der seltenen auktorialen Deutungen einflicht, wirft ein bezeichnendes Licht auf den Grad der gesellschaftlichen Ächtung, der jede Form einer imitatio Neronis seit flavischer Zeit unterworfen war. Weniger wahrscheinlich ist dagegen, daß diese eher vage Anspielung auf die Herrschaft Neros, die ebenso wie die Darstellung der Jugend des Vitellius unter den letzten Herrschern aus der julisch-claudischen Dynastie ohne Verweis auf die entsprechenden Viten erfolgt ${ }^{341}$ ausreicht, um Fernbezüge zwischen den beiden Biographien herzustellen. Es erscheint daher auch fraglich, ob Sueton Vitellius als einen „Néron pire encore“ erscheinen lassen wollte, ${ }^{342}$ nicht zuletzt deshalb, weil der Akzent in der Schilderung selbst eher auf Vitellius' unange-

335 Vgl. LeO 1901, 7: „... die kurzen Geschichten der Mănner, die erst in den letzten Monaten ein kaiserliches Dasein führen, hatten eine Richtung auf den Tod, von der nicht abzulenken war ...“. Zu den ,chronological signposts' bei der Behandlung lănger regierender Kaiser vgl. LEWIS 1991, 3664f.

336 Vgl. Suet. Vit. 11,2 (,Seine MiBachtung allen gottlichen und menschlichen Rechtes nahm in der Folgezeit mehr und mehr zu“).

337 Vgl. Suet. Aug. 26-28,2; Cal. 17,2; Claud. 14-16 u. Nero 14 sowie ferner StEIDLE 1951, $111 \mathrm{f}$.

338 Vgl. RÜPKE 1995, 567ff.

339 Vgl. Suet. Vit. 11,2 u. ferner Tac. hist. 2,91,1, der das Datum der Übernahme des Oberpontifikats in der Schwebe labt: apud civitatem cuncta interpretantem funesti ominis loco acceptum est, quod maximum pontificatum adeptus Vitellius de caerimoniis publicis XV kalendas Augustas edixisset, antiquitus infausto die Cremerensi Alliensique cladibus: adeo omnis humani divinique iuris expers, pari libertorum, amicorum socordia, velut inter temulentos agebat.

340 Vgl. Suet. Vit. 11,2 („Damit es jedem klar würde, wen er sich zum Vorbild fur seine Herrschaft ausgewăhlt hatte.") u. ferner Tac. hist. 2,95,1 .

341 Vgl. Suet. Vit. 3,2-4.

$342 \mathrm{Vgl}$. CizeK 1977, 153, u. ferner zur Nachwirkung dieser Gleichsetzung in Antike ASH 1999, $104 \mathrm{f}$. 
brachter Wertschătzung von Neros Liedkunst denn auf politischen Aspekten im engeren Sinne liegt. ${ }^{343}$

Nicht nur die seit Erasmus' Baseler Ausgabe von 1518 gebräuchliche Kapiteleinteilung, sondern auch einige Interpreten lassen mit der nun folgenden resümierenden Formulierung talibus principiis magnam imperii partem non nisi consilio et abitrio vilissimi cuiusque histrionum et aurigarum administravit et maxime Asiatici liberti einen neuen Abschnitt beginnen. ${ }^{344}$ Doch zeigt der Inhalt des Folgenden, in dem ausschließlich das Verhältnis des Vitellius zu dem Freigelassenen Asiaticus geschildert wird, daß es sich hier keineswegs um die sonst gelegentlich anzutreffende Rubrik zum schädlichen Einfluß schlechter Ratgeber handelt, ${ }^{345}$ sondern vielmehr die Reihe der gesellschaftlichen Verfehlungen des Vitellius fortgesetzt wird und daß die Kapiteleinteilung des codex Memmianus, der hier keinen Einschnitt setzt, sich erneut als kongruent mit den vom Autor gesetzten inhaltlichen Zäsuren erweist.

Waren maliziöse Untertöne schon bei der Erwähnung der ersten beiden Tabubrüche nicht zu überhören, gewinnen sie bei diesem betont an die letzte Stelle der Rubrik gesetzten Beispiel die Oberhand: Während Tacitus die Rolle des Asiaticus explizit mit der anderer kaiserlicher Freigelassener parallelisiert und dabei vor allem ihren Einfluß auf die Entscheidungen des jeweiligen Herrschers im Auge hat, ${ }^{346}$ geht es Sueton um das individuelle Agieren des Vitellius in der Beziehung zu Asiaticus. Diese malt er in einer ausführlichen und mit konkreten Details, wie der Bemerkung, daß der spăter zum römischen Ritter erhobenen Asiaticus in Puteoli Getränke verkauft habe, nicht geizenden Erzăhlung breit aus. ${ }^{347}$ Gemäß der thematischen Ausrichtung des Abschnittes überwiegt das Interesse an Vitellius' gesellschaftlichen Fehlverhalten hier auch

343 Erneut wird der Umstand, daß Vitellius Neros Gunst gerade dadurch gewonnen hatte, daß er ihm zu einem Auftritt als Kitharode verholfen hatte (vgl. Suet. Vit. 4), von Sueton nicht als Parallele explizit und zur Zeichnung eines Charakterbildes dienstbar gemacht.

344 Vgl. Suet. Vit. 12 („Nach einem solchen Beginn ubte er seine Herrschaft zum Großteil nicht anders aus, als indem er nach dem Rat und dem Urteil der verăchtlichsten Schauspieler und Wagenlenker und besonders seines Freigelassenen Asiaticus regierte.") sowie ferner z.B. STEIDLE 1951, 105, u. CIZEK 1977, 60f.

345 Vgl. Suet. Galba 14,2 u. Claud. 28-29.

346 Vgl. Tac. hist. 2,95,2-3: nondum quartus a victoria mensis, et libertus Vitellii Asiaticus Polyclitos, Patrobios et vetera odiorum nomina aequabat u. ferner ASH 1999, 112.

$347 \mathrm{Vgl}$. Suet. Vit. 12: hunc adulescentulum mutua libidine constupratum, mox taedio profugum cum Puteolis poscam vendentem reprehendisset, coiecit in compedes statimque solvit et rursus in deliciis habuit; iterum deinde ob nimiam contumaciam et furacitatem gravatus circumforano lanistae vendidit dilatumque ad finem muneris repente subripuit et provincia demum accepta manumisit ac primo imperii die aureis donavit anulis super cenam, cum mane rogantibus pro eo cunctis detestatus esset severissime talem equestris ordinis maculam u. ferner MURISON 1992, 159, zur Bedeutung von posca. 
Suetons oft gerugte curiositas in eroticis, ${ }^{348}$ die sich in dieser Vita noch in der Behauptung artikuliert, Vitellius habe seine frühe Jugend in den tiberianischen Villen auf Capri zugebracht, ${ }^{349}$ ohne sich jedoch zu einer eigenen Rubrik zu verdichten. ${ }^{350}$

Der folgende Abschnitt wird von einem titulus eingeleitet, der zugleich eine divisio darstellt: sed vel praecipue luxuriae saevitiaeque deditus. ${ }^{351}$ Unmittelbar anschlieBend findet sich nur die Behandlung der luxuria, während diejenige der saevitia in einem zweiten, im codex Memmianus als neuer Abschnitt markierten Teil erfolgt. ${ }^{352}$ Das in der ersten Rubrik zusammengetragene Material bezieht sich ausschließlich auf Vitellius' Tafelluxus, ohne daß Sueton beispielsweise auf die gleichfalls sehr aufwendige Ausrichtung öffentlicher Spiele zu sprechen kommt, obwohl die vom jeweiligen Herrscher veranstalteten spectacula sonst durchaus Beachtung finden und solche von Tacitus auch für Vitellius bezeugt werden. ${ }^{353}$ Es ist durchaus vorstellbar, daß Sueton die Behandlung der von ihm im allgemeinen unter die positiven Aspekte einer Herrschaft eingereihten spectacula ${ }^{354}$ in der Vitelliusvita absichtlich unterdrückt hat. Geht man aber von der früheren Entstehung der zweiten Hexade aus, ${ }^{355}$ so läßt sich zudem beobachten, daß Suetons Interesse an diesem Aspekt erst im Laufe der Arbeit an den Kaiserbiographien zugenommen hat, ${ }^{356}$ da sich innerhalb der zweiten Hexade nur in der Domitiansvita eine eigenständige Berücksichtigung dieses Punktes findet. ${ }^{357}$

348 Gegen den Vorwurf einer chronique scandaleuse ist Sueton verschiedentlich verteidigt worden: vgl. z.B. STEIDLE 1951, 11: „Noch ein weiterer Punkt erklart sich zu einem großen Teil aus dem Interesse der Biographie für die scheinbar unbedeutenden Züge, nămlich Suetons Ausspüren intimer Details, verborgener vitia, insbesondere in eroticis, kurz gesagt seine vielgeschmähte curiositas, die eine notwendige Begleiterscheinung fast jeder biographischen, ja uberhaupt jeder die Menschen individuell bewertenden Haltung ist."; GUGEL 1977, 73f.; BALDWIN 1983, 50Iff., U. WALLACE-HADRILL 1983, 175f., sowie ferner allg. KRENKEL 1980.

$349 \mathrm{Vgl}$. Suet. Vit. 3,2 .

350 Für eigene Rubriken vgl. Suet. Galba 22; Dom. 22; lul. 49-52; Aug. 68-71; Tib. 42-45; Cal. 24-25.36 u. Nero 28-29 sowie ferner GUGEL 1977, 73ff.

351 Vgl. Suet. Vit. 13,1 („Aber seine groBten Schwachen waren die Verschwendungssucht und die Grausamkeit.").

352 Vgl. Suet. Vit. 14,1.

353 Vgl. v.a. Tac. hist. 2,94,3: ipse sola perdendi cura stabula aurigis extruere, circum gladiatorum ferarumque spectaculis opplere, tamquam in summa abundantia pecuniae inludere sowie ferner Tac. hist. $2,70,1.71,1$ u. $2,95,1$.

354 Vgl. BRadLey 1981.

355 S.o. S. $254 \mathrm{ff}$.

356 Vgl. dag. STEIDLE 1951, 111 f., u. LEWIS 1991, 3662ff, die in den res gestae Divi Augusti das Vorbild für suetonische Rubriken wie congiaria, spectacula oder opera publica sehen.

357 Vgi. Suet. Vesp. 19,1; Tit. 7,3.8,2 u. Dom. 4,1-2 sowie ferner lul. 39; Aug. 43-45; Tib. 7,1.47; Cal. 18-20; Claud. 21 u. Nero 11-13. Zur zeitlich den Caesares vorausgehenden Schrift de spectaculis vgl. WALLACE-HADRILL 1983, $124 \mathrm{ff}$. 
Die von Sueton thematisch kohärent ausgewählten Fakten werden von ihm in einer sorgsam arrangierten gradatio dargeboten, ${ }^{358}$ die bei der schieren Menge der von Vitellius verzehrten Speisen einsetzt, um anhand zweier famosissimae super ceteras cenae detailliert $\mathrm{zu}$ verdeutlichen, welche enormen Aufwendungen er für Gelage aufbrachte und einforderte, um schließlich mit der das religiöse Gefuhl ebenso wie den guten Geschmack verletzenden Mitteilung zu schließen, Vitellius habe sich auch an Opferspeisen und an Resten vom Vortag vergriffen. ${ }^{359}$

Obwohl dieser Passus mit seinem ausgeprägten Invektivencharakter ein schlechtes Beispiel darstellt, ${ }^{360}$ läßt sich doch auch hier erahnen, welche Rolle Informationen über das Privatleben der Kaiser bei Sueton spielen können. Zwar berichten auch Tacitus und Cassius Dio über Vitellius' Vorliebe fur aufwendige Gelage, ${ }^{361}$ doch stellen weitergehende Informationen zum Tagesablauf eines Herrschers eine Besonderheit biographischer Literatur dar. ${ }^{362}$ Dabei beschränkt sich Suetons Interesse an Aspekten dieser Art durchaus nicht nur auf die Zahl der Mahlzeiten, sondern erstreckt sich gelegentlich auch auf den ganzen ordo vitae im Sinne eines geregelten Tageablaufes. ${ }^{363}$ Mit dem Interesse an Fragen der richtigen Lebensfuhrung gerade auch im Alltag steht Sueton in seiner Zeit ebensowenig alleine ${ }^{364}$ wie generell mit seiner Bereitschaft, Aspekte des Privatlebens ausführlicher zu thematisieren. ${ }^{365}$ Die Option, alltăgliche und aus der Perspektive der Historiographie periphere Begebenheiten zur Sprache bringen, die Sueton heute zur geschätzten Quelle für die Kulturgeschichte der römischen Kaiserzeit macht, ${ }^{366}$ stellte daher vielleicht auch schon furr ihn ein Argument dar, mit

358 Zu solchen ,crescendo'-Effekten bei Sueton vgl. ClzeK 1977, $118 \mathrm{ff}$., u. GASCOU 1984, 697ff.

$359 \mathrm{Vgl}$. Suet. Vit. 13 sowie ferner DEMANDT 1996, 37f., u. AsH 1999, 96ff. Ein religioser Frevel liegt allerdings auch bereits in der zuvor geschilderten Benennung einer gewaltigen Schussel als clipeus

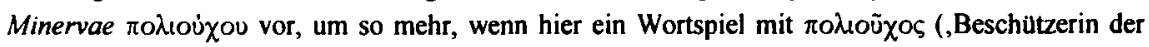
Stadt') und roגuxóos (,vielfassend') vorliegt (vgl. MURISON 1992, 161, u. SHOTTER 1993, 181).

$360 \mathrm{DaB}$ Sueton hier den von der flavischen Propaganda auf Vitellius applizierten klassischen Tyrannentopoi aufgesessen sei, wurde verschiedentlich konstatiert: vgl. z.B. MURISON 1992, 160, u. FLACH 1998,177 , sowie ferner allg. RICHTER 1992, $243 \mathrm{ff}$.

361 Vgl.Tac. hist. 2,62,1 (epularum foeda et inexplebilis libido: ex urbe atque ltalia inritamenta gulae gestabantur strepentibus ab utroque mari itineribus; exhausti conviviorum adparatibus principes civitatum; vastabantur ipsae civitates; degenerabat a labore ac virtute miles adsuetudine voluptatum et contemptu ducis); 2,95,2 u. Cass. Dio 64,3-4 sowie zu Vitellius' patina ferner Plin. n.h. 35,263 (at, Hercules, Vitellius in principatu suo $X^{\prime} H S$ condidit patinam, cui faciendae fornax in campis exaedificata erat, quoniam eo pervenit luxuria, ut etiam fictilia pluris constent quam murrina).

362 Die einzige Parallelstelle zu Vitellius, die zugleich eine Suetonrezeption darstellen durfte, entstammt wiederum einer Biographie: vgl. Eutrop. 7,18,2.

363 Vgl. v.a. Suet. Vesp. 21: ordinem vitae hunc fere tenuit u. ferner Suet. Aug. 78.

364 Vgl. z.B. Pin. ep. 3,1 u. 3,5 sowie ferner Demandt 1996, 34ff.

365 Dies kann auch ein Vergleich der Berucksichtigung privater Aspekte in Plinius' Panegyricus und in den res gestae Divi Augusti zeigen (vgl. BRADLEY 1991, 3718).

366 Vgl. z.B. WallaCe-HadRill 1983, 175ff.; Alföldy 1986, 398ff., u. PICCIRILli 1998, 183f. 
Blick auf die Interessen seiner zeitgenössischen Leser der Biographie den Vorzug vor der Geschichtsschreibung zu geben.

Eine ausführlichere Behandlung von Vitellius' vita privata in geschlossener Form findet allerdings nicht statt, wie überhaupt die diesbezügliche Disposition der Augustusbiographie manchmal etwas vorschnell als Programm der gesamten Kaiserviten aufgefaßt wird. ${ }^{367}$ Wenn Sueton das Privatleben in einer eigenen Rubrik behandelt, plaziert er diese ebenso häufig unmittelbar nach der Schilderung der vita publica wie nach der Schilderung des Todes des jeweiligen Herrschers. ${ }^{368}$ Die Darstellung der vita privata des Vitellius erfolgt dagegen en passant uber die gesamte Biographie hinweg, vor allem im thematischen Anfangsteil ${ }^{369}$ und in der Erfassung seiner Regierung unter den Kategorien von gesellschaftlichem Fehlverhalten, Speiseluxus und Grausamkeit.

Im nächsten Abschnitt erfolgt die Behandlung der in der gemeinsamen divisio zu beiden Rubriken bereits angekündigten saevitia. Erneut bilden die einzelnen hier versammelten Vorfälle eine Klimax, wie auch auf einer höheren Ebene die drei Rubriken untereinander eine sich steigernde Reihe ergeben. ${ }^{370}$ Sueton changiert in der Darstellung von Vitellius' saevitia zwischen der Verallgemeinerung seines Wütens auf möglichst weite Personenkreise und der Konkretisierung seines häufig sadistischen Verhaltens am Einzelfall: Dies gilt furr das wahllose Töten ihm nahestehender nobiles ${ }^{371}$ ebenso wie für sein Vorgehen gegen seine ehemaligen Gläubiger, ex quibus quendam in ipsa salutatione supplicio traditum statimque revocatum, cunctis clementiam laudantibus, coram interfici iussit, velle se dicens pascere oculos. ${ }^{372}$ Die antivitellianische Tendenz der Darstellung ist hier besonders augenfällig, da die von Sueton - oder bereits von seinen Quellen - suggerierte Quantität in der Parallelüberlieferung ebenso wenig Bestätigung findet ${ }^{373}$ wie die ,Qualität' der geschilderten Details, die zudem,

367 Vgl. Suet. Aug. 61,1: quoniam qualis in imperis ac magistratibus regendaque per terrarum orbem pace belloque re p. fuerit, exposui, referam nunc interiorem ac familiarem eius vitam quibusque moribus atque fortuna domi et inter suos egerit a iuventa usque ad supremum vitae diem u. ferner z.B. SCHMIDT 1891, 33. Zu den ,Abweichungen' in anderen Biographien STEIDLE 1951, 106; WITTKE 1974, 44f., u. LAMBRECHT 1984, $19 f$.

368 Zur ersten Gruppe gehören Augustus (61-96) noch Tiberius (68-71), Caligula (50-55) und Claudius (30-42), zur zweiten dagegen Nero (51-56), Galba (21-22), Otho (12,1) und Domitian (18-22). Die Vitelliusvita wurde von SCHMIDT 1891, 36ff., zu der letzteren Gruppe gezthlt, vgl. dag. aber den berechtigten Widerspruch von LAMBRECHT 1984, 20, Anm. 60.

$369 \mathrm{Vgl}$. v.a. Suet. Vit. 6.

370 Vgl. CizeK 1977, $132 \mathrm{f}$.

371 Vgl. Suet. Vit. 14,1.

372 Vgl. Suet. Vit. 14,2 ("Einen von ihnen ließ er direkt von der morgendlichen Aufwartung zur Richtstătte führen, dann rief er ihn wieder zuruck und, als alle seine Milde lobten, befahl er, ihn an Ort und Stelle zu toten, und fugte hinzu, er wolle seine Augen weiden.").

373 Vgl. Cass. Dio 64,5,2-3, mit der Version, daß Vitellius die sich vor ihm versteckenden Glaubiger gegen die Annullierung seiner Schulden verschont, u. ferner allg. MURISON 1992, 160ff. 
wie ein Blick in die taciteischen Historien zeigt, offenbar ursprunglich einer einzigen Situation entstammen und lediglich des Effekts halber auf mehrere Fälle verteilt wurden. ${ }^{374}$

Es folgen zwei weitere Beispielreihen, von denen die erste einen Einzelfall bringt, der eine Verbindung aus saevitia und avaritia darstellt, da Vitellius, nachdem ihm ein zum Tode Verurteilter zugerufen hat, heres meus es', nicht nur diesen, sondern auch seinen Miterben hinrichten läßt. Die anschließend genannte Opfergruppe, die aus den Anhängern des falschen Rennstalls besteht, bleibt ohne engeren inhaltlichen Bezug. ${ }^{375}$ Während in den zuvor erzählten Einzelfällen entsprechend der klassischen Struktur des Apophthegmas Vitellius als der Protagonist derjenige war, der auf die geschilderte Reaktion mit einem überraschenden und pointierten factum oder dictum reagierte, werden bei der nächsten Opfergruppe die Rollen vertauscht: Denn als Grund für die Verfolgung der vernaculi et mathematici wird angefuhrt, daß diese ein Edikt, mit dem Vitellius ihre Ausweisung aus Rom und Italien bis zu den Kalenden des Oktober befohlen hatte, ${ }^{376}$ ihrerseits mit einem offentlichen Anschlag beantwortet haben, der von Sueton im Wortlauf wiedergegeben wird: et Chaldaeos dicere, bonum factum, ne Vitellius Germanicus intra eundem Kalendarum diem usquam esset. ${ }^{377}$ Das wörtliche Zitat zeigt ebenso wie die akzentuierte Schlußstellung, daß Suetons Interesse hier weniger dem Schicksal der mehrfach aus Rom verbannten Wahrsager, sondern vielmehr dem Charakter ihrer Verlautbarung als prodigium gilt. Dieses stellt er, obwohl es sich erst mit einer gewissen Verspätung erfüllt, ${ }^{378}$ offenbar in eine Reihe mit anderen von ihm referierten Vorzeichen, die dazu dienen, die verbliebene Lebenszeit von Herrschern zu terminieren. ${ }^{379}$

Nach der Erwähnung dieses aus der Rubrik in gewisser Weise herausfallenden, aber wohl nicht explizit als Vorverweis instrumentalisierten prodigium, ${ }^{380}$ schließt Sueton die Reihe mit Beispielen fur die saevitia des Vitellius mit dem Vorwurf des Muttermordes ab. Dessen Ungeheuerlichkeit steigert er zunăchst noch durch die Figur einer germanischen Wahrsagerin, die ihn zu dieser Tat anstiftet, ehe er eine Alterna-

$374 \mathrm{Vgl}$. Tac. hist. 3,38-39 u. ferner MURISON 1992, 163: „We can now see what has happened: the individual parts of the story of this one murder [i.e. Junius Blaesus] (if that is what it was) were, generalized' into a separate murder or a series of murders in anti-Vitellian propaganda."

375 Vgl. Suet. Vit. 14,3.

376 Die Datierung des Ediktes ist unklar: Wahrend die Erwahnung bei Tacitus nahelegt, daß Vitellius noch nicht in Rom war (hist. 2,62,2), fuhrt es Cassius Dio unmittelbar nach der Ankunft an $(64,1,4)$.

377 Vgl. Suet. Vit. 14,4 (,Die Wahrsager lassen ihrerseits wissen, daß sich Vitellius Germanicus an den besagten Kalenden nirgends mehr aufhalten soll.").

378 Vgl. dag. Cass. Dio 64,1,4 u. ferner MURISON 1992, 164.

$379 \mathrm{Vgl}$. Suet. Dom. 14-16; Iul. 81 u. Aug. 97 sowie ferner vgl. SAUER 1930, $50 \mathrm{ff}$.

380 Vgl. WALLACE-HADRILL 1983, 191f., der festhalt, daß Sueton im Gegensatz zur Geschichtsschreibung die von ihm angeführten Vorzeichen nicht zur Dramatisierung des Geschehens nutzt. 
tivüberlieferung anführt, nach der seine Mutter sich aus Überdruß an seiner aktuellen Entwicklung Gift von ihm erbeten und haud sane difficulter erhalten habe. ${ }^{381}$ Diese wenig schmeichelhafte Episode, die bereits wenige Tage vor Vitellius' eigenen Tod spielt, bildet zugleich den Schlußpunkt des thematisch organisierten Teiles, in dem Sueton, nachdem er die wenigen von ihm als positiv eingestuften Maßnahmen im $\mathrm{Zu}$ sammenhang mit den initia imperii angefuhrt hatte, ${ }^{382}$ die negativ bewerteten Ereignisse aus Vitellius' kurzer Herrschaft in drei Rubriken zusammengefaßt hat. ${ }^{383}$

Dabei kann auch dieser Abschnitt in vielerlei Hinsicht wertvolle Aufschlüsse zur Entwicklung der suetonischen Darstellungstechnik in den thematisch organisierten Abschnitten seiner Biographien liefern. Dies gilt zum einen auf der technischen Seite für die Verwendung von divisiones, die durchaus auch großflächigere Textzusammenhănge strukturieren können, oder für das Prinzip der Anordnung der einzelnen Einträge einer Rubrik in der Form einer gradatio, das einen wichtigen Unterschied zu den zumindest überwiegend chronologisch aufgebauten narrativen Sequenzen darstellt. Von allgemeinem Interesse sind zum anderen aber auch einige Aspekte der inhaltlichen Seite: So lassen sich einige der Rubriken, die in den spăteren Biographien zum festen Repertoire der Darstellung der Regierung des jeweiligen Kaiser gehören, in der Vita des Vitellius bereits in nuce erkennen. Andere charakteristische Schwerpunkte, wie das Interesse am Privatleben der Herrscher, sind dagegen schon hier voll ausgeprägt. Das gilt nicht zuletzt auch für Suetons Vorliebe furr eine anekdotisch zugespitzte Darstellung des Geschehens, die vor allem in der an dicta et facta besonders reichen Rubrik zur saevitia des Vitellius zum tragen kommt.

e) Der Kaiser als Pförtner: Vitellius' Lebensende als narratio

Sueton läßt den folgenden Abschnitt mit einer Datierung beginnen - octavo imperii mense desciverunt $a b$ eo exercitus $-^{384}$ und markiert damit in wünschenswerter Deutlichkeit den erneuten Übergang von der Gliederung per species zur Anordnung per tempora, die für den nun einsetzenden chronologisch fortlaufenden Bericht vom Be-

381 Vgl. Suet. Vit. 14,5.

382 Vgl. Suet. Vit. 10,1.

383 Suetons moralische Bewertungskategorien sind verschiedentlich katalogisiert worden (vgl. z.B. WITTKE 1974, 47f.; WALLACE-HADRILL 1983, 152ff.; LEWIS 1991, 3628ff., u. LAMBRECHT 1995, 513 : „Immer wieder spricht er von den uirtutes abstinentia, ciuilitas, clementia, liberalitas, moderatio und den uitia arrogantia, auaritia, cupiditas, infamia (!), libidines, licentia, luxuria, saeuitia, superbia."), ohne daß sich eine überzeugende Erklärung für die Auswahl im konkreten Einzelfall ableiten ließe.

384 Vgl. Suet. Vit. 15,1 (,Im achten Monat seiner Herrschaft fiel das Heer von ihm ab“). Sueton rechnet offensichtlich von seiner Akklamation im Januar an, wăhrend Vitellius selbst von seiner im April erfolgten Anerkennung durch den Senat her datierte (vgl. SHOTTER 1993, 184). 
ginn des Bürgerkrieges mit Vespasian bis zu Vitellius' gewaltsamen Tod am 20. Dezember $69 \mathrm{n}$. Chr. ausschlaggebend ist. Das sich vor allem in Norditalien abspielende militärische Geschehen der folgenden Monate, dem Tacitus breiten Raum gewährt, ${ }^{385}$ findet bei Sueton nur am Rande Erwähnung, da sich Vitellius selbst in Rom beziehungsweise zur Erholung nach einer schweren Krankheit in dem latinischen Städtchen Aricia aufhielt. ${ }^{386}$ Aus dieser spezifisch biographischen Fokussierung heraus reduzieren sich der Frontwechsel mehrerer Legionen und die entscheidende Niederlage seiner verbliebenen Truppen in der zweiten Schlacht von Betriacum, deren narratio Tacitus zu einem Glanzstück dramatischer Geschichtsschreibung gemacht hat, ${ }^{387}$ bei Sueton auf eine einzige Partizipialgruppe: atque ubique aut superatus aut proditus. ${ }^{388}$ Mit dieser denkbar knappen Zusammenfassung der militärischen Lage leitet er bereits zu Vitellius' Versuch über, sein Leben durch eine freiwillige Abdankung zu retten, und konzentriert sich im folgenden ausschließlich auf das Geschehen im Gesichtsfeld seines Protagonisten.

Die Ereignisse in Rom zwischen dem 17. und 20. Dezember entfalten nun ihrerseits in einer der narrativ ambitioniertesten Passagen der Kaiserviten ${ }^{389}$ ihre Qualitäten als Tragödienstoff: ${ }^{390}$ Denn Vitellius, der laut Sueton zweimal von der Soldateska und der plebs urbana an seiner Abdankung und der Einhaltung der zu diesem Zweck mit Flavius Sabinus, dem Bruder Vespasians, getroffenen Vereinbarungen gehindert worden war, ${ }^{391}$ entschied sich schließlich um und ließ die auf dem Kapitol zusammengetriebenen Anhänger der Flavier mit Feuer und Schwert niedermachen ${ }^{392}$ Dabei soll er dem Schauspiel des brennenden Jupitertempels vom gegenüberliegenden Palatin aus zugesehen haben, und zwar inter epulas, wie Sueton maliziös hinzufügt. ${ }^{393} \mathrm{Da}$

385 Vgl. Tac. hist. 2,96-3,63.

386 Vgl. Tac. hist. 3,36,2 u. 3,38,1 mit HANSLIK 1962, 1722.

387 Vgl. Tac. hist. 3,21-34.

388 Vgl. Suet. Vit. 15,2 (,nachdem er an allen Fronten geschlagen oder verraten worden war") sowie femer GASCOU 1984, 358f., u. MURISON 1992, 164ff.

$389 \mathrm{Vgl}$. LOUNSBURY 1987, $99 \mathrm{f}$.

$390 \mathrm{Zu}$ den tragikomischen Zügen des Geschehens vgl. SCHEID 1984, 181f.187ff., der unter anderem aufgrund des Datums dieser Ereignisse die reizvolle Vermutung außert, daß Sueton Vitellius über die Beschreibung seines Endes als eine Art saturnalicius princeps darzustellen sucht.

391 Die knapp dargesteilte zweite Abdankungsszene bietet ein gutes Beispiel für Suetons Făhigkeit, mit der Erwähnung einiger bezeichnender Details das Charakteristische einer Situation zu erfassen: cunctis reclamantibus rem distulit ac nocte interposita diluculo sordidatus descendit ad rostra multisque cum lacrimis eadem illa, verum e libello testatus est (vgl. Suet. Vit. 15,2). Zu der Bedeutung von libellus an dieser Stelle vgl. LoYD 1969, 142f.

$392 \mathrm{Vgl}$. Tac. hist. 3,64-75, v.a. 3,72,1: facinus post conditam urbem luctuosissimum foedissimumque.

393 Vgl. Suet. Vit. 15,3. Von TowNEND 1964, 365, stammt die reizvolle Vermutung, hier eine Anspielung auf Neros Verhalten beim Brand Roms zu sehen (vgl. Suet. Nero 38,2: hoc incendium e turre Maecenatiana prospectans laetusque flammae, ut aiebat, pulchritudine Halosin llii in illo suo scaeni- 
ihn wenig später Reue über sein Vorgehen überkam, leitet zur detaillierten Schilderung einer weiteren Abdankungsszene über, in deren Mittelpunkt Vitellius' Versuche stehen, seinen Dolch als Symbol der Herrschaft ${ }^{394}$ an die ihn umstehenden Würdenträger zu übergeben. Als diese sich weigern, versucht er schließlich, den Dolch im Concordia-Tempel niederzulegen, ${ }^{395}$ doch auch daran hindert ihn die Volksmenge und ruft ihm statt dessen zu, er sei die concordia, woraufhin er seine Entscheidung ein weiteres Mal ändert und sogar Concordia als neuen Beinamen annimmt. ${ }^{396}$

Mit der Entsendung von Unterhändlern zu den gegnerischen Truppen endet diese Szenefolge, die aufgrund ihrer bewußt gestalteten Dramaturgie erneut die Vermutung einer charakterisierenden Tendenz nahelegt. Diesen Eindruck verstärkt noch ein Blick auf die Parallelüberlieferung: So gibt Tacitus einen deutlich differenzierteren Bericht der Vorkommnisse, in dem manche für Vitellius vorteilhafte Einzelheiten, wie seine passive Rolle bei der Erstürmung des Kapitols, enthalten sind. ${ }^{397}$ Sueton macht hier bewußt Gebrauch von der ,Macht des Faktischen', indem er durch gezieltes Erwähnen und Verschweigen seinen Lesern ein bestimmtes Bild der Ereignisse vor Augen stellt, das gerade durch seine Detailfülle und Plastizität keine geringe Suggestionskraft entfaltet. Mit um so größerer Verwunderung erfährt der Leser aber unmittelbar im Anschluß, daß der zuvor geradezu als ,model of perfidy ${ }^{398}$ gezeichnete und durch den Brand des Jupitertempels religiös desavouierte Vitellius ausgerechnet die Vestalinnen als Unterhänderinnen für seine Sache gewinnen konnte. ${ }^{399}$ Hierin kommt besonders eindrucksvoll die schon zuvor beobachtete Tendenz zum Ausdruck, daß sich Suetons Interesse an der kohärenten Zeichnung und Bewertung eines Charakters auf das für die Erzählbarkeit einer Geschichte notwendige Maß beschränkt.

co habitu decantavit), doch ist aufgrund des weitgehenden Fehlens anderer Beispiele fur Verweise zwischen den Biographien der von MURISON 1992. 170, artikulierten Skepsis der Vorzug zu geben.

$394 \mathrm{Vgl}$. Tac. hist. 3,68,2: velut ius necis vitaeque civium reddebat.

$395 \mathrm{Vgl}$. Suet. Vit. 15,4. Tacitus faßt diesen Abdankungsversuch mit den fruheren zusammen: vgl. Tac. hist. 3,68 sowie ferner KÖNIG 1984 u. MURISON 1992, I68f.: „Vitellius may well have tried to abdicate once more, and it looks as if Tacitus has artistically reshaped a somewhat repetive and untidy reality; at any rate, it is easier to imagine that three attempts were reduced to one than to explain how a single attempt came to be tripled."

396 Concordia ist als cognomen singular, als Parole auf kaiserlichen Munzserien allerdings gängig und auch fur Vitellius belegt (vgl. MATTINGL Y/SYDENHAM 1923, 274ff., u. MATTINGLY 1965, 368ff.).

397 Vgl. Tac. hist. 3,69-71.75,3 sowie ferner WISEMAN 1978; WELLESLEY 1981; SCOTT 1984; MURISON 1992, 170f., u. ASH 1999, $118 \mathrm{ff}$. Es ist allerdings auch zu bedenken, ob hier nicht die von STEIDLE

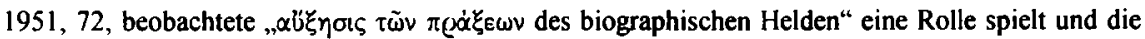
aktivere Rolle des Vitellius daher zumindest zum Teil aus der Gattungsdifferenz und weniger mit der Absicht einer damnatio durch memoria erklärt werden kann.

398 Vgl. BALDWIN 1983, 285.

399 Vgl. Suet. Vit. 16. 
Vor der sich anschließenden, durch vielleicht noch großere évó Schilderung, wie Vitellius zunächst zu fliehen versucht, dann aber in den menschenleeren Palast zurückkehrt und sich schließlich in der Zelle des Pfortners versteckt, ${ }^{400}$ findet sich im codex Memmianus ein Absatz. Auf diese Weise wird die zwischen seinen letzte politische Aktionen und der Schilderung seines Todes eingeschobene Episode, die ihn noch einmal gleichsam in Nahaufnahme zeigt, dort auch formal deutlich abgesetzt. Die wie häufig in den chronologischen Teilen eher leichte Zäsur wird dabei erneut in Form einer Zeitangabe realisiert: postridie responsa opperienti nuntiatum est per exploratorem hostes appropinquare. ${ }^{401}$ Sueton laß auf diese Nachricht, mit der er auch implizit das Scheitern der zuvor erwähnten Verhandlungen mitteilt, unmittelbar Vitellius' letzten Fluchtversuch folgen, während er von Tacitus und Cassius Dio erst nach der Eroberung der Stadt durch die flavischen Truppen angesetzt wird. ${ }^{402}$ Überhaupt scheint die Gestaltung der Stelle wesentlich von der Absicht getragen zu sein, Vitellius' schwankendes und kopfloses Verhalten in seinen letzten Stunden dem Leser plastisch vor Augen zu stellen.

Und doch ist es Tacitus, der an dieser Stelle mit mobilitas ingenii und pavor explizit auf moralphilosophische beziehungsweise psychologische Erklärungsmuster rekurriert, während Sueton den von ihm gegebenen Bericht unkommentiert läßt. ${ }^{403}$ Von den individuellen Entscheidungen der beiden Autoren abgesehen wird hier zugleich ein genereller Unterschied in der Erzählstruktur der beiden Gattungen deutlich. Für weite Teil der römischen Geschichtsschreibung war das bereits von Sempronius Asellio in Rom eingeführte thukydideisch-polybianische Programm verbindlich, demzufolge der Historiker nach den hinter den Handlungen und Ereignissen stehenden Motiven und Überlegungen zu fragen hatte: non nobis modo satis esse video, quod factum esset, id pronuntiare, sed etiam, quo consilio quaque ratione gesta essent, demonstrare. ${ }^{404}$ Mit dieser scharfen Abgrenzung ${ }^{405}$ wurde in der Geschichtsschreibung ein Erwartungshorizont etabliert, der in der in dieser Hinsicht weniger ambitionierten

400 Vitellius' Versteck, das Tacitus nur sehr vage als pudenda latebra bezeichnet (vgl. Tac. hist. 3,84,4 sowie allgemein zum Unterdrucken anstoßiger Details durch Tacitus, SYME 1958a, 189f., dag. aber auch SCHUNK 1955, 125f.), beschreibt Sueton detailliert: confugitque in cellulam ianitoris, religato pro foribus cane lectoque et culcita obiectis (vgl. Suet. Vit. 16).

401 Vgl. Suet. Vit. 16 („Als er am folgenden Tag auf Nachrichten wartete, wurde ihm von einem Kundschafter mitgeteilt, daß die Feinde im Anmarsch seien.").

402 Vgl. Tac. hist. $3,84,4$ u. Cass. Dio $64,20,1$.

403 Vgl. Tac. hist. 3,84,4 sowie ferner SYME 1958a, 189f.; EKTOR 1980, 325f.; BRAUN 1990, 208, u. ASH 1999, 124.

404 Vgl. Frg. 1 HRR = Gell. 5,18,8 (,Meiner Ansicht nach reicht es nicht aus, wenn ich nur die Ereignisse berichte, sondern ich muß auch zeigen, aufgrund welchen Planes und welcher Überlegung diese geschehen sind.").

405 Die durch Asellios Verdikt uber das gegenteilige Verfahren noch verstärkt wird: id fabulas pueris est narrare, non historias scribere (vgl. Frg. $2 \mathrm{HRR}=$ Gell. 5,18,9). 
Biographie keine Parallele hatte. Dadurch erhält Sueton, weil er nicht zu einer Deutung des Geschehens in ethisch-moralischen oder psychologisierenden Kategorien verpflichtet ist, die Freiheit, sein Augenmerk stärker auf eine möglichst ansprechende narratio zu legen. Damit verbindet sich für den Biographen zugleich der Vorteil, daß er die Details seiner Erzählung zur Charakterisierung des Protagonisten nutzen kann. So ist es denn auch Sueton, der die beiden letzten Getreuen des Vitellius als Băcker und Koch identifiziert ${ }^{406}$ und damit seinen Lesern uber die aktuelle Szenerie hinaus die Möglichkeit gibt, einen - von ihm freilich nicht explizit realisierten - Bezug zur Darstellung seiner Speisegewohnheiten zu schlagen. ${ }^{407}$

Es ist erneut eine der zeitlichen Orientierung dienende Angabe - irruperant iam agminis antecessores $^{408}$-, mit der Sueton die Szene von der nächsten abgrenzt. Diese eröffnet er mit dem Eindringen der ersten flavischen Soldaten in den verlassenen Kaiserpalast und präsentiert dem Leser im folgenden die Ereignisse bis zum Tode des Vitellius in deutlich angezogenem Erzăhltempo, ohne jedoch auf eine detaillierte narratio zu verzichten. ${ }^{409}$ In dieser Schilderung, die häufig als wenig anspruchsvoll und von Sensationslust geprägt abqualifiziert wurde, ${ }^{410}$ tritt ebenso wie in der vorherigen Episode Suetons Interesse an der Darstellung der, letzten Stunden' seiner Protagonisten deutlich zutage, das hier wie auch in den anderen Kaiserviten mit einer stilistisch ambitionierten Präsentation des Lebensendes und seiner Umstände einher geht. ${ }^{411} \mathrm{Da}$ Sueton mit dieser Schwerpunktsetzung keineswegs alleine steht, kann die allgemein intensive Beschäftigung mit Sterbeszenen in der römischen Literatur der Kaiserzeit verdeutlichen, ${ }^{412}$ mit der wir uns bereits am Beispiel der plinianischen Portrătbriefe ausführlicher auseinandergesetzt haben. ${ }^{413}$

406 Der Authentizită dieser Nachricht skeptisch gegenuber steht MURISON 1992, 172.

407 Eine Anspielung auf Vitellius' luxuria ist wohl auch darin zu sehen, daß Sueton als Fluchtziel anstelle des von Tacitus angegebenen konkreten Ortes Terracina, den Vitellius' Bruder besetzt hielt (vgl. Tac. hist. 3,84,4 u. Cass. Dio 64,20,1), nur allgemein auf das zu vielfaltigen Assoziationen Raum gebende Kampanien venweist (vgl. STÄRK 1995, 131f.). Zur generellen Tendenz, in der Schilderung der Sterbeszene verschiedene Motive der Lebensbeschreibung wiederaufzunehmen s.u. S. 312 mit Anm. 462.

$408 \mathrm{Vgl}$. Suet. Vit. 17,1 ("Die Vorhut war bereits [sc. in den Palast] eingedrungen").

409 Vgl. Suet. Vit. 17,1-2.

410 Vgl. die Angaben bei BraUn 1990, 205, dag. aber auch SAUER 1930, 52: „Mit dem Tod des Domitian enden die Viten des Sueton auf einer Hơhe der Darstellung, wie sie die Geschichtsschreibung nicht oft erreicht hat. Dies Ende ist, da uns die Kaiserviten des Marius Maximus verloren gegangen sind, das Ende der großen Todesdarstellungen uberhaupt. Man könnte dann erst wieder den Lactanz, de mortibus persecutorum nennen."

411 Vgl. Suet. Galba 19-20; Otho 9,3-12,1; Vesp. 20; Tit. 10; Dom. 17,1-2; lul. 81,4-82,3; Aug. 97-99; Tib. 72-74; Cal. 58; Claud. 44-45 u. Nero 47-49 sowie ferner LEWIS 1991, 3638: „An emperor's death was never trivial: it touched the whole Roman world.".

412 Vgl. SCHUNK 1959, 41 ff.; STEILDE 1951, 91; LOUNSBURY 1987, 63ff., u. ARAND 2002, v.a. $18 \mathrm{f}$.

413 S.o. S. $88 \mathrm{ff}$. 
Dabei weisen Suetons Schilderungen insbesondere zur exitus illustrium virorumLiteratur, die sich in der Adoptivkaiserzeit aus ihrer ursprünglich engen okkasionellen Bindung zusehends löste, vielfältige Parallelen auf. ${ }^{414}$ Dies gilt zum einen für die Wirkungsabsicht in Hinblick auf die Nachwelt, wenn diese bei den negativ gezeichneten Kaisern in Umkehrung der positiven Kommemorationsabsicht der Autoren der exitusSchriften auch die Form einer partiellen damnatio durch memoria annehmen kann. ${ }^{415}$ Zum anderen gilt dies aber vor allem für die Darstellungstechnik, zu deren Rekonstruktion wir aufgrund der schlechten Überlieferungslage der exitus-Literatur allerdings auf indirekte Zeugnisse, vor allem auf einige Szenen in den taciteischen Geschichtswerken, angewiesen sind. ${ }^{416}$ Dennoch können vor allem die Dramatisierung und Emotionalisierung des Geschehens sowie die Detailliertheit der Schilderung als charakteristisch für diese Literaturform gelten. ${ }^{417}$

Vor diesem Hintergrund ist auch die kleine, in der Überlieferung zu Vitellius singuläre Szene zu sehen, in der Sueton mit wenigen Strichen einen Dialog zwischen dem in seinen Versteck aufgespürten Kaiser und seinen Häschern skizziert, dessen Pointe darin besteht, daß diese den von ihnen Gesuchten zunächst nicht erkennen und den vermeintlichen Pförtner nach Vitellius' Aufenthaltsort ausfragen. ${ }^{48}$ Die Kuriosität der Szene zielt sicherlich auf die delectatio der Leser, die Art der Darstellung dient aber auch erneut der Demontage des letzten Bürgerkriegsherrschers, der seinem kaiserlichen Amt so wenig würdig erscheint, daß er sogar mit dem Türwächter verwechselt werden konnte. In ähnlicher Weise gewinnt der Fortgang des Dialoges vor der Folie der zeitgenössischen Erwartungen an das Verhalten eines römischen nobilis den Charakter einer Invektive, wenn der schließlich erkannte Vitellius - erneut nur bei Sueton - die gegnerischen Soldaten mit einer fadenscheinigen Begrilndung bittet, ihn in sicheren Gewahrsam zu nehmen, und sei es im Gefängnis. ${ }^{419}$ Nicht nur die Angst um sein Leben, die hier erkennbar wird, mußte Vitellius dabei aus der Perspektive seiner

414 Vgl. dag. WALLACE-HaDRILL 1983, 58, der ausgehend von der Beobachtung, daß die Autoren von exitus illustrium virorum-Schriften von Sueton in seinen viri illustres offenbar nicht behandelt wurden, dessen Desinteresse an dieser Literaturform ableitet.

415 Vgl. RONCONı 1966, 1261ff., mit der aufgrund der Überlieferungslage nicht verifizierbaren Vermu-

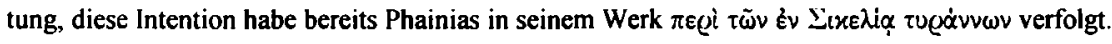

416 Vgl. v.a. Tac. ann. 16,7-35 sowie ferner z.B. 15,60-63 u. 15,67.

417 Vgl. MARX 1937, 97f; LOUNSBURY 1987, 63ff., u. LEWIS 1991, $3657 \mathrm{ff}$.

418 Vgl. Suet. Vit. 17,1: irruperant iam agminis antecessores ac nemine obvio rimabantur, ut fit, singula. ab his extractus e latebra, sciscantes, quis esset - nam ignorabatur - et ubi esse Vitellium sciret, mendacio elusit.

$419 \mathrm{Vgl}$. Suet. Vit. 17,1: deinde agnitus rogare non destitit, quasi quaedam de salute Vespasiani dicturus, ut custodiretur interim vel in carcere. 
Zeitgenossen zum Nachteil gereichen, ${ }^{420}$ sondern auch die Bereitschaft, nötigenfalls ins Gefängnis zu gehen, was einem Mann von Stand gewöhnlich erspart blieb. ${ }^{421}$

Von dem Kontrast, daß Vitellius, der eben noch auf dem römischen Kaiserthron $\mathrm{saß}$, in der Rolle des gemeinen Verbrechers gezeigt wird, ${ }^{422}$ lebt auch die sich anschließende Schilderung, wie er in Fesseln und unter Spottrufen in der Parodie eines Triumphzug über die via sacra zum Kapitol geführt wird. ${ }^{423}$ Dieser Bezug wird von Sueton explizit hergestellt, wenn er bei der Erwähnung der auch für die Blickführung des Lesers aufschlußreichen Einzelheit, ${ }^{424}$ daß Vitellius von seinen Peinigern gezwungen wurde, der umherstehenden Menge sein Gesicht zu zeigen, hinzufugt ceu noxii solent. ${ }^{425}$ Dies gilt in gleicher Weise fur die Hinrichtung auf den scalae Gemoniae $e^{426}$

420 Die Sichtweise der rơmischen Kaiserzeit kommt am deutlichsten bei Valerius Maximus zum Ausdruck, der seine Rubrik de cupiditate vitae, in der er zahlreiche Beispiele fur unwürdiges Verhalten angesichts des Todes zusammengestellt hat, folgendermaßen einleitet: verum quia excessus e uita et fortuitos et viriles, quosdam etiam temerarios oratione attigimus, subiciamus nunc aestimationi enerves et effeminatos, ut ipsa comparatione pateat quanto non solum fortior, sed etiam sapientior mortis interdum quam vitae sit cupiditas (vgl. Val. Max. 9,13 praef.). Der gleichen Kategorien bedient sich aber auch noch RUDOLF HANSLIK in seinem Fazit zu Vitellius' Leben: „Vitellius war ein Mann von ausgesprochen spießburgerlichem Charakter. Er aB und trank gerne und liebte Freunde um sich, in deren Wahl er keine glückliche Hand hatte. ... Was ihm vollig fehlte, war die Charakterfestigkeit eines L. Verginius Rufus, den Lockungen einer Erhebung auf den Kaiserthron zu widerstehen, und die eines Otho, einem verlorenen Spiel durch ein mannhaftes Ende einen einigermaßen versohnlichen Ausgang zu geben." (vgl. HANSLIK 1962, 1733).

421 Der communis opinio, daß es in Rom außer der Untersuchungshaft und der Verwahrung vor der Hinrichtung keine Gefangnisstrafe gegeben hat, wird allein von EISENHUT 1972, widersprochen, doch auch er kann nur auf wenige Falle fur eine Inhaftierung hochstehender Personen verweisen.

422 Vgl. WallaCE-HADRILL 1983, 109: „... Suetonius not only took for granted the traditional social hierarchy but attached great significance to a man's precise place within it, and the fluctuations in his standing."

423 Vgl. Cass. Dio 64,20,3 mit SCHEID 1984, 183ff., u. SHOTTER 1993, 189.

424 Wahrend Sueton die passive und hilflose Rolle des abgesetzten Kaisers betont, nutzt Tacitus daruber hinaus den Blick durch die Augen des Vitellius, um dessen Herrschaft noch einmal in Kurzform vor seinen Lesem Revue passieren zu lassen (vgl. Tac. hist. 3,85: Vitellium infestis mucronibus coactum modo erigere os et offere contumelis, nunc cadentes statuas suas, plerumque rostra aut Galbae occisi locum contueri $\mathrm{u}$. ferner KEITEL 1992, 350f.).

425 Vgl. Suet. Vit. 17,1 ("wie es bei Verbrechern ublich ist") u. ferner Plin. paneg. 34,3 mit MURISON 1992, $172 \mathrm{f}$.

$426 \mathrm{Vgl}$. z.B. Suet. Tib. 53,2; 61,4; 75,1 u. Tac. ann. 6,19,3-4 sowie ferner SHOTTER 1993, 190, u. BURKE 1998: "In the final scene there is no need to subvert an official imperial advertisement, for the meaning of the locus is self-evident. The details and sensationalism, which were previously parodic, now emphasize propriety and consistency through minute characterological correspondences. This is the reason that Suetonius' recapitulation of Vitellius' life at this point is so effective: because character is related so closely to the locus which typifies it. ... Now at last, status, character, place, space and text are one, in a complex but satisfying unity that is the product of Suetonius' own subtle - and easily underestimated - literary artistry." 
und das Schleifen des Leichnams am Haken in den Tiber, ${ }^{427}$ ohne daß Sueton seinen zeitgenössischen Lesern diese Deutung hătte vorgeben müssen. ${ }^{428}$

In der Betonung der schmerzlichen und schmachvollen Momente bei der Schilderung des Todes eines Herrschers kann in gewisser Weise ein Topos der literarischen Tyrannendarstellung erblickt werden. ${ }^{429}$ Allerdings vermögen die beiden in der Regel für die Verwendung eines solchen Topos ausschlaggebenden Motive an dieser Stelle nicht völlig zu überzeugen. Da nämlich Vitellius' Leben nicht durchgăngig negativ bewertet wird, besteht auch keine innere Notwendigkeit, die Biographie mit der Schilderung eines ,schmählichen Endes' des Protagonisten inhaltlich abzurunden. ${ }^{430}$ Auch macht das generell eher distanzierte und nüchterne Verhältnis Suetons zu den von ihm dargestellten Herrschern unwahrscheinlich, daß der Gedanke einer gerechten Strafe für ein moralisch verfehltes Leben einen zwingenden Beweggrund dargestellt hat. ${ }^{431}$

Möglicherweise hat in diesem Zusammenhang neben dem moralisch fragwürdigen Reiz, den eine solche dramatische Schilderung bereits per se entfaltet, ${ }^{432}$ aber die Auseinandersetzung mit der in der zeitgenössischen Literatur dominierenden Form von Todesdarstellungen eine wichtige Rolle gespielt. Denn indem Sueton die unruhmlichen Aspekte der Situation ganz in den Vordergrund treten läßt, rückt er seine Schilderung von Vitellius' Lebensende in einen scharfen Gegensatz zur Gattungstradition der exitus illustrium virorum-Schriften, deren Anliegen es war, das Sterben ihrer Protagonisten in einer möglichst würdigen Weise zu zeigen. ${ }^{433}$ Suetons Bruch mit den Wahrnehmungsgewohnheiten seiner Leser dürfte um so prononcierter gewesen sein, da er selbst an anderen Stellen das Lebensende seiner Protagonisten durchaus in den

427 Zur Mißhandlung des Leichnams als fester Bestandteil der Schilderung eines als unwurdig empfundenen Lebensendes bei Sueton und anderen antiken Autoren vgl. ARAND 2002, 114ff.214ff.

428 Die drastischen Details erfahren in der spăteren Historiographie noch eine Steigerung: vgl. z.B. Eutr. 7,18,4-5 u. Oros. 7,8,8 sowie ferner ARAND 2002, 62 Anm. 340.

$429 \mathrm{Vgl}$. z.B. CIzEK 1975 u. SCHEID 1984, 181 f. 185.187 ff., sowie ferner allg. ARAND 2002, v.a. $102 \mathrm{ff}$.

430 Vgl. ARAND 2002, 242: „Hauptfunktion der Todesdarstellung schlechter Herrscher ist es daher, das zuvor dargestellte schlechte Leben durch ein schlechtes Ende dergestalt inhaltlich ,abzurunden' beziehungsweise Leben und Tod so in einen fur die Gesamtabsicht glaubwurdigen Kausalzusammenhang zu bringen, daß sich Prinzipien des geschilderten schlechten Lebens auch im Tod wiederfinden." Für eine in diese Richtung weisende Deutung der exitus-Szene des Vitellius vgl. ClzeK 1975, 126ff.: „Et là, dans l'absence du courage et dans la cruauté des dieux à son égard, se trouve la clef de voûte de la biographie et réside aussi la portée de sa mort."

431 Vgl. ARAND 2002, 218: „Deutlich ist ... geworden, daß die Darstellungen der Vermittlung eines Strafgedankens dienen, in dem in einem Konsens zwischen Leserschaft und Autor das negativ bewertete Leben mit einem entsprechendem Tod bestraft wird."

432 Vgl. ARAND 2002, 242: „Eine ebenfalls nicht zu unterschatzende Funktion der Todesdarstellungen ist die Unterhaltung. ,Sex \& Crime' sind nicht erst in der Literatur oder im Film der Moderne ein erfolgreiches Muster der Unterhaltung."

$433 \mathrm{Zu}$ den exitus-Schriften s.o. S. 88ff. Auch in den Sterbeszenen der alteren römischen Literatur laßt sich die Tendenz beobachten, das decorum des jeweiligen Todes zu betonen (vgl. SAUER 1930, 40ff.). 
traditionellen Kategorien beschreibt. Dies gilt vor allem für die auch sonst vorwiegend positiv gezeichneten Herrscher wie Caesar, Augustus oder Vespasian, ${ }^{434}$ während bei der detaillierten Schilderung von Neros gleichfalls sehr unheroischen exitus und bei dem relativ ausführlichen Bericht uber Claudius' Pilzvergiftung ein ähnliches Spiel mit den Gattungskonventionen zu vermuten ist. ${ }^{435}$

Überraschenderweise verzichtet Sueton im Falle des Vitellius auch darauf, seine letzten Worte mitzuteilen, obwohl die ultima verba sonst einen festen Bestandteil der Kaiserviten ${ }^{436}$ wie auch von exitus-Szenen ganz allgemein bilden. ${ }^{437}$ Welche Bedeutung dem letztem Diktum eines Sterbenden zugemessen werden konnte, zeigt beispielsweise Suetons verschiedene Versionen berücksichtigende Diskussion dieses Aspektes in der Galbabiographie. ${ }^{438}$ Aus der von Tacitus an einer Stelle ausdrücklich hinzugefugten Bemerkung, der Betroffene sei nullo dicto factove memorando gestorben ${ }^{439}$ geht überdies hervor, daß eine solche Mitteilung von den zeitgenössischen Lesern geradezu erwartet wurde. Um so erstaunlicher muß das Fehlen dieser Information an unserer Stelle wirken, das nur damit erklärt werden kann, daß die einzigen bekannten ultima verba nur schlecht zu dem von Sueton hier sehr dicht und kohärent gezeichneten Bild eines sich unwürdig und passiv verhaltenden Vitellius gepaßt hätten. ${ }^{440}$ In die gleiche Richtung weist es, wenn Sueton im Gegensatz zu Tacitus und Cassius Dio den gescheiterten Versuch eines miles Germanicus, Vitellius mit seinem Schwert Schlimmeres zu ersparen, unerwăhnt läßt, ${ }^{441}$ da die auf diese Weise zum Ausdruck gebrachte Loyalität wenigstens eines seiner ehemaligen Untergebenen das einheitlich gezeichnete Bild beeinträchtigt hätte.

434 Vgl. Suet. Galba 19-20; lul. 81,4-82,3 u. Aug. 97-99.

435 Vgl. Suet. Nero 47-49 u. Claud. 44-45 sowie ferner ARAND 2002, $115 \mathrm{f}$.

436 Vgl. Galba 20,1; Otho 11,1; Vesp. 24; lul. 82,2-3; Aug. 99, I u. Nero 49,1-4 sowie femer Mouchová 1968 , 52, u. GUGEL 1977, 95ff., die beide die Funktion der ultima verba vor allem in ihrem Beitrag zur Charakterisierung erblicken.

437 Vgl. Sauer 1930, 14 mit Anm. 4; MarX 1937, 97f.; SCHUNK 1959, 53f.; GNiLKa 1979, 7; LounsBuRY 1987, 77f., u. ARAND 2002, 116f., sowie zur Bedeutung ,letzter Worte' in der Neuzeit GUTHKE 1990.

$438 \mathrm{Vgl}$. Suet. Galba 20,1 sunt qui tradant, ad primum tumultum proclamasse eum: quid agitis commilitones? ego vester sum et vos mei; donativum etiam pollicitum. plures autem prodiderunt optulisse ultro iugulum et ut hoc agerent ac ferirent, quando ita videretur, hortatum u. ferner Tac. hist. 1,41,2: extremam eius vocem, ut cuigue odium aut admiratio fuit, varie prodidere. alii suppliciter interrogasse, quid mali meruisset, et paucos dies exsolvendo donativo deprecatum; plures obtulisse ultro percussoribus iugulum: agerent ac ferirent, si ita e re publica videretur. non interfuit occidentium, quid diceret.

439 Vgl. Tac. ann. 15,70,2.

440 Tacitus hingegen führt sie an und thematisiert den sich aus ihnen zu seiner ubrigen Darstellung ergebenden Kontrast: una vox non degeneris animi excepta, cum tribuno insultanti se tamen imperatorem eius fuisse respondit (vgl. Tac. hist. 3,85).

$441 \mathrm{Vgl}$. Tac. hist. 3,84,5 u. Cass. Dio 64,21,1-2. 
Sueton, der an anderen Stellen durchaus auch konkurrierende Versionen erwähnt, zeichnet das Bild von Vitellius' exitus hier mit großer Bestimmtheit. ${ }^{442}$ Doch die klare Darstellung kommt nicht durch die Verwendung moralphilosophisch-psychologischer termini oder durch auktoriale Deutungen des Geschehens zustande, wie sie fur die Historiographie taciteischer Prägung kennzeichnend sind: Während Tacitus Vitellius' Gang über das Forum explizit als foedum spectaculum bezeichnet, ${ }^{443}$ beschränkt sich Sueton auf einen rein ,faktischen' Bericht, der allerdings durch gezieltes Erwăhnen und Verschweigen eine stärker charakterisierende Tendenz aufweist als die Darstellung in den taciteischen Historien. ${ }^{444}$ Obwohl bereits Tacitus' Technik an dieser Stelle fast biographisch zu nennen ist, ${ }^{445}$ geht Suetons Fokussierung auf die Hauptperson hier wie auch in anderen exitus-Szenen noch darüber hinaus. ${ }^{446}$ Der Protagonist bleibt dabei allerdings erstaunlich passiv: „The Tacitean Vitellius is an actor upon a stage; action is passed before the eyes of the Suetonian Vitellius like a film."

Ehe Sueton Vitellius' eigentlichen exitus auf den scalae Gemoniae schildert, geht er zunächst ausführlicher auf die Reaktion der dem spectaculum beiwohnenden plebs urbana ein, die denjenigen, dem sie vor kurzem noch als Kaiser gehuldigt hatte, ${ }^{448}$ mit Mist und Kot bewirft sowie als incendiarius und patinarius beschimpft. Stellt schon

442 Vgl. BALDWIN 1983, 508f. „Suetonius' displays two basic techniques in these scenes. In some, variant accounts are surveyed and research is paraded in the shifting of rival details. ... Others are retailed with confidence, as though there were no dispute over the details."

443 Vgl. Tac. hist. 3,84,5 sowie ferner BORZSÁK 1973, 65f.; PERKINS 1990 u. KeITEl 1992, die zeigen konnten, daß Tacitus die Kategorie des spectaculum als Leitmotiv bei der Gestaltung der Ereignisse des Vierkaiserjahres und insbesondere bei der Darstellung der kurzen Herrschaft des Vitellius verwendet hat (vgl. Tac. hist. $2,70,1$ u. 2,88,3).

444 Vgl. LounsBury 1987, 67ff., u. Braun 1990, 208: „Bezeichnend fur Sueton ist dabei, daß er die Handlungsweise wie auch sonst die Sachen fur sich sprechen laßt, im Gegensatz zu Tacitus, der Eigenschaften und Stimmungen expliziert, Urteile ausspricht und uberhaupt die Dinge beim Namen nennt: ..." sowie femer die Interpretation von Neros exitus durch STEIDLE 1951, 94f.: „Auf diese Weise ist eine ganz einheitliche Gestaltung zustande gekommen, die - daran kann kein Zweifel sein mit großem Kunstverstand gemacht ist und so gut wie ausschließlich auf Auswahl und Gruppierung der Fakten beruht. Wenn einmal ein charakterisierendes Abstraktum wie die erwathnte fiducia auftaucht, so geschieht es - ebenso wie bei allem bisher Behandelten, obwohl es bis jetzt noch nicht ausdrücklich erwahnt wurde - mehr nebenbei und ohne daB seine beherrschende Funktion im Ablauf der Erzăhlung irgendwie hervorgehoben wurde. Zur Abstraktion gezwungen ist erst die moderne Interpretation, die Leitmotive aufspürt, wo bei Sueton nichts anderes vorliegt als eine bestimmte Auswahl und Ordnung der Ereignisse selbst."

445 Vgl. SCHUNK 1959, 73.

$446 \mathrm{Vgl}$. LOUNSBURY 1987, 71, u. BRAUN 1990, 205ff.

$447 \mathrm{Vgl}$. LOUNSBURY 1987, 104.

448 Explizit gemacht wird dieser Gedanke wiederum nur von Tacitus: et vulgus eadem pravitate insectabatur interfectum qua foverat viventem (vgl. Tac. hist. 3,85 sowie zur Interaktion der plebs mit Vitellius ferner YAFETZ 1969 u. NEWBOLD 1972). 
diese von Sueton unter den wahrscheinlich weitaus zahlreicheren Beleidigungen getroffene Auswahl einen geschickten, wenn auch erneut nicht explizit gemachten Verweis auf den zuvor dargestellte Brand des Kapitol einerseits ${ }^{499}$ und die als besonders illustratives Beispiel seines Tafelluxus erwähnte gewaltige patina andererseits ${ }^{450} \mathrm{dar}$, so ist für die Entwicklung seiner biographischen Technik vor allem der folgende Abschnitt von Bedeutung:

parte vulgi etiam corporis vitia exprobrante; erant enim in eo enormis proceritas, facies rubida plerumque ex vinulentia, venter obesus, alterum femur subdebile impulsu olim quadriguae, cum auriganti Gaio ministratorem exhiberet. ${ }^{451}$

Die Beschreibung der äußeren Erscheinung der Kaiser, die in praktisch allen anderen Biographien eine eigene, manchmal recht umfangreiche Rubrik bildet, ${ }^{42}$ stellt hier einen Teil der narratio dar und wird zudem gleichsam dem Publikum seiner Hinrichtung in den Mund gelegt. Den einzigen vergleichbaren Fall bietet die Othovita, in der die Beschreibung des Äußeren zwischen der Darstellung des Selbstmordes und der Reaktion auf seinen Tod steht und auch thematisch eng eingebunden unter der Fragestellung erfolgt, wie der Gegensatz zwischen Othos verweichlichter Erscheinung und seinem ,mannhaften' Freitod erklärt werden kann. ${ }^{453}$ Gleichfalls im Anschluß an die Schilderung der Sterbeszene, jedoch ohne enge inhaltliche Anbindung, findet sich diese Rubrik in den Biographien Galbas und Domitians, während Titus' äußere Erscheinung schon zu Beginn seiner Vita behandelt wird. ${ }^{454}$ In der zweiten Hexade steht diese Rubrik lediglich in der Vespasiansvita vor der exitus-Schilderung und bildet mit den übrigen ,privaten' Eigenschaften einen thematischen Komplex, ${ }^{455}$ wie es dann in den Biographien der julisch-claudischen Kaiser mit Ausnahme der Nerovita zur Regel wird. ${ }^{456}$ In der unterschiedlichen Plazierung der Beschreibung des Äußeren, ${ }^{457}$ die

$449 \mathrm{Vgl}$. Suet. Vit. 15,3

450 Vgl. Suet. Vit. 13,2 u. ferner SHOTTER 1993, 190.

451 Vgl. Suet. Vit. 17,2 („Daneben machte ihm ein Teil des Pobels auch seine korperlichen Gebrechen zum Vorwurf; er war namlich sehr groß, sein Gesicht war vorm vielen Wein gerötet, sein Bauch stand vor und ein Bein war lahm, seit dem ZusammenstoB mit einem Rennwagen, als er sich fur Caligula bei einem Wagenrennen als Helfer zur Verfügung gestellt hatte.").

452 Vgl. Suet. Galba 21; Otho 12,1; Vesp. 20; Tit. 3,1; Dom. 18; Iul. 45; Aug. 79-80; Tib. 68; Cal. 50; Claud. 30-31 u. Nero 51 sowie Cal. 3,1 (zu Germanicus) u. Galba 3,3 (zum Vater Galbas) mit STOK 1995, 109ff. Zu den Beschreibungen des Äußeren in den viri illustres vgl. BALDWIN 1983, 495ff., u. Sток $1995,133 \mathrm{ff}$.

453 Vgl. Suet. Otho 12,1: tanto Othonis animo nequaquam corpus aut habitus competit.

454 Vgl. Suet. Galba 21; Dom. 18 u. Tit. 3.

455 Vgl. Suet. Vesp. 20.

456 Vgl. Suet. Iul. 45; Aug. 79-80; Tib. 68; Cal. 50 u. Claud. 30-31 sowie Nero $5 \mathrm{I}$ (nach der exitus-Schilderung). 
sich von ihrem ,natürlichen' Platz am Ende des Lebens ${ }^{458}$ hin zu einem festen Punkt in der Darstellung der vita privata bewegt, wird erneut der experimentelle Charakter der Biographien der späteren Kaiser deutlich.

Als experimentell muß im Falle des Vitellius aber nicht nur die Plazierung gelten, sondern in erster Linie die narrative Umsetzung. Sueton wiederholt diese ambitionierte Form der Präsentation solcher Informationen ${ }^{459}$ in den spăteren Biographien nicht mehr. Der Grund hierfür dürfte wohl darin zu suchen sein, daß durch eine solche Anordnung das gezielte Nachschlagen dieses Aspektes deutlich erschwert wurde und Sueton offenbar hier der utilitas gegenüber dem ästhetischen Lesegenuß den Vorrang eingeräumt hat. Diese Entscheidung wird verständlicher, wenn man sich vor Augen hält, daß die zeitgenössische Öffentlichkeit an der äußeren Erscheinung ein so großes Interesse hatte, daß man geradezu von einer physiognomischen Mode sprechen kann, die sich unter anderem in den Werken des Polemon von Laodikeia spiegelt. ${ }^{460}$ Die Relevanz der Informationen steigert sich außerdem noch einmal dadurch, daß gerade das Aussehen der Kaiser im ganzen imperium Romanum durch verschiedene Medien, vor allem in Form von Statuen und Münzbildern, verbreitet wurde und somit vielfältige Vergleichsmöglichkeiten zu Suetons literarischer Darstellung bestanden. ${ }^{461}$

Dies gilt auch für das von Vitellius gezeichnete Porträt, dessen Einzelheiten zudem wie auch schon die Beleidigungen auf das bisher geschilderte Leben verweisen sollen, ${ }^{462}$ wobei Sueton mit dem Hinweis, daß Vitellius' Hinken von seinen Hilfsdiensten bei den Wagenrennen Caligulas herrührt, explizit auf den Anfangsteil der Vita zurückgreift. ${ }^{463}$ Suetons Vitelliusbild erhält auf diese Weise ein geschickt realisiertes Fazit, in dem er einige der zur negativen Charakterisierung beitragenden Fakten noch

457 Die Beschreibung der außeren Erscheinung spielt in der Biographie vor Sueton eine eher untergeordnete Rolle (vgl. BALDWIN 1983, 497f., u. STOK 1995, 112f.), zumindest hinsichtlich einer Darstellung, ,in which the whole body is photographically described“ (vgl. EVANS 1969, 5.89ff.).

458 Vgl. LEWIS 1991, 3661, der auf die Tradition der laudatio funebris verweist.

459 Vgl. aber auch MURISON 1992, 173, der zu recht von einer „somewhat tasteless artistry“ spricht.

$460 \mathrm{Zu}$ Polemon vgl. z.B. GLEASON 1995, $21 \mathrm{ff}$. Sueton wurde verschiedentlich in engen Zusammenhang mit dieser ,Schule' gebracht (vgl. Evans 1935, 61 ff.77ff.; Couissin 1953, u. v. ALBRECHT 1992, II 1114), doch geben seine Schilderungen wenig konkrete Anhaltspunkte, die uber die weitverbreitete Meinung, daß ein Zusammenhang zwischen außerer Erscheinung und Charakter besteht, hinausgehen (vgl. GaSCOU 1984, 598ff.; BRADLEY 1991, 3726f., u. STOK 1995, 117ff.129f.).

461 Vgl. v.a. Suet. Claud. 30 u. ferner Bradley 1991, 3726f.

462 Die pointenhafte Verwendung von Motiven aus der Lebensbeschreibung gehört zur generellen Strategie Suetons und anderer antiker Autoren, um einen engen Bezug der Schilderung des Todes auf das Leben des Protagonisten zu erreichen (vgl. ARAND 2002, 106.112ff.).

$463 \mathrm{Vgl}$. Suet. Vit. 4,1. Über die von Sueton der facies rubida plerumque ex vinulentia und dem venter obesus vor dem Hintergrund des zeitgenössischen Interesses an Fragen der Diătetik zugemessene Bedeutung wübten wir sicher mehr, wenn sich seine Schrift de vitiis corporalibus erhalten hatte (vgl. Serv. ad Aen. 7,627 sowie ferner BALDWIN 1983, 498; STOK 1995, 127ff., u. AsH 1999, 10 If.). 
einmal Revue passieren läßt. ${ }^{464}$ Damit zählt dieser Abschnitt zu den nicht allzu zahlreichen Stellen innerhalb der Kaiserbiographien, an denen die Intention einer Invektive oder vielleicht besser einer damnatio durch memoria deutlich in den Vordergrund tritt. Gleichzeitig fehlt aber auch hier das nüchterne Interesse an der reinen Informationsvermittlung nicht völlig, da mit Vitellius' enormis proceritas auch eine nicht per se negativ konnotierte Eigenschaft Erwähnung findet.

Auf dieses eher implizit gezogene Fazit folgt nach der relativ kurzen Darstellung seines Todes das gleichsam offizielle und in allen Kaiserbiographien wiederkehrende Fazit, für das Sueton analog zur Geburtsnotiz ${ }^{465}$ ein festes Formular verwendet. Dies besteht in der Regel aus der Perfektform eines Verbums des Sterbens mit dem verstorbenen Herrscher als Subjekt und aus Angaben zum Alter, der Dauer der Herrschaft sowie gelegentlich zum Todesort. ${ }^{466} \mathrm{Im}$ Falle des Vitellius verwendet Sueton nur eine rudimentäre Form dieser Notiz, die sich auf die Angabe des Lebensalters in Jahren beschränkt, ${ }^{467}$ dafür aber eine singuläre Mitteilung zum Schicksal zweier naher Verwandter enthălt: periit cum fratre et filio anno vitae septimo quinquagesimo ${ }^{468}$ Ein Leser, der sich die Mühe macht, das hier angegebene Alter auf das zuvor mitgeteilte

464 Vgl. Braun 1990, 210.

465 S.o. S. $280 f$.

$466 \mathrm{Vgl}$. Suet. Galba 23 (periit tertio et septuagesimo aetatis anno, imperii mense septimo); Tit. 11 (excessit in eadem qua pater villa ld. Sept. post biennium ac menses duos diesque XX quam successerat patri, altero et quadragesimo aetatis anno); Dom. 17,3 (occisus est XIIII. Kal. Octb. anno aetatis quadragensimo quinto, imperii quinto decimo); Iul. 88 (periit sexto et quinquagensimo aetatis anno); Aug. 100,1 (obiit in cubiculo eodem, quo pater Octavius, duobus Sextis, Pompeio et Ap $<p>$ uleio, cons. XIIII. Kal. Septemb. hora diei nona, septuagesimo et sexto aetatis anno, diebus Vet XXX minus); Cal. 59 (vixit annis viginti novem, imperavit triennio et decem mensibus diebusque octo); Claud. 45 (excessit III. Id. Octob. Asinio Marcello Acilio Aviola coss. sexagesimo quarto aetatis, imperii quarto decimo anno) u. Nero 57,1 (obiit tricensimo et secundo aetatis anno, die quo quondam Octaviam interemerat). Erneut stammen zwei der drei Ausnahmen, in denen diese formelle Fazit in die narratio des exitus integriert ist, aus der zweiten Hexade: vgl. Otho 11,2 (et circa lucem demum expergefactus uno se traiecit ictu infra laevam papillam irrumpentibusque ad primum gemitum modo celans modo detegens plagam exanimatus est et celeriter, nam ita praeceperat, funeratus, tricensimo et octavo aetatis anno et nonagensimo et quinto imperii die); Vesp. 24 (dumque consurgit ac nititur, inter manus sublevantium extinctus est VIIII. Kal. Iul. annum agens aetatis sexagensimum ac nonum superque mensem ac diem septimum) u. Tib. 73,1 (sed tempestatibus et ingravescente vi morbi retentus paulo post obiit in villa Lucullana octavo et septuagesimo aetatis anno, tertio et vicesimo imperii, XVII. Kal. Ap. Cn. Acerronio Proculo C. Pontio Nigr<in>o conss.).

467 Aus den zum Teil widersprilchlichen Angaben der Quellen zum Todestag ergibt sich ein Datum zwischen dem 20. und 23. Dezember $69 \mathrm{n}$. Chr. (vgl. HolZAPFEl 1913, 296ff.), die gröBte Plausibilitat hat der 20. Dezember fur sich (vgl. HolZAPFEL 1918, v.a. 102, u. ferner MURISON 1992, 171.173).

468 Vgl. Suet. Vit. 18 (,Er starb zusammen mit seinem Bruder und seinem Sohn im Alter von 56 Jahren."). Die Entscheidung Suetons an dieser Stelle auf Bruder und Sohn des Vitellius zu verweisen ist merkwürdig, zumal von einer wirklichen zeitlichen Koinzidenz der Todesfalle nur bedingt die Rede sein kann (vgl. Tac. hist. 4,80,1 u. Cass. Dio 64,22,1-2 mit Murison 1992, 173). 
Geburtsjahr zurückzurechnen, wird eine Diskrepanz zur früheren Angabe feststellen, die ihre Ursache vielleicht in einer Verwechslung mit dem Bruder Lucius hat. ${ }^{469}$ Eine fehlende Harmonisierung dieser Art ist in den Kaiserbiographien jedoch nicht ohne Parallele ${ }^{470}$ und liegt auf einer Linie mit Suetons generellem Verzicht zur Synthetisierung der von ihm dargebotenen Informationen. ${ }^{471}$ Sueton geht an Stellen wie dieser offenbar von einem Leser aus, der die Angaben der Geburtsnotiz und der Todesnachricht aus unterschiedlichen Anlässen nachschlägt und isoliert zur Kenntnis nimmt.

In ähnlicher Weise verwendet auch Tacitus Todesnachrichten, die aus dem Fluß der historiographischen Erzählung heraustreten und nicht selten über die Angabe des Alters hinaus einige zentrale persönliche Daten enthalten, die einer kurzen Charakterisierung des Verstorbenen dienen. ${ }^{472}$ Dabei ist Tacitus nicht der erste Historiker, der beim Tod einer bedeutenderen Persönlichkeit dieser eine Art Nekrolog innerhalb seiner historiographischen Darstellung gewährt, vielmehr ist dieses Verfahren bereits vom Älteren Seneca als Bestandteil der Gattungstradition erkannt und in seiner diachronen Entwicklung zutreffend beschrieben worden:

quotiens magni alicuius <viri> mors ab historicis narrata est, totiens fere consummatio totius vitae et quasi funebris laudatio redditur. hoc, semel aut iterum a Thucydide factum, item in paucissimis personis usurpatum a Sallustio, T. Livius benignus omnibus magnis viris praestitit. sequentes historici multo id effusius fecerunt. ${ }^{473}$

Aus der bloßen Todesnachricht entwickelte sich also eine Art biographisches Fazit, das gerade innerhalb der annalistischen Historiographie einen wichtigen Anlagerungspunkt für eine dramatisierte Schilderung der exitus-Szene bildete. ${ }^{474}$ Die Angabe des Alters, der Dauer der Regierung oder eines anderen für die betreffende Person relevanten Zeitraumes gehört dabei zu den festen Bestandteilen dieser Resümees. ${ }^{475} \mathrm{Ob}$

$469 \mathrm{Vgl}$. Suet. Vit. 3,2 u. 18 sowie ferner HOLZAPFEl 1918, $105 \mathrm{ff}$.

$470 \mathrm{Vgl}$. Suet. Galba 23 u. Otho 11,2 sowie ferner SHOTTER 1993, 191.

471 S.o. S. $282 f$.

472 Vgl. z.B. Tac. hist. 3,86,1-2 (Vitellius); hist. 2,49,4-50,2 (Otho) u. hist. 1,49,2-4 (Galba) sowie ferner SYME 1958b; SCHUNK 1959, 54f., u. POMEROY 1991, 192ff.

$473 \mathrm{Vgl}$. Sen. Suas. 6,21 (,Jedesmal wenn der Tod eines bedeutenden Mannes von den Historikern berichtet wird, geben sie fast immer eine kurze Zusammenfassung seines ganzen Lebens und halten gleichsam seine Leichenrede. Diese literarische Technik wurde, nachdem sich Thukydides ihrer einoder zweimal bedient hatte, von Sallust nur bei sehr wenigen Personen angewandt, doch Livius war so frei, sie bei allen bedeutenden Mănnern zu verwenden. Die spăteren Historiker sind damit noch weitaus großzügiger verfahren.“) u. ferner BRUNS 1898, 55f.: „Konnen wir uns diesem Urtheil anschliessen? Bei Sallust fehlt uns die Moglichkeit der Kontrolle, denn Seneca denkt naturlich an die veriorenen Historien, nicht die erhaltenen Monographien. Was Thukydides betriff, so hat Seneca offenbar die Worte über Themistokles und Perikles im Sinn.“

$474 \mathrm{Vgl}$. BRUNS 1898, 53ff., der furr eine ausfuhrlichere summa die Bezeichnung als Elogium eingefuhrt hat.

475 Vgl. BRUNs 1898, 56. 
hierin eine auch für die Biographie verbindliche Gattungstradition greifbar wird oder ob Sueton diesen historiographischen ,Baustein' in seine Kaiserviten integriert hat, ${ }^{476}$ weil er mit seiner Hilfe zentrale Informationen in einer festen und daher von seinen Lesern antizipierbaren Form vermitteln konnte, läßt sich aufgrund des fragmentarischen Überlieferungszustandes gerade der hellenistischen Biographie nicht mit letzter Sicherheit entscheiden. $\mathrm{Da} B$ bei Nepos und in den suetonischen viri illustres ein festes Formular für Todesnachrichten fehlt, weist aber in die Richtung einer bewußten Übernahme Suetons, die vielleicht in naheliegender Analogie zum Formular der Geburtsnotiz erfolgt ist.

Sueton läßt auf die Todesnachricht in der Regel thematisch passende Angaben zu den letzten Ehren, ${ }^{477}$ der Reaktion der Bevölkerung auf den Tod des Herrschers ${ }^{478}$ oder zur Konsekration ${ }^{479}$ folgen. Im Vergleich mit den übrigen Kaiserviten als erneut singulär erweist sich dagegen die Verknüpfung der Todesnachricht des Vitellius mit der Deutung eines Prodigiums, das zuvor innerhalb der chronologischen Erzählung seiner Herrschaftsübernahme und im Zusammenhang mit anderen sich auf seine Regierung beziehenden Vorzeichen erwähnt worden war: Auf seinem Marsch von Köln nach Italien hatte sich während eines Gerichtstages ein Hahn auf die Schulter und den Kopf des Vitellius gesetzt, was in Suetons Deutung mit der Niederlage gegen den flavischen General Antonius Primus parallelisiert wird, der während seiner Kindheit im heutigen Toulouse auf den Spitznamen ,Hahnenschnabel' hörte. ${ }^{480}$ Diese eher skurril anmutende Erklärung dürfte auch auf Suetons zeitgenössische Leser einen gesuchten Eindruck gemacht haben. Dabei muß es leider offen bleiben, ob er die angesichts der Herkunft des Antonius Primus wesentlich näher liegende Deutung über das Homonym gallus/Gallus in der Bedeutung Hahn/Gallier schlichtweg übersehen hat ${ }^{481}$ oder ob er eine bewußt abweichende und ausgefallene Interpretation vorlegen wollte.

Während die pointierte Schlußstellung dieser Prodigiendeutung mit dem generellen Interesse des Autors wie seiner Zeit an übernatürlichen Phänomenen dieser Art hinreichend erklärt werden kann, ${ }^{482}$ so ist es doch bemerkenswert, daß hier einer der wenigen expliziten Querverweise in den Kaiserbiographien und das einzige Beispiel

476 Vgl. dag. LEWIS 1991, 3638.3661, der gemaß seinem generellen Ansatz auch dieses Element auf autochthon römische Traditionen zurückgefürt wissen will.

477 Vgl. Suet. Galba 23; Otho 11,2; Dom. 17,3 u. Cal. 59

478 Vgl. Suet. Tit. 11 u. Nero 57,1-2.

479 Vgl. Suet. Iul. 88; Aug. 100,2-4 u. Claud. 45.

$480 \mathrm{Vgl}$. Suet. Vit. 9 u. 18: nec fefellit coiectura eorum qui aurugio, quod factum ei Viennae ostendimus, non aliud portendi praedixerant quam venturum in alicuius Gallicani hominis potestatem, siquidem ab Antonio Primo adversarum partium duce oppressus est, cui Tolosae nato cognomen in pueritia Becco fuerat: id valet gallinacei rostrum.

$481 \mathrm{Vgl}$. SHOTTER 1993, 191.

482 Vgl. Plin. ep. 1, 18 mit WALLACE-HADRILL 1983, $191 \mathrm{ff}$. 
aus der zweiten Hexade vorliegt. ${ }^{483}$ Dieser empirische Befund verweist noch einmal auf den experimentellen Charakter der Viten der chronologisch spăteren sechs Kaiser, in denen Sueton seine biographische Technik, die er in der Kleinform der viri illustres entwickelt hatte, seinem neuen Gegenstand anpaßt.

Mit der Auflösung dieses Vorzeichens endet die Vitelliusvita. In diesem ,Triumph der Prodigien' über Vitellius' Herrschaft, die aus Suetons Perspektive offenbar von vorneherein unter einem schlechten Stern stand, durfte in rudimentärer Form auch ein abschließendes Urteil enthalten sein, doch wird von Sueton weder hier noch in anderen Biographien ein formelles Fazit gezogen. Vielmehr gewinnt am Ende der Lebensbeschreibung erneut sein Interesse an der Vermittlung auch solcher Informationen, die uns abseitig und irrelevant erscheinen mögen, die Oberhand gegenüber dem Entwurf eines einheitlichen Charakterbildes und seiner Bewertung. ${ }^{484}$ Zugleich liefert aber gerade die exitus-Szene der Vitelliusvita ein prominentes Beispiel dafür, daß Sueton innerhalb kleinerer Abschnitte durchaus an einer kohärenten Charakterisierung seiner Personen interessiert ist. Zu diesem Zweck bedient er sich in erster Linie einer geschickten Auswahl der von ihm präsentierten Informationen, doch es gelingt ihm auch, über die reine Ebene der Fakten hinaus literarische Darstellungsmuster und Lesegewohnheiten der zeitgenössischen Rezipienten für seine Intentionen fruchtbar zu machen. Dies gilt vor allem fur den Rekurs auf die exitus illustrium virorum-Literatur, deren kommemorative Funktion von Sueton an dieser Stelle jedoch zu einer damnatio durch memoria umgedeutet wird.

Der Negativcharakterisierung des Protagonisten dient im Falle des Vitellius auch die Beschreibung des Äußeren, die in den späteren Biographien als eigene und in der Regel wertneutrale Rubrik in Erscheinung tritt, hier aber von Sueton in einer äußerst raffinierten Form zugleich zu einem resümierenden Rückverweis auf die Biographie des letzten Bürgerkriegsherrschers genutzt wird. Experimentellen Charakter zeigt ferner die sich anschließende Todesnachricht, die statt der später innerhalb dieses biographischen ,Bausteins' üblichen Angaben unter anderem den Hinweis darauf enthălt,

483 Vgl. Suet. Aug. 90; Tib. 70,5; Cal. 8,6.32,3.35,2; Claud. 29,1.35,1.36,2 u. Nero 22,5 sowie ferner MOUCHOVÁ 1968, 65ff.

$484 \mathrm{Vgl}$. SHOTTER 1993, 12: „When Suetonius and Tacitus have describend the same event, the difference between them is immediately obvious. For example, in their account of the death of Vitellius whilst characteristically Suetonius provides more items of information, it is Tacitus who comes nearer to understanding Vitellius and appreciating the loneliness of the man-in-power, no matter how unscrupulous he may have been. Suetonius account is external and inquisitive, whilst Tacitus' is aimed at revealing the mind of Vitellius, and providing the reader with the means to understand. Tacitus' understanding of the event is encapsulated in Vitellius' patethetic, but pertinent, observation, "yet I was your emperor", whilst Suetonius' indifference is demonstrated by the fact that he appears more conscerned to press on the derivation of Becco, the childhood name of the Flavian General, Antonius Primus." 
daß sich mit seinem Tod ein zuvor berichtetes Prodigium erfullt habe. Dabei stellt bereits die explizite Bezugnahme auf das an einer anderen Stelle geschilderte Vorzeichen eine singuläre Erscheinung innerhalb Caesares dar. Überhaupt gehört der weitgehende Verzicht auf die Explizierung von Zusammenhängen und auf die auktoriale Deutung des Geschehens zu den auffälligsten Merkmalen von Suetons biographischer Technik, eine Besonderheit, die bei einem Vergleich mit der historiographischen Darstellung der gleichen Ereignisse etwa bei Tacitus noch deutlicher zutage tritt.

Während Sueton seinem Leser in dieser Hinsicht gewissermaßen weniger bietet als die Geschichtsschreibung, so erweist sich die von ihm gewăhlte Form auf anderen Gebieten doch als ebenbürtig, wenn nicht überlegen. Dies zeigt sich vor allem in der konsequenten Fokussierung auf den Protagonisten und der damit einhergehenden gröBeren Detailliertheit bei der Schilderung von Ereignissen in seiner unmittelbaren Umgebung, die eine effektvolle Dramatisierung des historischen Geschehens ermöglicht. Mit der auch stilistisch ambitionierten Darstellung, wie sie für die narrativen Partien der Kaiserbiographien, insbesondere bei der Ausgestaltung der exitus-Szenen charakteristisch ist, gelingt es Sueton daher durchaus, in Konkurrenz zu der Schilderung der gleichen Ereignisse beispielsweise bei Tacitus zu treten und der durch die Geschichtsschreibung vermittelten historischen, vulgata' für den Leser interessante neue Facetten hinzufügen.

\section{Form und Funktion der suetonischen Biographie}

Die Vita des letzten Bürgerkriegskaisers, an der sich trotz ihres in vielen Punkten singulären Charakters die Entwicklung der biographischen Technik Suetons vorteilhaft und gleichsam in statu nascendi studieren läßt, liefert reiches Anschauungsmaterial für die beiden zentralen Intentionen des Autors: die an den Bedürfnissen der Bildungskultur des 2 . Jh. $n$. Chr. orientierte Vermittlung biographischen Wissens und die delectatio des Lesers durch eine narrativ und stilistisch ansprechende Präsentation ausgewählter Passagen. Zwar werden die meisten Zeitgenossen die Reihe der ersten zwölf römischen Kaiser ganz unwillkürlich auch in ,geschichtsphilosophischen' Kategorien wahrgenommen haben, doch wurde diese Sichtweise von Sueton im Gegensatz zu Tacitus nicht in den Vordergrund gestellt. Ebenso dürfte es generell kaum möglich sein, eine Biographie zu schreiben, ohne über eine bestimmte Vorstellung vom Charakter der dargestellten Person zu verfügen, doch im Gegensatz zu Plutarch besteht in der Vermittlung dieses Bildes nicht Suetons zentrales Anliegen. Aus diesem Grund müssen auch Vergleiche der Kaiserbiographien mit Gattungen wie dem griechischen Enkomion, der römischen laudatio funebris oder den res gestae des Augustus ihr Ziel 
verfehlen, ${ }^{485}$ da diese dem Spektrum biographischer Literatur zwar am Rande angehören, aufgrund ihrer dezidiert panegyrischen Zielsetzung jedoch andere Strategien der Personendarstellung favorisieren.

Da Sueton keine Synthese der präsentierten Wissensbestände anstrebt, bleiben die Ansătze zu einer positiven Kommemoration ebenso isoliert wie diejenigen Stellen, an denen die Darstellung eines Herrschers durch Auswahl und gegebenenfalls Interpretation der wiedergegebenen Fakten den Charakter einer Invektive mit dem Ziel einer damnatio durch memoria gewinnt. Daß Sueton von der sich aus der Tradierung historischer Wissensinhalte ergebenden Möglichkeit, das Bild einer Person bei der Nachwelt dauerhaft zu prägen, nur zurückhaltend und gleichsam partiell Gebrauch gemacht hat, stellt vielleicht eine der auffälligsten Besonderheiten seiner Kaiserbiographien dar. Mit diesem sachlichen Umgang mit seinen Protagonisten unterscheidet sich Sueton auch signifikant von der Personendarstellung in den plinianischen Porträtbriefen oder den gellianischen noctes Atticae, in denen vor allem das zeitgenössische Anliegen des claros viros colere sehr viel deutlicher zu spüren ist.

Auch die Präsentation von Handlungsmodellen spielt bei Sueton eine geringere Rolle als bei den beiden zuvor untersuchten Autoren oder als in den Parallelbiographien Plutarchs. Dennoch läßt sich auch in den Caesares ein paränetisches Element beobachten. Es bezieht sich allerdings nicht im Sinne eines Fürstenspiegels auf die Persönlichkeit der portrătierten Kaiser in ihrer Gesamtheit, sondern beschränkt sich auf einzelne Züge vorbildlichen Verhaltens, deren Träger die Herrscher selbst, aber auch andere im Rahmen der Biographien auftretende Figuren sein können. Inhaltlich handelt es sich bei den Stellen, die einen ausgeprägten Modellcharakter aufweisen, in der Regel nicht um politische oder militärische Großtaten. Vielmehr stehen für Sueton - wohl mit Blick auf die realen Nachahmungsmöglichkeiten seiner Rezipienten - eher ,private' Aspekte, wie beispielsweise die adäquate Organisation des Tagesablaufes, im Vordergrund. ${ }^{486}$

Wer in der Beschăftigung mit Suetons Kaiserbiographien den Aspekt der Wissensvermittlung in den Vordergrund rückt, erweckt leicht den Anschein, das Rad der Forschung zurückdrehen zu wollen. Denn in den letzten Jahrzehnten hat man sich zu recht mehr und mehr von dem Bild eines Autors verabschiedet, dem sein Rang als Literat streitig gemacht wurde, weil er angeblich ,nicht mit dem Geiste, sondern wesentlich mit den Händen“" gearbeitet habe. ${ }^{487}$ Doch weit davon entfernt, die wichtigen Fortschritte in der Bewertung der literarischen Qualităt der Caesares aufzugeben zu wollen, versteht sich die vorliegende Untersuchung vielmehr als Weiterentwicklung

485 Vgl. NisSEn 1886, 496ff., u. STUART 1928, 189ff, sowie dag. SCHMidt 1891, 8ff.; STEIDLE 1951, 109f., u. LEWIS 1991, $3641 \mathrm{f}$.

486 Vgl. z.B. Suet. Vesp. 21 u. Aug. 78; s.o. S. 260.

487 Vgl. SCHANZ 1896, 44, u. ferner die Zeugnisse bei BradLEy 1991, 3702 Anm. 5. 
dieses Ansatzes. Dabei gilt es allerdings den heterogenen Charakter der Kaiserbiographien, die sich aus stilistisch und narrativ anspruchsvolleren Passagen einerseits und aus primär der Informationsvermittlung dienenden Partien andererseits zusammensetzen, stärker zu betonten. Ein vertieftes Verständnis des Zusammenspiels dieser beiden Elemente, das sich aus narratologischer Perspektive als Wechsel zwischen summary und Szene beschreiben läßt und mit einer Veränderung der erzăhlerischen Dichte einhergeht, ${ }^{488}$ würde möglicherweise auch eine Erklärung dafür liefern, warum Suetons schriftstellerische Făhigkeiten zu Beginn und am Ende des 20. Jh. so konträre Bewertungen gefunden haben.

Suetons Ambitionen als Schriftsteller konzentrieren sich zum einen auf das anekdotische Erzählen, das bei ihm wie allgemein im biographischen Schriftum der Antike eine prominente Rolle spielt. Die Vermittlung personenbezogenen Wissens in anekdotischer Zuspitzung vereint dabei die Vorteile einer gesteigerten Lesbarkeit ${ }^{489}$ mit einem höheren Grad an Memorabilităt der gleichsam szenisch präsentierten Fakten. Daruber hinaus liegen die biographischen Informationen auf diese Weise bereits in einer Form vor, die eine unmittelbare ,Wiederverwendung' des durch die Lektüre erworbenen Wissens in der gebildeten Gesprächskultur erlaubt. ${ }^{490}$ In der Vitelliusvita lassen verschiedene Partien eine solche ,Aufbereitung' des Wissensstoffes erkennen, so etwa die Sammlung von Belegen für das Vitellius' Vater attestierte mirum in adulando ingenium, ${ }^{491}$ die sich in ihrer Tendenz zur Bildung einer thematischen Reihe

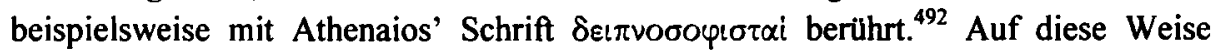
wird der Leser in die Lage versetzt, auch bei fortgeschrittener Behandlung eines Themas noch mit einem neuen Beitrag glänzen zu können. Daß die Anwendung auch entlegenen Wissens in zahlreichen Situationen möglich war oder sogar erwartet wurde, können schlaglichtartig die Rahmenhandlungen der noctes Atticae verdeutlichen: ${ }^{493}$ Solche gellianische Szenen, in denen der gelehrte Gedankenaustausch in einer Buchhandlung ${ }^{494}$ ebenso gepflegt wird wie an Bord eines Schiffes ${ }^{495}$ oder im Vorfeld einer

488 S.o. S. $233 \mathrm{ff}$.

$489 \mathrm{Vgl}$. TOWNEND 1967, 93: „The last proof of Suetonius' success must be that he is intensely readable."

$490 \mathrm{DaB}$ auch die Biographien Plutarchs in diesen Kategorien rezipiert werden konnten, verdeutlicht die von Menander Rhetor $(392,28-33)$ im Zusammenhang mit der Vorbereitung der $\lambda \alpha \lambda \dot{\alpha}$ gegebene Lek-

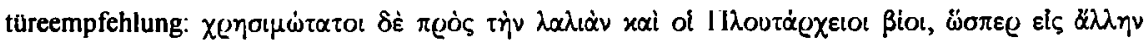

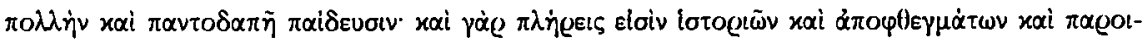

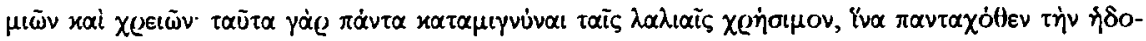

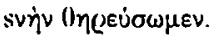

491 S.o. S. 279.

$492 \mathrm{Vgl}$. z.B. Athen. 4,165d-169a; 6,248d-2252f u. 8,338d-347c.

493 Vgl. KRASSER 1995, 87ff., u. KraSSER 1999, 57ff.; s.o. S. 14f.

494 Vgl. Gell. 5,4; 13,31 u. $18,4$.

495 Vgl. Gell. 2,21 u. 19,1 . 
kaiserlichen salutatio, ${ }^{496}$ dürften treffend den sozialen Kontext beschreiben, in dem sich auch für die zeitgenössischen Lesern der suetonischen Caesares die Gelegenheit bot, ihre der bei der Lektüre erlernten Wissensbestände anzuwenden.

Zum anderen sind es die hăufig in der Art einer chronologischen narratio angelegten längeren Abschnitte, auf die Sueton vor allem zur Schilderung zentraler Vorgänge wie der Herrschaftsübernahme oder dem Tod eines Kaisers zurückgreift, in denen sich ein deutlich gehobener Gestaltungswille artikuliert. Hier bedient er sich auch der von ihm sonst eher gemiedenen narrativen Strategien der Geschichtsschreibung, wobei er vor allem ihre dramatischen Elemente effektvoll zu nutzen weiß. In der Dramatisierung und Emotionalisierung des Geschehens, die Sueton unter anderem durch eine Form der źvá $\varrho \gamma \varepsilon \iota \alpha$ erreicht, die gezielt auch von der Geschichtsschreibung in der Regel vernachlässigte Details in den Blick nimmt, ${ }^{497}$ zeigt sich allerdings eine stärkere Ausrichtung an der curiositas und delectatio des Publikums.

Doch neben diesen von Sueton bewußt eingesetzten literarischen lumina bestehen die Caesares zugleich aus Partien, in denen die Interessen des Fachschriftstellers, die am deutlichsten in der Gliederung und Organisation der Biographien durch Rubriken, Präskripte und divisiones zutage treten, auch im Text selbst die Oberhand behalten. $\mathrm{Da}$ Sueton nicht zuletzt aus seinem antiquarischen Hintergrund zu verstehen ist, hat in jüngerer Zeit vor allem ANDREW WALLACE-HADRILL nachdrucklich hervorgehoben. ${ }^{498}$ Die Betonung des primär informativen Charakters eines Textes geht allerdings beinahe zwangsläufig mit der Attestierung geringerer stilistischer Qualităt einher, wie bereits das Urteil der historia Augusta verdeutlichen kann, Sueton schreibe non tam diserte quam vere. ${ }^{499}$ Doch die Entscheidung gegen die anspruchsvollen Darstellungstechniken der Historiographie ist nicht gleichbedeutend mit dem Verzicht auf jeden literarischen Anspruch. Vor allem in der Ausrichtung am Prinzip der brevitas, ${ }^{500}$ aber

$496 \mathrm{Vgl}$. Gell. 6,4.

$497 \mathrm{Vgl}$. LOUNSBURY 1987, $116 \mathrm{ff}$.

498 Vgl. WALLACE-HADRiLl 1983, v.a. 128: „Antiquarianism is the key, not only to his chapter on games, but to his whole picture of Caesars as administrators. This is the Ariadne's thread to which we must hold if his chapters are not to appear (as they have to many) an ill-assorted jumble of quirkishly selected trivia." u. ferner z.B. v. ALBRECHT 1992, II 1105.

499 Vgl. SHA Probus 2,6: illud tantum contestatum volo me et rem scripsisse, quam, si quis voluerit, honestius eloquio celsiore demonstret, et mihi quidem id animi fuit, <ut> non Sallustios, Livios, Tacito $<s>$. Trogos atque omnes disertissimos imitarer viros in vita principum et temporibus disserendis, sed Marium Maximum, Suetonium Tranquillum, Fabium Marcellinum, Gargilium Martialem, Iulium Capitolinum, Aelium Lampridium ceterosque, qui haec et talia non tam diserte quam vere memoriae tradiderunt u. ferner STEINMETZ 1982, $141 \mathrm{ff}$.

$500 \mathrm{Vgl}$. LOUNSBURY 1987, 115f: ,The age was captivated by brevitas. A capacious concept, it was a virtue, or a fault, of style and of matter: it embraced, or was related to, rapidity, haste, compresssion, density, it would encourage, ingenious amplification of the whole through a stelly and pointed brevity in each part. ... Brevitas was a virtus narrandi,..." 
auch in seinem Bemühen um variatio zeigt Sueton vielfaltige Beruhrungspunkte mit den generellen stilistischen Strömungen der Kaiserzeit.

Dennoch steht in den informativen Passagen der literarische Anspruch sicher erst an zweiter Stelle. ${ }^{501}$ Gerade weil sein primäres Interesse der Vermittlung biographischen Wissens gilt, wäre es wünschenswert Aufschluß darüber zu gewinnen, welche Überlegungen bei der Bewertung der Relevanz einer Information ausschlaggebend waren. Doch die Eruierung von allgemeinen Auswahlkriterien erweist sich vor allem aufgrund der Flexibilităt, mit der Sueton innerhalb seines Rubrikenschemas auf die individuellen Lebensumstănde der jeweiligen Person eingeht, als schwierig. Auch die relativ wenigen Stellen, an denen die Auswahl der präsentierten Fakten thematisiert wird, geben inhaltlich keinen weiteren AufschluB, im Gegenteil tritt gerade hier sein Anspruch hervor, Vollständigkeit zumindest summatim anzustreben ${ }^{502}$ Rückschlüsse auf die Interessen des Autors erlauben jedoch naturgemäß vor allem diejenigen Themen, die in der Mehrzahl der Viten Berücksichtigung finden, wie die Rechtsprechung, die spectacula sowie andere Formen der kaiserlichen Euergesie oder die Beschäftigung der Herrscher mit den studia liberalia. ${ }^{503}$

$\mathrm{Da} B$ es sich hierbei nicht nur um zentrale Interessenfelder des Autors, sondern auch um Gegenstände von allgemeiner Relevanz für das zeitgenőssische Publikum handelt, ist eine hăufig gezogene, hermeneutisch allerdings nicht ganz unproblematische Schlußfolgerung, die wesentlich auf der Erwähnung dieser Gegenstände in den Kaiserbiographien beruht. Da das von Sueton gezeichnete Bild der kaiserzeitlichen Gesellschaft und ihrer Interessen aber in sich konsistent ist und nicht im Widerspruch zur Parallelüberlieferung steht, kann die Annahme, daß Autor und Publikum dem Inhalt gleichermaßen Bedeutung beigemessen haben, dennoch eine große Plausibilităt für sich verbuchen. ${ }^{504}$ Dem Versuch, aus den Biographien Suetons einen ,Kanon' des in Hinsicht auf die ersten zwölf römischen Herrscher Wissenswerten zu extrahieren, stehen jedoch die unsystematische Auswahl der jeweils tradierten Fakten sowie der generelle Charakter der Caesares als subsidiäre Literatur entgegen, da Sueton nicht von einem Leser ausgegangen ist, der seine Informationen zur Geschichte der frühen römischen Kaiserzeit nur seinen Werken entnehmen konnte.

Die Einbettung der Caesares in die überaus reiche literarische Landschaft ihrer Entstehungszeit, in der Werke, die der Vermittlung historischen Wissens dienten, in

501 Vgl. SHOTTER 1993, 38: „In short, Suetonius did not consider himself an artist in a primary sense; his aim was to produce information, and style was only a vehicle for this."

$502 \mathrm{Vgl}$. z.B. Suet. Tib. 61,2; singillatim crudeliter facta eius exequi longum est; genera velut exemplaria saevitiae, enumerare sat erit u. ferner Dom. 1,3; lul. 34,1; Aug. 51,1; Cal. 26,1.37,3; Claud. 29,1; Nero 37.1 sowie STEIDLE 1951, 108f., der an diesen Stellen allerdings Suetons Verzicht auf die vollstăndige Wiedergabe aller verfugbaren Fakten in den Vordergrund ruckt.

503 Vgl. z.B. WALLACE-HADRILL 1983, 119ff., 124ff., u. 83ff.

$504 \mathrm{Vgl}$. WALLACE-HADRILL 1983, 176. 
großer Zahl und in vielfaltigen Formen - deren Spektrum von traditionellen Geschichtswerken taciteischer Prägung bis hin zu verschiedenen Breviarien und Epitomierungen reicht - präsent und verfügbar waren, ${ }^{505}$ ist auch die Vorraussetzung für eine adäquate Bestimmung des zeitgenössischen Publikums. Dabei erschwert es der Umstand, daß der ursprüngliche Rezipient aus einer breiten Angebotspalette historiographischer und biographischer Literatur wählen konnte, zugleich erheblich, aus dem Inhalt der Kaiserbiographien Rückschlüsse auf die vom Autor intendierten Leser zu ziehen, da das in ihnen präsentierte Wissen kein geschlossenes Ganzes darstellen muß. ${ }^{506}$ Es kann daher auch nicht verwundern, wenn die bislang vorwiegend sozioökonomisch ausgerichteten Versuche, Suetons Publikum zu verorten, ${ }^{507}$ als gescheitert gelten können, obwohl insbesondere das von FRANCESCO DELLA CORTE etablierte Bild des ,piccolo equestre' als Rezipient der Kaiserbiographien ${ }^{508}$ trotz vielfăltig geäußerter Kritik ${ }^{509}$ weiterhin Vertreter findet. ${ }^{510}$

Von der Einschränkung abgesehen, daß die im 2. Jh. n. Chr. freilich kaum noch anzutreffenden Anhänger einer dezidiert senatorischen und zum Prinzipat in Opposition stehenden Sicht der römischen Geschichte an Suetons ,unkritischem' Umgang mit der Vergangenheit möglicherweise Anstoß genommen hätten, ${ }^{511}$ kommt als Rezipient der suetonischen Caesares prinzipiell jeder über eine hinreichende Lesefăhigkeit und die entsprechende freie Zeit verfugende Römer in Frage. Wenn der Verzicht auf eine durchgängige Orientierung an elaborierten stilistischen Prinzipien auch zunächst auf ein „Publikum mittlerer Bildung“ hindeuten könnte, ${ }^{512}$ so ermöglicht die durchdachte Organisation des Textes doch zugleich andere Rezeptionsformen als lediglich die einer Lektüre in toto. Daher ist auch die punktuelle Verwendung der Biographien als ,Wissensspeicher' durch denjenigen denkbar, der für eine narrativ ansprechendere

505 Vgl. Z.B. SteINMETZ 1982, 145, u. FLACH 1998, 259.

506 Vgl. WALLACE-HADRILL 1983, 24f.: „The error is to make the Caesars an alternative type of history to the Annals, written differently because of a different type of person. It is not history at all."

507 Die Spanne reicht von der Identifizierung senatorischer Ansichten in den Kaiserbiographien (vgl. PeTER 1897, 70, u. MACÉ 1900, 84ff.) bis zur Konzeption des, Mannes auf der Straße' als dem intendierten Publikum (vgl. PARATORE 1959).

508 Vgl. DELLA CORTE 1958, v.a. $173 \mathrm{ff}$.

509 Vgl. z.B. GaSCOU 1976; WALLACE-HADRILL 1983, 24f.74f.99ff., u. LEWIS 1991, $3625 f$.

510 Vgl. z.B. CONTE 1994, 549, u. PICCIRILLI 1998, 185 f.

511 Vgl. WallaCe-Hadrill 1983, $110 \mathrm{ff}$; BaLDWN 1983, 337ff., u. ALFÓldY 1986, 400f.: „Somit konnen wir von Sueton erwarten, daß fur ihn das romische Staats- und Gesellschaftsdenken nicht nur ein Grund fur das Nachtrauern guter, aber vergangener Zeiten ist, sondern da $B$ er uns das vermittelt, was die breite Mehrheit der Oberschicht im römischen Reich auf dem Hőhepunkt der Geschichte des Imperium Romanum von seiner eigenen staatlichen und gesellschaftlichen Ordnung aus einer realistischen und gesunden Position gedacht hat."

512 Vgl. FunAIOLI 1931, 62If. 
Präsentationsform historischen Wissens möglicherweise zu den Geschichtswerken des Tacitus greift.

Innerhalb des Spektrums potentieller Leser dürfte allerdings die breite Schicht der wirtschaftlich und sozial aufsteigenden homines novi, die nicht aber den Bildungshintergrund der eingesessenen Oberschicht verfügten, ein besonderes Interesse an einem Werk wie den Caesares gehabt haben, da sie diesen Lesern als eine Art ,short cut' zu dem gesellschaftlich geforderten Wissen über die zentralen Personen der Vergangenheit gedient haben dürfte. ${ }^{513}$ Suetons Publikum sollte jedoch nicht auf diese Leserschicht eingeschränkt werden, da die in den Kaiserviten enthaltenen Informationen in thematischer wie in quantitativer Hinsicht weit über das hinausgegangen sein dürften, was im Rahmen auch der oberschichtlichen Schulbildung vermittelt wurde. Historische Gegenstände gerieten dort zwar im Zusammenhang mit der Vergillektüre ${ }^{514}$ oder als Materialvorlage für Deklamationsübungen in den Blick, ${ }^{515}$ spielten aber stets eine untergeordnete Rolle. Außerdem lagen die inhaltlichen Schwerpunkte eher auf der Geschichte des klassischen Griechenlands und der römischen Republik, während die frühe Kaiserzeit weitgehend unberücksichtig blieb. ${ }^{516}$

Suetons Kaiserbiographien schließen also in gewisser Weise eine Lücke in der zeitgenőssischen literarischen Landschaft und reihen sich als historisch-biographisches Wissenskompendium in ein dichtes Netz ähnlich gelagerter Werke ein, die im Kraftfeld der Bildungskultur des 2. Jh. n. Chr. entstanden sind. Die Form der Präsentation und der mit ihr verbundene literarische Anspruch dürfte dabei zwischen den verschiedenen Veröffentlichungen ebenso variiert haben wie in den Caesares selbst zwischen den Partien ein und derselben Schrift. Dennoch lassen sich mit den Schlagworten der utilitas und delectatio die allgemeinen Interessen der Zeit recht treffend auf den Punkt bringen. Eine Kontextualisierung der Caesares, die ihre Interaktion mit den Bedürfnissen und den Interessen der zeitgenössischen Bildungsgesellschaft berücksichtigt, liefert daher nicht nur für den Inhalt, sondern auch für die spezifische Form der suetonischen Biographie überzeugendere Erklärungen als der Rekurs auf die

513 Diese These ist von BLOOMER 1992, II ff.259, fur die facta et dicta memorabilia des Valerius Maximus vertreten worden (vgl. dag. auch SKIDMORE 1996, 53ff.103ff., der in diesem Werk ein ethischmoralisches Kompendium mit der römischen Oberschicht als Adressaten erblickt).

$514 \mathrm{Vgl}$. Serv. Aen. 6,752: qui bene considerant, inveniunt omnem Romanam historiam ab Aeneae adventu usque ad sua tempora summatim celebrasse Vergilium sowie ferner HÄUSSLER 1976, 299ff.; NICOLAI 1992, 177ff., u. EIGLER 2003, 64ff.

$515 \mathrm{Vgl}$. Quint. inst. 2,4,18-21. Bei Quintilian bildet historiographische Literatur mit Blick auf eine Erweiterung des stilistischen Repertoires daruber hinaus einen integralen Bestandteil des von ihm empfohlenen Lektürekanons (vgl. Quint. inst. 10,1,31-34 sowie ferner AX 1990 u. NiCOLAl 1992, 55ff. 61 ff.).

516 Vgl. NiCOLAI 1992, 32ff., u. HOSE 1994, $5 \mathrm{ff}$. 
Gattungstradition, deren Verbindlichkeit angesichts der Pluralităt biographischer Literaturformen in der Antike ohnehin nicht allzu hoch veranschlagt werden sollte. 